Florida International University

FIU Digital Commons

FIU Electronic Theses and Dissertations

University Graduate School

6-20-2016

\title{
Organizational Social Capital and Performance Information Use: Analyzing the Link and Its Implications for Public Management
}

Michele Tantardini

Florida International University, mtant001@fiu.edu

DOI: $10.25148 /$ etd.FIDC000698

Follow this and additional works at: https://digitalcommons.fiu.edu/etd

Part of the Civic and Community Engagement Commons, Other Public Affairs, Public Policy and Public Administration Commons, Public Administration Commons, and the Public Affairs Commons

\section{Recommended Citation}

Tantardini, Michele, "Organizational Social Capital and Performance Information Use: Analyzing the Link and Its Implications for Public Management" (2016). FIU Electronic Theses and Dissertations. 2627.

https://digitalcommons.fiu.edu/etd/2627

This work is brought to you for free and open access by the University Graduate School at FIU Digital Commons. It has been accepted for inclusion in FIU Electronic Theses and Dissertations by an authorized administrator of FIU Digital Commons. For more information, please contact dcc@fiu.edu. 


\section{FLORIDA INTERNATIONAL UNIVERSITY}

Miami, Florida

\section{ORGANIZATIONAL SOCIAL CAPITAL AND PERFORMANCE INFORMATION USE: ANALYZING THE LINK AND ITS IMPLICATIONS FOR PUBLIC MANAGEMENT}

A dissertation submitted in partial fulfillment of the requirements for the degree of DOCTOR OF PHILOSOPHY

in

PUBLIC AFFAIRS

by

Michele Tantardini 2016 
To: Dean John F. Stack, Jr.

Steven J. Green School of International and Public Affairs

This dissertation, written by Michele Tantardini, and entitled Organizational Social Capital and Performance Information Use: Analyzing the Link and Its Implications for Public Management, having been approved in respect to style and intellectual content, is referred to you for judgment.

We have read this dissertation and recommend that it be approved.

John F. Stack, Jr.

N. Emel Ganapati

Alexander Kroll, Co-Major Professor

Allan Rosenbaum, Co-Major Professor

Date of Defense: June 20, 2016

The dissertation of Michele Tantardini is approved.

Dean John F. Stack, Jr. Steven J. Green School of International and Public Affairs

Andrés G. Gil

Vice President for Research and Economic Development and Dean of the University Graduate School

Florida International University, 2016 
ABSTRACT OF THE DISSERTATION

ORGANIZATIONAL SOCIAL CAPITAL AND PERFORMANCE INFORMATION

USE: ANALYZING THE LINK AND ITS IMPLICATIONS FOR PUBLIC

MANAGEMENT.

by

Michele Tantardini

Florida International University, 2016

Miami, Florida

Professor Allan Rosenbaum, Co-Major Professor

Professor Alexander Kroll, Co-Major Professor

The use of performance information is the backbone of performance management. Performance information use refers to the willingness of public managers or other relevant stakeholders to incorporate quantitative or qualitative data in their decisionmaking. Both routine and nonroutine performance information is considered essential in managers' decision making. Understanding the organizational factors that motivate public managers to use performance information is an important topic in the literature and practice of performance management.

Although the number of studies on information use is growing, little is known about the impact of Organizational Social Capital (OSC). OSC is composed of the subdimensions of social interaction, trust, and shared goals. The main argument of this study is that OSC fosters performance information use in public administrations. It is 
expected that departments with high levels of organizational social capital are more likely to use both routine and nonroutine performance information.

To test the hypothesized effect, department heads, middle managers, and other individuals with a supervisory role from 513 Florida County Government departments were surveyed. Furthermore, interviews, focus groups, and analysis of secondary data were performed to provide the context and the narrative surrounding the hypothesized effect. Analysis of the survey data reveals evidence in support of the hypothesized effects. Furthermore, the comparative case study analysis shows the existence of substantial differences in the history, background, organizational culture, and management between the two counties. The main findings show how reorganization processes as well as a lack of leadership may have detrimental effects to organizational social capital.

Organizational social capital could be considered a relevant predictor of performance information use and thus deserves further attention from both researchers and practitioners. 


\section{TABLE OF CONTENTS}

CHAPTER

PAGE

Chapter 1: Introduction 1

Overview of Chapters

Chapter 2: Performance Literature Review ............................................................... 9

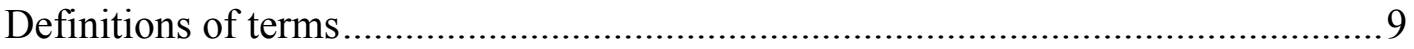

Information use in the managerial decision-making process ................................. 10

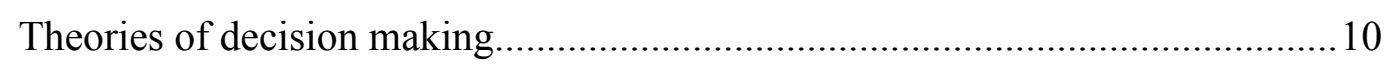

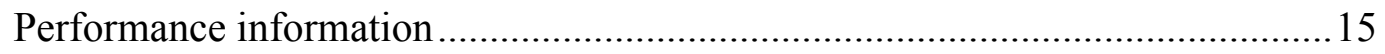

Different uses of performance information ....................................................... 19

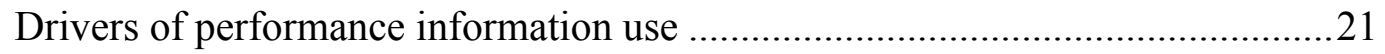

Chapter 3: Organizational Social Capital Literature Review …................................23

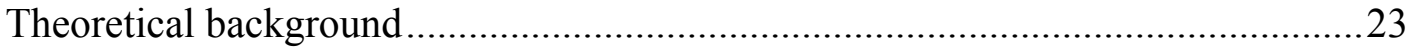

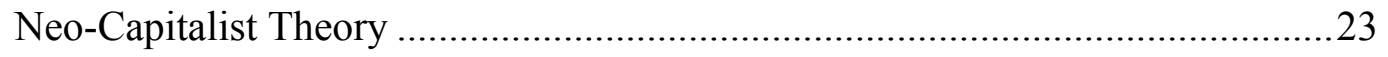

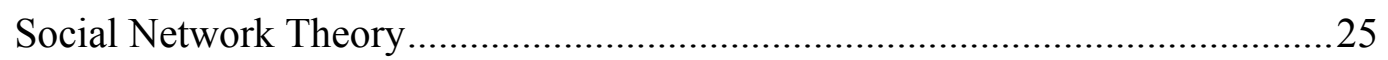

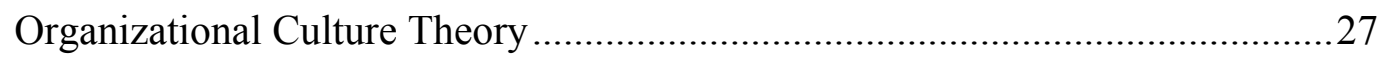

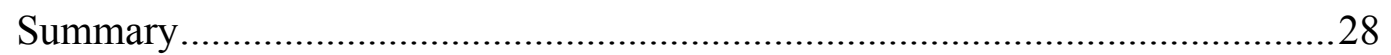

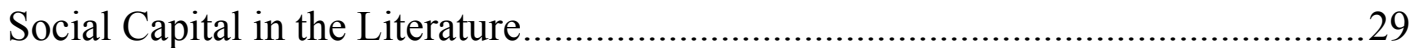

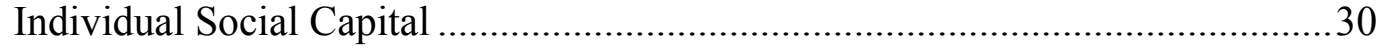

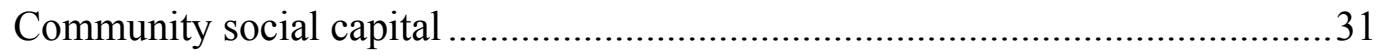

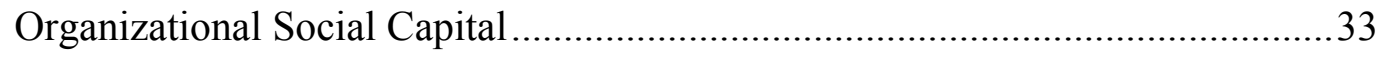

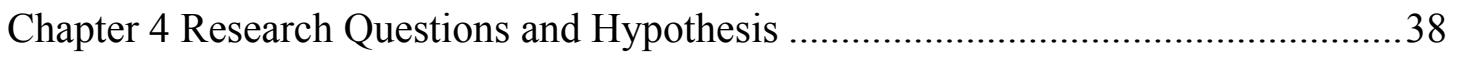

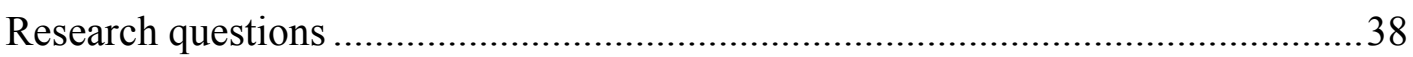

Organizational Social Capital and Performance Information Use: Hypotheses .......38

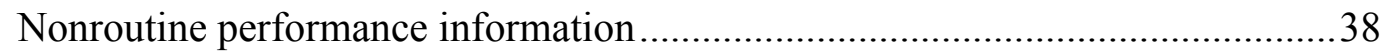

Nonroutine performance information and routine performance information.......40

Chapter 5: Quantitative Research Design and Methods ............................................48

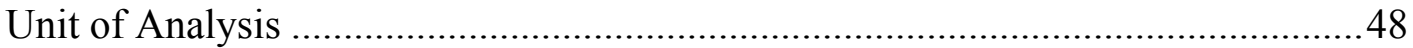

Historical and geographical overview of the State of Florida .............................50

Overview of the State of Florida County Governments .......................................54

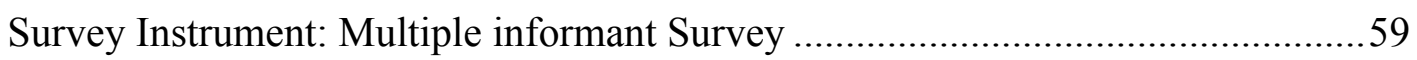


Operationalization of the dependent variables 62

Operationalization of the main independent variable ..........................................65

Operationalization of the control variables …................................................. 70

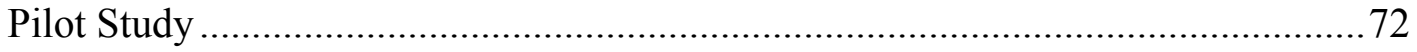

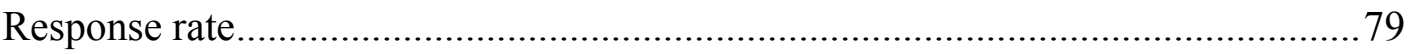

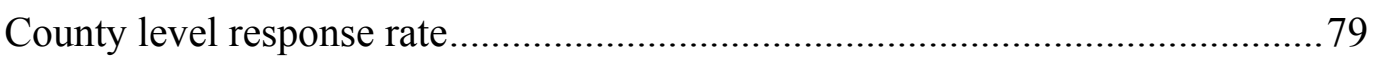

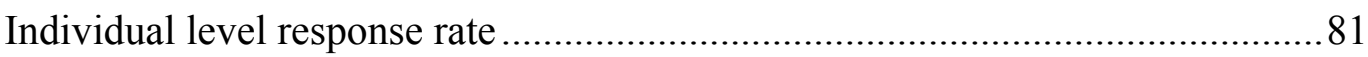

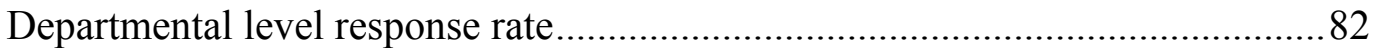

Construction of the main dependent and independent variables ............................84

Construction of the dependent variable Routine PI Use........................................8 85

Construction of the dependent variable Nonroutine PI Use ................................86

Construction of the independent variable Organizational Social Capital.............88

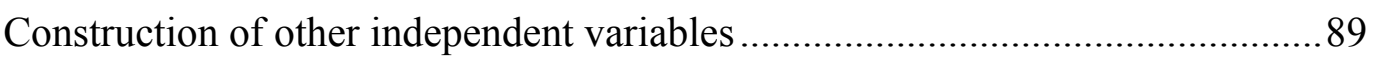

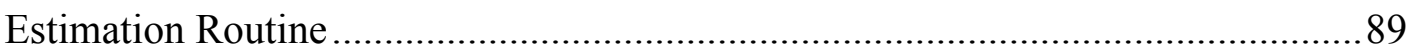

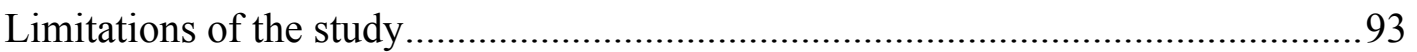

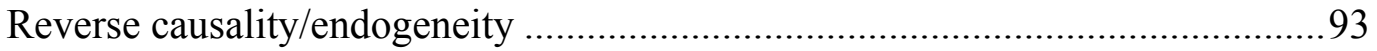

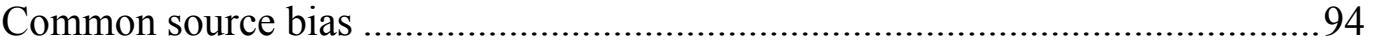

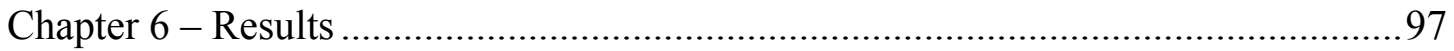

Nonroutine Performance Information Use ......................................................97

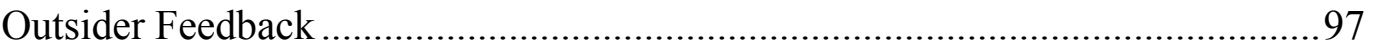

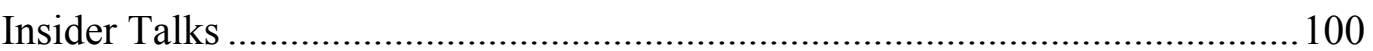

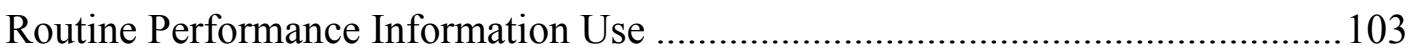

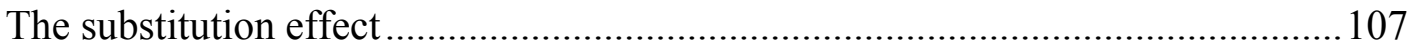

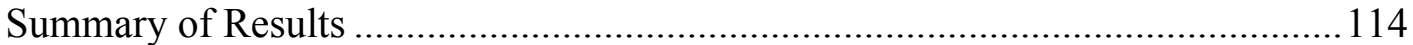

Chapter 7 Complementary Qualitative Research Design .......................................115

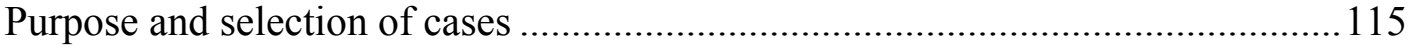

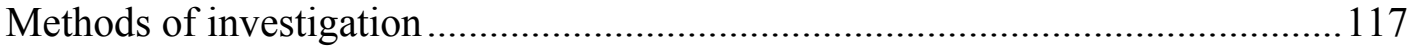

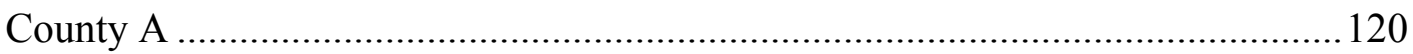

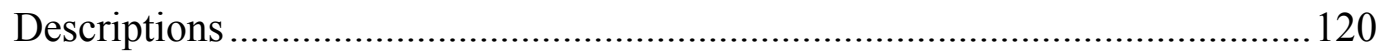

Results: Performance Measurement and Information use................................ 124

Results: Organizational Social Capital ...........................................................131

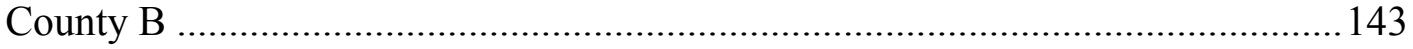

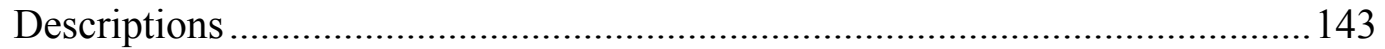

Results: Performance Measurement and Information use ................................. 147 
Results: Organizational Social Capital

Comparative analysis

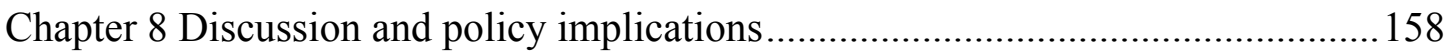

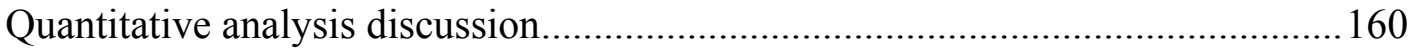

Nonroutine Performance Information Use .....................................................160

Routine Performance Information Use ............................................................ 164

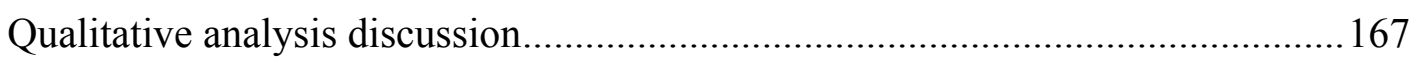

Policy implications: how to create and foster OSC ............................................ 170

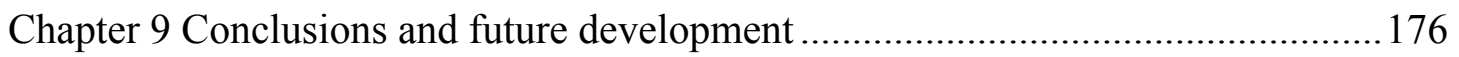

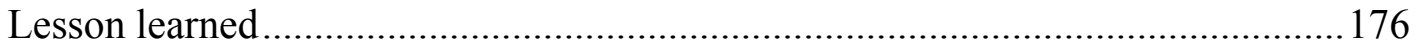

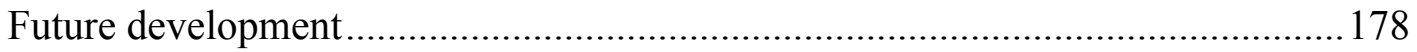

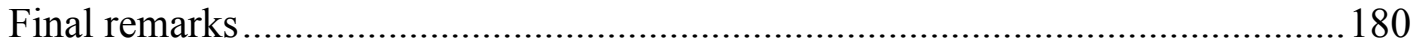

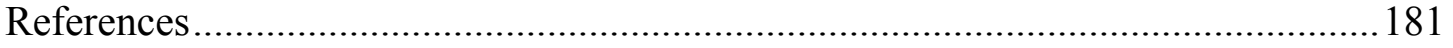

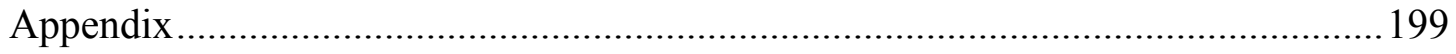

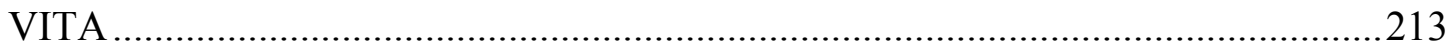




\section{LIST OF TABLES}

TABLE

PAGE

Table 1: List of Florida Counties and County Facts ....................................................55

Table 2: Department categorization according to Lowi's typology ............................61

Table 3: Measures of Organizational Social Capital ................................................67

Table 4: Additional Measures of Organizational Social Capital ...............................68

Table 5: List of Counties' respondents and non-respondents .................................... 80

Table 6: Routine Performance Information Use Factor Analysis................................86

Table 7: Nonroutine Performance Information Use Factor Analysis .........................87

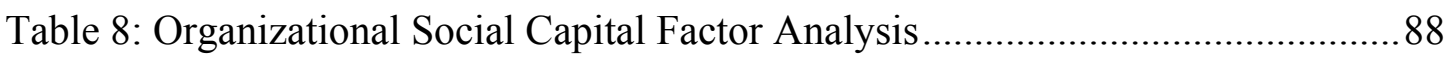

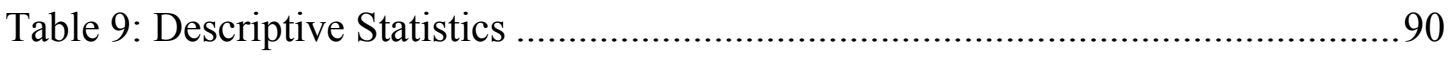

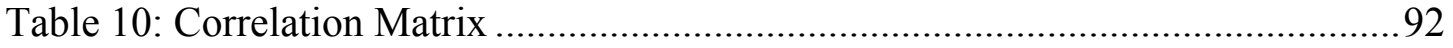

Table 11: Estimation results. DV: Nonroutine PI Use—Outsider Feedback...............99

Table 12: Estimation results. DV: Nonroutine PI Use-Insider Talks...................... 102

Table 13: Estimation results. DV: Routine Performance Information Use ............... 105

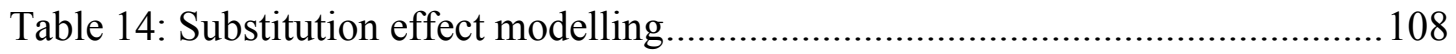

Table 15: Estimation results. DV: Routine Performance Information Use ............... 109

Table 16: Estimation results. DV: Nonroutine PI Use - Outsider Feedback..............111

Table 17: Estimation results. DV: Nonroutine PI Use-Insider Talks......................113

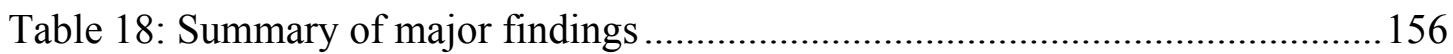




\section{Chapter 1: Introduction}

Attempting to improve the performance of public administrations is an objective that has characterized the political debate in modern democratic states (Pollitt \& Bouckaert, 2002). In 1887, Woodrow Wilson stated that public administration studies should define what government can properly accomplish and "how it can do these proper things with the utmost possible efficiency and at the least possible cost either of money or of energy" (p. 197). However, it is not until the 1980s that "a remarkable movement to reform public management has swept the globe” (Kettl, 2005, p. 1). Many scholars refer to this movement as New Public Management (NPM) (Hood, 1998).

The origins of this movement, which has been fully embraced by politicians around the world, could be traced back in the influence from "large, high performing organizations in the private sector" (Kamensky, 1996, p. 248). Classical economic theory, public choice theory, principal-agent theory, transaction cost, liberation management, market-driven management are some of the theories that constitute the backbone of NPM (Kamensky, 1996, Terry, 1998). Among the core components that characterize this movement (Caiden, 1994; Kamensky, 1996, Kettl, 2005; Terry, 1998), productivity and accountability have received the most attention — both in theory and in practice of NPM.

According to Kamensky (1996), NPM advances progress toward achieving better performing public administrations. He stated that NPM "is not just a series of recommendations, but an evolving movement whose vision and philosophy is trying to adapt democratic governance to new public expectations" (p. 253). Not all scholars have been keen to accept and embrace what NPM has offered to the public sector. 
According to Terry (1998), managerialism is "an updated version of the older tradition rooted in the work of Frederick Winslow Taylor," which makes public managers "selfinterested, opportunistic innovators, and risk-takers who exploit information and situation to produce radical change" (Terry, 1998, p. 197). Similarly, Caiden (1994) states that the focus of NPM, at least in the American context, is on wrong targets and does not resolve the real problems of American public administrations.

Two core concepts of NPM, productivity and accountability, allowed for performance management practices to be widely adopted and implemented across countries (Bouackaert \& Halligan, 2008; Van de Walle \& Bovaird, 2007). From a managerial perspective, performance measurement and management systems have a dual function. First, they allow to define the logic model that connects objectives, inputs, processes, and outputs and outcomes (Kaufmann, 1986; Bouckaert \& Halligan, 2008). Second, they allow to evaluate the achieved performance and trigger learning processes aimed at improving the efficiency, effectiveness, and quality of public administrations (Dunsire, 1986).

In the United States, during the 1990s, the Federal Government implemented major initiatives to assess performance such as the Chief Financial Officers Act in 1990 and the Government Performance and Results Act (GPRA) in 1993 and in 2010. At the same time, the executive produced the National Performance Review in 1993 with the aim of creating a government that would work more and better and cost less. Not only at the Federal level, but also state and local governments have been very proactive in adopting and implementing performance management practices even before the Federal government itself (Ammons \& Rivenbark, 2008; Behn, 2006). 
NPM aims to help contemporary public administrations bridge the divide between the administration and citizens by increasing public confidence in administrations' effectiveness, efficiency, and accountability. Irrespective of the success of these efforts, the literature has focused on determining if these reforms, which cost public resources during adoption and implementation, have actually been successful (Behn, 2002; Holzer \& Yang, 2004; Moynihan, 2013a, 2013b). To measure the success of these reforms, the literature has identified the use of performance information in the managerial decision making process (Moynihan \& Pandey, 2010; Van Dooren \& Van de Walle, 2008). Performance information use is defined as the purposeful use of performance information by public managers in their decisionmaking process to steer, learn, and improve not only the delivery of public services, but also the organizational environment in which the administrative action takes place. Understanding whether managers use performance information and the organizational factors that lead managers to the use of performance information is of fundamental importance to the field of public management.

The literature has identified several drivers of performance information use, including benchmarking (Ammons \& Rivenbark, 2008), organizational culture (Moynihan \& Pandey, 2010), learning forums (Moynihan, 2008, p. 359), stakeholder involvement (Berman \& Wang, 2000), political support (Yang \& Hsieh, 2007), and leadership support (Kroll, 2014). Much of the previous work has mainly focused on managerial drivers of performance information use and not enough research has focused on sociological factors. To address this gap in the literature, the concept of organizational social capital is used in this dissertation as a potential driver of performance information use. This concept comprises three different dimensions: the 
structural dimension, or the level of interaction among members of an organization; the relational dimension, or the level of trust among members of an organization; and the cognitive dimension, or the capacity of an organization to have shared goals and achieve this goals collectively (Leana \& Van Buren, 1999; Nahapiet \& Ghoshal 1998).

In this dissertation, it is hypothesized that managers are more likely to use performance information in their decision making process if:

(1) they interact and collaborate with each other and with employees (structural dimension),

(2) they have trust in each other and they trust their employees (relational dimension),

(3) they have shared goals and they achieve these goals collectively (cognitive dimension).

Therefore, this dissertation contributes to the literature on public management for the following reasons:

1. It constitutes a novel study of performance information use because it examines the sociological and organizational factors that lead public managers to use performance information to make meaningful decisions that affect not only the administration itself but also the delivery of more efficient and effective public services. This investigation addresses a gap in the literature and delivers a new sociological and organizational perspective to the field of public management and public administration.

2. This study will expand empirical knowledge on the ramifications (positive and negative) of organizational social capital in the public administration field. Applying the concept of organizational social capital to public 
administration gives researchers in our field the opportunity to take a leading role in researching an innovative concept that has been primarily explored in other disciplines. This research sets the basis for understanding if and how organizational social capital is a relevant explanatory factor that drives performance information use. Furthermore, it can set the basis for a future research agenda with the goal of studying whether social interaction, trust, and common goals are organizational factors that are relevant to other areas in public administration research (e.g., organizational commitment, intrinsic motivation, job satisfaction, and turnover intention).

3. Most of the research on how to measure organizational social capital has been more theoretical than empirical. No measure of organizational social capital has been empirically validated and widely established among scholars. This research will test and validate an index for the measurement of organizational social capital that has never been applied in the American context but that has been tested in the UK local government.

4. Finally, on a prescriptive basis, if social capital has a positive effect on performance information use, this research will provide recommendations and practical tools to managers on how to create and foster organizational social capital not only for improving performance information use but, more in general, for a more effective and efficient public administration.

To test the hypothesized effect, department heads, middle managers, and other individuals with a supervisory role from 513 Florida County Government departments were surveyed. Furthermore, a complementary case study analysis was performed to provide the context and the narrative surrounding the hypothesized effect. Interviews, 
focus groups, and analysis of secondary data were performed as data collection activities. Based on the results of the survey, the two counties represent, respectively, a case exhibiting a high level of organizational social capital and a case exhibiting a low level of organizational social capital.

Analysis of the survey data reveals partial evidence in support of the hypothesized effects. Organizational social capital could be considered a predictor of performance information use. Furthermore, the comparative case study analysis shows the existence of substantial differences in the history, background, organizational culture, and management between the two counties that resulted in different levels of organizational social capital and performance information use. The main findings show how reorganization processes as well as a lack of leadership may have detrimental effects on organizational social capital.

A mixed-methods approach is used to test and understand organizational social capital and performance information use — indicating that organizational social capital deserves further attention from both researchers and practitioners.

\section{Overview of Chapters}

This dissertation is organized as follows. The second chapter reviews the literature on performance management and performance information use. This chapter analyzes in detail the features of availability of performance measures and subsequent possible use of performance information in managerial decision making. The organizational social capital literature is reviewed in Chapter 3. The chapter begins with a discussion of the theories at the foundation of organizational social capital. In particular, neo-capitalist theory, social network theory, and organizational culture theory are presented and discussed. The third chapter continues by presenting the 
concept of social capital. Most of the chapter focuses on organizational social capital; however, community and individual social capital are also discussed. Following the literature reviews of both performance information use and organizational social capital in the previous chapters - and noting the gap in the literature-Chapter 4 presents the research questions and the subsequent hypotheses that will be tested in this dissertation.

The fifth chapter describes in detail the quantitative research design. The chapter starts by presenting the unit of analysis-Florida county government departments - and by narrating the evolution of Florida county governments from a historical perspective. Facts and figures regarding Florida counties are also provided. The chapter continues by describing the multiple informant survey instrument used to collect data and how the concept of performance information use and organizational social capital have been operationalized in the analysis. The results of the pilot study are then presented. The chapter advances by reviewing the survey response rate and by describing the estimation routine. Then, the two main methodological limitations, reverse causality and common sources bias, are discussed. The construction of the main dependent and independent variables concludes this chapter. The sixth chapter presents the results of the quantitative analysis. The results pertaining to the first research question are illustrated in sequence: routine performance information use, outsider feedback, and insider talks. A discussion on substitution effect, the focus of the second research question, complete this chapter.

Chapter 7 introduces the complementary qualitative research design. It commences by explaining the purpose of case study research and by explaining the selection criteria for the two cases. Two counties with similar demographic and administrative characteristics were chosen. The two counties differ in their level of 
organizational social capital and in their use of performance information. Methods of investigation are then outlined. The results of the interviews and focus groups are then presented for each of the two selected counties.

The last two chapters, Chapters 8 and 9, conclude the dissertation. Chapter 8 discusses the results of both the quantitative and qualitative analysis. The aim is to ground the results presented in Chapters 6 and 7 into the existing literature and into the Florida County governments' context. The chapter also provides policy implication to practitioners. In particular, it focuses on how to create and foster organizational social capital in the public administration framework. The last chapter provides an overview on the lessons learned from this study and it sets the groundwork for future development of research both on performance information use and on organizational social capital. 


\section{Chapter 2: Performance Literature Review}

This chapter reviews the literature on performance management in general and performance information use in particular. After a short paragraph that defines performance information use, the chapter builds on the previous work of Van de Walle and Boivard (2007) by describing several theories of decision making (e.g., rational decision making, bounded rationality, incrementalism, the garbage can model, and mixed-scanning). The chapter then focuses on performance information use and, in particular, routine and nonroutine use of performance information. The goal of this chapter is to explain the link between established theories of decision making and the research presented in this dissertation. This chapter provides the reader with a more realistic understanding of what performance information use means and how data are likely to be used or not used.

\section{Definitions of terms}

As stated in the first chapter, the New Public Management movement has led to the adoption and implementation of performance management systems in the public sector; these systems require the measurement, incorporation, and use of performance information in the managerial decision making process. Lately, research on performance management has focused on whether managers actually use performance information to make decisions (Kroll, 2013; Moynihan \& Pandey, 2010; Van Dooren, 2006). Bouckaert and Halligan (2008) defined performance information use as the:

debates and institutionalized procedures for stakeholders for the purpose of designing policies, for deciding, for allocating resources, competencies and responsibilities, for controlling and redirecting implementation, for (self) 
evaluating and assessing behaviour and results and for substantiating reporting and accountability mechanism (p. 28).

Kroll (2013) defined performance information use as "purposeful utilization in order to steer, learn, and improve public services" (p. V). Expanding on that definition, in this dissertation, performance information use is defined as the purposeful use of performance information by public managers in their decision-making process to steer, learn, and improve not only the delivery of public services, but also the organizational environment in which the administrative action takes place.

\section{Information use in the managerial decision-making process}

This section first presents several theories of decision making, including rational decision-making process, bounded rationality, incrementalism, the garbage can model, and mixed scanning. Second, it presents three different sources of information that can be used by public managers: evaluation research, scientific information, and performance information. Performance information will be analyzed in detail by presenting both routine and nonroutine use of performance information.

\section{Theories of decision making}

In this subsection, theories of decision making, including rational decisionmaking process, bounded rationality, incrementalism, the garbage can model, and mixed scanning, are briefly presented as the theoretical basis for performance information use in the managerial decision-making process. Although other theories of decision making exist (e.g., organizational procedure view, political view, individual characteristics perspective, naturalistic decision making, multiple perspective approach), they will not be described or analyzed here to maintain focus on the theories at hand. 


\section{Rational decision-making process}

The rational model in decision making stems from neo-classical microeconomic theory that described the homo oeconomicus (economic man) as completely rational and completely informed about all available alternatives. According to Kreitner and Kinicki (2001), decision makers are assumed to:

- know of all possible alternatives;

- know the consequences of implementing each alternative;

- have a well-organized set of preferences for these consequences; and

- have the computational ability to compare consequences and to determine which is preferred.

In neo-classical microeconomic theory, the decision with the highest utility function among all other options is the one selected. Numerous critics followed the rational decision-making process, contesting in particular the assumptions underlying this theoretical model, which are not likely to exist in a real world scenario (see for example Bazerman, 2002; Cohen, March, \& Olsen, 1972; Etzioni, 1967; Lindblom, 1980; March, 1987; Simon, 1972). It is a model that describes how decisions should be made rather than how decisions are really made (Van de Walle \& Boivard, 2007).

\section{Bounded rationality}

As a critique of the rational decision-making process, Simon (1972) proposed the theory of bounded rationality. According to Simon (1972), the rational decision making theory has several limitations. The theory of bounded rationality is built, by modifying in various ways, the assumptions that govern rational choice decision making. Rationality can be bounded by introducing the following assumptions either in the demand function, cost function, or both (Simon, 1972): 
- Risk and uncertainty: the rational assumption that the actor knows perfectly these functions, has been replaced with the more realistic assumption that actors may only know the distribution of either the demand or cost functions.

- Incomplete information about alternatives: in their decision-making process, actors may not have all the necessary information about all the available alternatives he/she can choose from.

- Complexity: the introduction of complexity in the cost function; only approximation in the decision-making process can be achieved.

When these assumptions are integrated into the decision-making process, rational decision making is unlikely to occur. Decisions are based on optimizing and satisfying approaches (Simon, 1972). Through optimizing approaches, the decision maker continues to simplify complexity until he/she is able to manage it. Through satisfying approaches, the decision maker continues to simplify complexity until he/she reaches a satisfactory decision.

\section{Incrementalism}

Like Simon, Lindblom's (1980) decision making theory is a critique of the rational decision making model. In particular, he criticizes the fact that rational decision making theory (p.19):

- Is fallible and people believe it to be so;

- Cannot wholly resolve conflicts of values and interests;

- Is slow and costly;

- Cannot tell conclusively which problem to attack. 
The core of Lindblom's disjointed incrementalism relies on the fact that the decisionmaking process is not complete with the selection of one of the available options. The selection of a first option opens up a step-by-step process that updates the selected option throughout marginal and incremental adjustments. According to Lindblom (1959), decision makers muddle through the process while comparing alternatives. Therefore, the decision-making process is the result of incremental adjustments, "influenced by the power structure and the dependencies in the decision making process" (Van de Walle \& Boivard, 2007, p. 20).

\section{Garbage can model}

According to Cohen, March, and Olsen (1972), who first described the garbage can model, "a decision is an outcome or interpretation of several relatively independent streams in an organization" (p.4). The main idea underlying the garbage can model is that problems and information are all thrown into a garbage can from which a possible solution might be found. There is no direct link between the problem and the possible solution (Cohen et al., 1972). Once again, the garbage can model originates as a critique of rational decision-making process and also as a critique of Simon's bounded rationality. In this model, decisions are made in garbage cans that constitute subsystems of an organization. These subsystems are not fixed and stable, but are more fluid and able to adjust to different situations with different actors. Organizations and the decision-making process can be described as "organized anarchies [which are] collections of choices looking for problems, issues and feelings looking for decision situations in which they might be aired, solutions looking for issues to which they might answer, and decision makers looking for work" (Cohen et al., 1972, p.1). 


\section{Mixed scanning}

Etzioni (1967) presents his mixed-scanning approach as a critique of both the rational and the incremental approach to decision making. The mixed-scanning approach provides "both a realistic description of the strategy used by actors in a large variety of fields and the strategy for effective actors to follow" (p. 389). In particular, the mixed-scanning approach provides "a particular procedure for the collection of information [...], a strategy about the allocation of resources $[\ldots]$, and [...] guidelines for the relation between the two" (p. 389). The mixed-scan approach borrows some features of the rational choice approach and some features of the incremental approach because it differentiates between "fundamental decisions" and "incremental decisions" (p. 390). The fundamental decisions require an overview of the main alternatives, and incremental decisions are made as adjustments to the fundamental decisions. Mixedscanning integrates the best features of the rational model and the incremental model, discarding the shortcomings of both to create a "third approach in decision making" ( $\mathrm{p}$. $385)$.

\section{Summary}

In this section, several theories of decision-making have been reviewed. All of these theories are important to understanding the managerial decision making process. It is fundamental now to explain the link between these theories and the research presented in this dissertation. These theories provide a better and more realistic understanding of what performance information use means and how data are likely to be used or not used. According to Van de Walle and Boivard (2007), the perception of a "good manager" is dependent on whether he or she can defend his or her decision making process as rational (i.e., based on the use of performance data). The authors go on to state that the use of performance information not only would improve the quality 
of the decision making process but also would legitimize the decision itself. The other theories can explain why managers may or may not use performance information in their decision making process. Other factors such as common sense, anecdotes and storytelling, and psychological factors may also be used by managers instead of performance information in their decision making process.

\section{Performance information}

In this subsection, routine performance information and nonroutine performance information will be presented and analyzed. Before focusing on performance information, we will examine evaluation research and scientific information as sources of information for public administrations in their decisionmaking processes (Van de Walle \& Boivard, 2007). Evaluation research offers valuable information regarding a particular policy that could be used to improve the policy itself. Scientific research offers technical and scientific information to the policy making process. Although information that stems from either evaluation research or scientific research are considered in decision making, neither are the focus of this dissertation. Therefore, we now proceed to descriptions of routine and nonroutine performance information.

\section{Routine Performance Information}

According to Kroll (2013), routine performance information is systematically collected, based on ex-ante indicators, often quantitative in nature, and even aggregated at different levels. To better understand what routine performance information is and how it is originated, a useful framework developed by Bouckaert and Halligan (2008) can be taken into consideration. The framework is composed of three dimensions: measurability, incorporation of performance information into (official) documents, and use of performance information by public managers. While measurability refers to the 
collection and processing of performance related data (Hatry, 2006; Moynihan, 2005), incorporation refers to integration of performance data and information into (official) documents and into decision-making processes (Van Dooren et al., 2010).

Depending on the evolution and extent that these three dimensions assume in a specific public administration or a specific country, four ideal-types of performance have been identified (Bouckaert \& Halligan, 2008): performance administration, management of performances, performance management, and performance governance. Regarding the performance management ideal-type (Van Dooren et al., 2010), first, public administrations have developed and defined comprehensive performance measurement systems. Second, performance information is incorporated systematically into public administration documents and used on a regular basis by public managers in decisions that affect both the "daily management practice" (Van Dooren, 2006, p. 21) and the citizens that the administration serves.

Information within a public administration can be considered a good or service: “one party provides information; while another party consumes it" (Van Dooren, 2006). Supply and demand of performance information is a critical component in performance management systems. Historically, the supply side of performance information had been the first component of the framework proposed by Bouckaert and Halligan (2008). A more extensive discussion of managers' demand for performance information for decision making appears later. While the demand of performance information by managers to be used in their decision making process needs much further discussion and explanation as it will be proposed later on in this chapter.

Though the problem of false information exists, routine performance information can be considered accurate and reliable and managers can purposefully use 
this performance information in making decisions that affect both their organization and the delivery of public services to citizens.

\section{Nonroutine Performance Information}

Another type of performance information, or feedback, that differs from the aforementioned routine performance information is labelled "nonroutine" (Kroll, 2013). Kroll defines nonroutine performance information "as the residual that remains when we subtract routine performance reports from all potential feedback" (p. 266) and refers to this type of performance feedback as "rich, soft, and timely qualitative information that managers often obtain from social interactions with employees and peers, including phone calls, meetings, and observational tours" (Tantardini \& Kroll, 2015). The importance of nonroutine performance information is known to researchers; Mintzberg (1973), Ouchi (1979), and Kotter (1990) previously noted the importance of this informal feedback and information for managerial decision making.

In particular, Mintzberg (1973) identifies three main roles that managers undertake to govern their organizations: interpersonal, decisional, and informational. The interpersonal role originates from manager's hierarchical position and endorses the use of interpersonal skills with subordinates. The second is the decisional role, which comprises the following tasks and responsibilities: seeking opportunities, dealing with situations that are not formalized in bureaucratic procedures, and allocating resources. The last managerial role that Mintzberg described is informational. Managers acquire nonroutine performance information both from internal sources-such as other managers within the same department or across departments - and external sourcessuch as local politicians, interest groups, relevant stakeholders, local media, and managers in other organizations both private and public. In the informational role, 
managers, according to Mintzberg (1973), also disseminate and spread information, norms, and values within their organizations and they also transmit information to others outside their organization. Therefore, managers have a dual role as collectors of information and distributors of information. Regarding the type of information that managers receive and use, Mintzberg (1973) stresses that most of this information is informal and face-to-face in nature and that it can come from both inside (see also Kroll, 2013; MacRae \& Wilde, 1985; Weiss, 1981) and outside (see also Kroll, 2013; Suchman, 1995) the organization.

Others have studied this particular kind of performance information. In particular, Ouchi (1979) states that this kind of information "is contained in the rituals, stories, and ceremonies which convey the values and beliefs of the organization" (p. 839) and that there is no need to complex and sophisticated system to collect this information because "it is just there" (p.840). More recently, Kotter (1990), in a study on managers similar to Mintzberg (1973), discovered that the majority of communication within an organization is oral and informal rather than written and formal. Even through humorous, informal discussions with someone related to the organization, managers can acquire important information that can be used in their decision making.

Nonroutine performance information, especially in the form of oral and informal feedback, is a great source of facts and news that managers can use in their decision-making process. However, the use (or abuse) of email, mobile phones, and other means of digital communication might have replaced oral and informal feedback with something written (i.e., email) that might be informal or formal in nature. 


\section{Different uses of performance information}

The use of performance information can vary significantly (Behn, 2003; Van Dooren \& Van de Walle, 2008). According to Behn (2003), public managers have eight uses for performance information: to evaluate, to control, to budget, to motivate, to promote, to celebrate, to learn, and to improve. Similarly Van Dooren and Van de Walle (2008) proposed a categorization of forty-four different uses of performance information. In another classification proposed by Van Dooren et al. (2010), three different uses are noted: to learn, to steer and control, and to give account. Other managerial tools such as strategic planning, budgeting, program evaluation, quality improvement, benchmarking, or the monitoring of daily activities have also been investigated in efforts to characterize performance data use (de Lancer Julnes \& Holzer, 2001; Poister \& Streib, 1999; Wang, 2002).

For example, Poister and Streib (1999) in an analysis on managerial use of performance information show that most public managers surveyed use performance information for strategic planning, strategic management and budgeting, evaluation of programs, processes of continuous quality improvement, benchmarking activities, and processes of management by objectives. The majority also indicated that performance measures have improved decision-making processes at least moderately. In a study of U.S. public administrations, Wang (2002) shows how managers can use performance information to increase monitoring of daily activities and strategic planning, and for budgeting purposes to facilitate the allocation of resources. The use of performance information in those studies relies primarily on performance information that is incorporated into official documents, reports, and databases. However, the literature shows that while managers do rely on those routine measures, they also rely on nonroutine performance information. Kroll (2013) finds that nonroutine performance 
information is as important as routine performance information and could be used even "more frequently by public managers than information from routine reports" (p. 273); however, diverse studies have found different and sometimes contradictory results about the implementation of performance management systems (Yang \& Hsieh 2007).

Moynihan (2009) suggested four different uses of performance information: purposeful, passive, political, and perverse. Purposeful use occurs when performance information is used to deliver better services to public administration stakeholders. This is in line with expectations of the new public management reforms: to utilize performance information to better manage public organizations and their programs and services. Passive use occurs when managers merely comply with such laws without using performance information to make decisions. Information is used politically whenever it is used as a "means of advocacy in a political environment" (Moynihan, 2009, p. 593). Perverse use of performance information includes "making up data, cheating easy-to-serve clients, changing performance goals to limit comparison across time, or manipulating measures" (Moynihan, 2009, p. 593). Purposeful use appears to be best suited for examinations of whether performance measurement has had a positive impact and it is also the focus of this study.

Regarding performance information use, an aspect that is worthy of analysis is whether performance management reforms that measure and incorporate performance information actually ameliorate the managerial decision-making process. In other words, what are the impact factors of performance information use? Research on this particular topic is not yet well developed. Therefore, when information is available and that information is perceived as reliable, managers will tend to use it to make decisions. The literature shows that a better informed decision making-process is therefore 
possible, as the new public management reforms envisioned, leading public managers to make not necessarily better, but at least better-informed decisions. The literature analyzed so far posits a further issue. What factor can be used to explain public managers' use of performance information? The answer to this question is addressed in the next section.

\section{Drivers of performance information use}

Past scholars have attempted to determine how to evaluate the success of performance management reforms. The general consensus is that reforms can be considered successful if managers use performance information in their decision making process. (Kroll 2014; Van Dooren \& Van de Walle, 2008).

Scholars have also identified several drivers of performance information use. In particular, Ammons and Rivenbark (2008) found that benchmarking is an important driver of performance information use. A study by Moynihan and Pandey (2010) finds that organizational culture "is supportive of performance information use" (p. 854). Other relevant drivers identified by scholars are: learning forums (Moynihan, 2008, p. 359); stakeholder involvement (Berman \& Wang, 2000); and political support (Yang \& Hsieh, 2007). Moreover, Kroll (2014) indicates how organizational variables (e.g., measurement system maturity, leadership support, support capacity and resources, innovative culture, and goal clarity) are important to understand managerial use of performance information.

Although many organizational factors have been used to explain and predict performance information use, the concept of organizational social capital has been previously neglected in the literature. The next chapter introduces organizational social capital and explores the concept in greater detail. The chapter argues that organizational 
social capital, which consists of three sub-dimensions (i.e., structural, relational, and cognitive), is an important driver of performance information use in public administrations.

This chapter has reviewed the literature on performance management in general and performance information use in particular. The chapter started by describing several theories of decision making and upon them introduced the use of performance information in the managerial decision making process. It has described the differences between routine and nonroutine performance information, different uses, and its drivers. The chapter concludes by introducing the concept of organizational social capital, a factor neglected in the literature of performance information use. 


\section{Chapter 3: Organizational Social Capital Literature Review}

This chapter reviews the literature on social capital in general and organizational social capital in particular. The chapter highlights the central theories of organizational social capital: neo-capitalist theory, social network theory, and organizational culture theory. Subsequently, the chapter describes three types of social capital: community social capital, organizational social capital, and individual social capital. Particular attention is given to the construct of organizational social capital.

\section{Theoretical background}

Although social capital and organizational social capital are increasingly popular topics in different areas of research, there is not a definite, categorical, and settled definition for them (Fukuyama, 1995). To provide a solid foundation for such an undefined and blurry construct, we will examine three organizational theories: neocapitalist theory, to understand the "capital" component and social network theory and organizational culture theory to understand the "social" and "organizational" component.

\section{Neo-Capitalist Theory}

Etymologically, the word capital derives from the classic Latin word caput, "head," and from Medieval Latin capitalis, "of the head." However, it was not until 1611 that "capital" assumed its modern meaning. A "capital grant" was land granted from the King (Head of State) to non-aristocratic individuals, what would later become the bourgeois, as the foundation for a new endowment.

Karl Marx $(1933,1995)$ makes three tiered argument to describe capital. In the first tier, only the circulation of commodities that appeared in history at a specific time allowed the accumulation of capital. The next tier, there is a clear distinction between 
money per se and money as capital. The former type of money is used in the exchanges of commodities, what Marx defined as the Commodity-Money-Commodity (C-M-C) paradigm. The latter type of money - capital — is used to buy something with the ultimate goal of reselling it, defined by Marx as the Money-Commodity-Money (M-CM) paradigm. The final tier of his argument is that capital is the type of money that allows one to resell a commodity at a higher price, which allows one to profit (M-C-M paradigm).

In other words, capital constitutes the surplus value in a given exchange (Marx, 1933, 1995). This surplus value is captured by those who initially had the capital and control production means in the circulation of commodities and monies between the production and consumption processes (Lin, 1999). In the classical Marxist theory of capital, two classes exist: the laborers (or working class) and the capitalists (or bourgeois). The social relation between these two classes is based on conflict. In traditional Marxist theory, a wage is given to laborers in exchange of their work in the production of commodities - the same commodities their wages allow them to buy in the market. Commodities that are produced by the workers are sold on the market by the capitalists at a higher price. The difference between the production price and the market price is the surplus value that is captured by the bourgeois. Thus, capital is both surplus value in the M-C-M paradigm but also represents the initial investment that the bourgeois class has made in the production means (Lin, 1999).

In neo-capitalist theories, the notion of capital remains unchanged. Capital is still considered a surplus value and an investment from which a return is expected (Lin, 1999). However, the main difference between classical Marxist theories of capital and neo-capitalist theory is that now the working class-the laborers-can invest and 
acquire capital in the form of human capital (Becker, 1964; Johnson, 1960; Schultz, 1961;) or in the form of cultural capital (Bourdieu, 1990; Bourdieu \& Passeron, 1977). Because anybody can now capture the surplus values of capital and can make investments in capital, even the original dichotomy between the bourgeois (i.e., those who invest and capture capital) and the working class (i.e., those who are exploited in the surplus value acquisition) becomes obsolete.

\section{Social Network Theory}

In organizational theory, social network theory "contrasts with the type of sociological theory that defines society as built up of individuals" (Williams \& Durance, 2008, p. 1). According to this theory, society is composed of networks of relations described as nodes and ties. Nodes are the individual actors within the networks, and ties are the relationships between the actors. Williams and Durance (2008) describe the following important components of social networks:

- Actors and their actions are viewed as interdependent rather than independent, autonomous units;

- Relational ties (linkages) between actors are channels for transfer or "flows" of resources (either material or nonmaterial);

- Network models focusing on individuals view the network structural environment as providing opportunities for, or constraints on, individual action;

- Network models conceptualize structure (social, economic, political, and so forth) as lasting patterns of relations among actors.

In particular, social network theory places analytical importance on the following characteristics: nodes, hierarchy, transitivity, and homophily, and the two approaches 
that characterize social network analysis (i.e., whole network analysis and egocentric network analysis) (Williams \& Durance, 2008). Nodes constitute the backbone of social networks. However, not every node is tied to another node. There are clusters of nodes with very connected ties and "bridges-ties" that connect these clusters to other existing clusters or single nodes. Hierarchy in social network theory is defined in terms of nodes being at the center of a particular network and nodes being in a more peripheral position.

The property of transitivity allows that if $\mathrm{A}$ is connected to $\mathrm{B}$, and $\mathrm{B}$ is connected to $\mathrm{C}$, then $\mathrm{A}$ and $\mathrm{C}$ are connected to each other. This property is specifically discussed by Granovetter (1973). The property of homophily refers to the tendency of actors to have connections and relations to people with whom they have something in common or with whom they can relate with. Therefore, social networks tend to be very homogeneous in nature. According to McPherson et al. (2001), the following factors make networks more homogeneous: gender, occupation, education, religion, age, and above all race and ethnicity. These factors are in ascending order.

To study networks, two approaches of network analysis exist: whole network analysis and egocentric network analysis. Whole network analysis considers the entire network, examining it from the outside and collecting data on all the ties and nodes. Egocentric network analysis considers only one node (ego) and its ties (also called alters), thus examining the network from the inside.

Kadushin (2012) identifies three types of social networks: ego-centric networks, socio-centric networks, and open-system networks. Ego-centric networks refer to networks that are tied to a single individual (a person and his close friend). Socio-centric networks are closed networks (e.g., a department in an organization). In an open-system network, ties among nodes are not clearly defined. The three types of social capital that 
will be analyzed in the following sections - individual, organizational, and community social capital—refer respectively to the above types of social networks.

\section{Organizational Culture Theory}

According to Andrew M. Pettigrew (1979), who first defined Organizational Culture Theory, organizations "may profitably be explored as a continuing system with a past, a present, and a future" (p.570). Culture itself is not a unitary concept but it is the product of a family of concepts that includes symbol, language, ideology and belief, ritual, and myth. Symbols are used to create group or organizational identity. Language is used to typify experience and create the jargon that identifies a member of an organization. Language is essential in creating culture in an organization (Pettigrew, 1979). Ideologies and beliefs connect attitudes with action in an organization. Both rituals and myths are important in defining organizational culture. Rituals create a sense of belonging in the members of an organization, while myths help define what is tolerant or intolerant in an organization (Pettigrew, 1979).

A more recent definition of organizational culture is proposed by Schein (1992, p. 18):

a pattern of shared basic assumptions learned by a group as it solved its problems of external adaptation and internal integration, which has worked well enough to be considered valid and, therefore, to be taught to new members as the correct way to perceive, think, and feel in relation to those problems.

According to Schein (1992), there are three levels of culture within an organization: artifacts, exposed values, and basic underlying assumptions. 
Organizational culture is reinforced by these three levels and each level reinforces itself. Artifacts can be both visible products such as language, technology, products, creations, and style (e.g., myths and stories), and less visible but more superficial such as sees, hears, and feels. Even if it is easy to perceive these artifacts, it is more difficult to interpret and classify them. Exposed values refers to values that an organization would like to embody, but that are not in practice within the organization. Exposed values reflect the original values of an organization; they are initially started by the founder or leader of the organization and then assimilated by the other components. The final component is composed of basic underlying assumptions, which refer to unconscious, taken-for-granted beliefs, perceptions, thoughts, and feelings. To analyze group culture, one must analyze these three level of basic assumptions and the culture it is built upon.

\section{Summary}

In this section, several theories that underlie the concept of organizational social capital have been reviewed. These theories provide a contextual foundation for this complex concept. It is fundamental now to explain the link between these theories and the concept of organizational social capital itself. Regarding Neo-Capitalist Theory, by studying the capital component of organizational social capital in the context of neocapitalist theories, we see that any individual can capture the surplus value derived from an investment in organizational social capital, even if that individual was not part of the initial investment of social capital (Inkpen \& Tsang, 2005). By extension, even the distinction between managers and employees is blurred in the context of neo-capitalist theories: both can tap into the surplus derived from existing, and further investment of, social capital; neither is excluded. 
Regarding social network theory, nodes (actors) and ties (relationships), which constitute the backbone of networks, also function as the backbone of social capital. Without social relations among actors, the concept of social capital would not exist. As noted by Wasserman and Faust (1994), the ties among actors allow the transfer (i.e., flow) of material or nonmaterial resources. The link between these theory and classical Marxist and neo-capitalist theories is straightforward. In the M-C-M paradigm, the initial capital (M; using Marxist terminology) or the initial resource (using Social Network Theory terminology) is used in exchanges between people to gain more of that resource. Networks facilitate these exchanges because they directly or indirectly connect more people that could benefit from the exchanges. Therefore, Marxist and neo-capitalist theories and social network theories are dependent on each other. Marxist and neo-capitalist theories need social network theories to explain how exchanges of capital are made, while social network theories need Marxist and neo-capitalist theories to explain how resources that flow within a network can be capitalized and create spillover effects among the members of those networks.

Finally, the concept of organizational social capital fits the theory of organizational culture for the following reasons. Like culture, social capital is rooted within an organization. Symbols and language (Pettigrew, 1979), as well as artifacts and underlying assumptions (Schein, 1992), are part of organizational social capital. As organizational culture may evolve in a given organization due to the effect of a leader (Schein, 1992), so can the level of organizational social capital.

\section{Social Capital in the Literature}

Different types of capital are known to exist and they vary according to their form: physical or intangible. Natural capital (Costanza et al., 1997) takes physical forms and 
includes trees, minerals, the atmosphere, etc. Human capital (Coleman, 1988) takes intangible forms and includes people' expertise and knowledge. Manufactured capital takes physical forms and includes machineries, buildings, and fixed assets. Financial capital takes intangible forms and includes cash, bonds, and stocks. The last type of capital is social capital which takes intangible forms.

Putnam (2000, p. 19) has defined social capital as "the connections among individuals - social networks and the norms of reciprocity and trustworthiness that arise from them." Social capital allows for "potential benefits accruing to actors because of their insertion into networks or broader social structures." (Portes, 1998, p. 19). Portes (1998) identifies three levels at which connections and interactions may exist: micro (individual), meso (group), and macro (society). Different levels of social capital are noted to exist (Portes, 1998); three of these levels-individual social capital, community social capital, and organizational social capital—will be examined in the next section.

\section{Individual Social Capital}

Some public administration scholars view social capital as a private resource that belongs to individuals (e.g., Anderfuhren-Biget, 2012; Brewer, 2003; Chen et al., 2014, Tepe, 2015). Most of the literature on individual social capital focuses on the level of personal trust of individuals toward others. For example, Anderfuhren-Biget (2012) uses social trust as a proxy of social capital to explain the Public Service Motivation (PSM) level of public employees. Taylor (2010) shows that American and Australian civil servants are to some extent more trusting than private employees. Similarly, Chen and colleagues (2014) use the trust component of social capital to explain public employees' trust in citizens. Tepe (2015), in an experimental study, 
shows that students of public administration have more trust and trustworthiness than students of business or law.

All these studies employ social capital, but in reality, they are using the trust component of social capital to explain the level of PSM of either public employees or students. PSM is an individual personality trait that people may or may not have. In contrast to social capital, PSM does not translate into an organizational or community level. The question here is whether trust itself is enough to characterize a more complex and composite concept like social capital. However, it is considered that the trust component alone is not sufficient to portray what social capital really is and all the facets that constitute such a construct.

\section{Community social capital}

Like organizational and individual social capital, there is no univocal definition of community social capital, which is also referred to simply as social capital. Putnam's (1995) definition has been previously presented. Coleman (1988) defined social capital as a "variety of different entities, with two elements in common: they all consist of some aspect of social structure, and they facilitate certain actions of actors-whether personal or corporate actors - within the structure" (p. 598). Similarly, Fukuyama (1995) defined social capital as "the ability of people to work together for common purposes in groups and organizations" (p. 10). These three definitions, as well as other definitions of social capital not reported in this study, all stress the following elements:

1. Connections or some form of network linking individuals;

2. Among these individuals, there is some form of trust;

3. Social capital facilitates the production of outcomes that would not be possible without such facilitation. 
The concept of social capital has been widely studied, especially in fields outside the public administration context, namely economics, sociology, and political science. Most of these studies focus on its consequences, highlighting especially its benefits. Social capital fosters economic growth and economic development (Coleman, 1988; Putnam, 1995). Social capital and especially its trust and collaboration components lead actors toward socially efficient collective action (La Porta et al., 1997). From a political science perspective, social capital has a positive correlation with political accountability (Claibourn \& Martin, 2007), political tolerance attitudes (Cigler \& Joslyn, 2002) and political culture (Jackman \& Miller, 1998). From a sociological and public administration perspective, social capital improves organizational performance (Andrews, 2010, 2011; Coffé \& Geys, 2005; Pierce et al., 2002; Rice, 2001; Tantardini et al., forthcoming), quality of government (Knack, 2002), and educational performance (Meier \&O'Toole, 2003). However, as it will be described later in the chapter, the literature has not only focused on the positive aspects of social capital but also on its negative impact (Arrow, 2000; DeFilippis, 2001; Durlauf, 2002; Ganapati, 2013; Portes, 1998; Solow, 2000).

The big question concerning social capital is: what are the determinants of social capital (Rupasingha et al., 2006; see also Alesina \& La Ferrara, 2000; Brehm \& Rahn, 1997; Glaeser et al., 2000, 2002)? Most of the literature (Becker, 1965 1974) utilizes economic theory to explain the sources of social capital using the rationale provided in the previous section on neo-capitalist theory. Rupasingha et al. (2006), found that the following factors are associated with social capital production (or destruction) in the U.S. counties: ethnic division, income and income inequality, level of education, community attachment, role of women, marriage and family, age, suburbanization, type 
of employment, and home ownership. Ganapati (2009) in a study that links disaster to social capital formation in the Turkish context found that disasters could actually help the formation of social capital in terms of solidarity and in terms of new connections among the victims and their government.

The next section will highlight the third variation in the conceptualization and level of analysis of social capital, redirecting focus and attention from communities to organizations.

\section{Organizational Social Capital}

Leana and Van Buren (1999) defined organizational social capital "as a resource reflecting the character of social relations within an organization" (p. 538). Furthermore, organizational social capital can be considered an asset that can create positive effects for organizations and for the people that are part of those organizations (Leana \& Van Buren, 1999). According to Inkpen and Tsang (2005), organizational social capital is a public good because the "members of an organization can tap into the resources derived from the organization's network of relationships without necessarily having participated in the development of those relationships" (p. 151). In general, theories that analyze organizational social capital state that positive and productive interactions and relationships between members of an organization are fundamental to creating and sharing knowledge (Andrews, 2011). However, the negative aspects of social capital must be acknowledged as well. According to Aldridge et al. (2002), social capital can foster behavior that worsens economic performance or that can exclude actors or possible incumbents from joining a particular network. On the same path, Morrow (1999) and Szreter (2000), in different studies, find that different kinds of 
groupings and associations that can generate social capital are potentially more likely to exclude other actors.

According to Nahapiet and Ghoshal (1998), three key components constitute organizational social capital: structural social capital, which measures the connections among actors; relational social capital, which measures trust among actors; and cognitive social capital, which measures the level of shared goals and values among actors. However, other categorizations of organizational social capital also exist. Uphoff and Wijayaratna (2000), for instance, identify only two components of organizational social capital: the structural and the cognitive dimensions. This dissertation adopts the Nahapiet and Ghoshal (1998) categorization because it has been used in several other research focusing on organizational social capital—both in the private and public sector-making it the most accepted conceptualization in the literature of organizational social capital.

\section{The Structural Dimension}

According to Nahapiet and Ghoshal (1998, p. 244), structural social capital refers to the "configurations of linkages between people and units." According to Andrews (2011), formal and informal collaboration and coordination as well as interaction between colleagues, units, and departments creates spillover effects that ameliorate working conditions and individual and organizational performance. Structural social capital components are: network ties and network configuration. According to Nahapiet and Ghoshal (1998, p. 252), "the fundamental proposition of social capital theory is that network ties provide access to resources." Those resources are defined as information (Nahapiet \& Ghoshal, 1998). Network configuration constitutes the channels by which information is transmitted within an organization. 
Furthermore, "the overall configuration of these ties constitutes an important facet of social capital” (Nahapiet \& Ghoshal, 1998, p. 252). Other scholars (Granovetter, 1973; Jacobs, 1965) show how network configuration and network ties are associated with the concept of flexibility and ease of information exchange within an organization.

\section{The Relational Dimension}

With relational social capital, the literature refers to the level of trust and reciprocity between individuals in the same organization. According to Andrews (2011), a higher level of trust is associated with easier interaction, easier exchanges of information, and less conflict in organizational change. The main component of relational social capital is trust (Nahapiet \& Ghoshal, 1998). Trust can be defined as the "positive expectations individuals have about the intent and behaviors of multiple organizational members based on organizational roles, relationships, experiences, and interdependencies" (Shockley-Zalabak et al. 2000, p. 35). Trust has been widely studied by different authors and identified as fostering and creating social capital both at a community level and at an organizational level (Fukuyama, 1995; Putnam, 1993, 2000; Leana \& Van Buren, 1999; Ring \& Van de Ven, 1992). High levels of trust between organizational leaders and members in particular may permit the transfer of sensitive information, foster collaborative action in the absence of formal mechanisms for that purpose (Coleman, 1988), and diminish resistance to organizational change (Kramer, 1999).

According to Cohen and Prusak (2001), "social capital depends on trust. The relationships, communities, cooperation, and mutual commitment that characterize social capital could not exist without a reasonable level of trust" (p. 29). Organizational trust is not merely "the sum total of personal trust relationship within the organization" 
(p. 35), but also the ability of the organization itself to influence it (Cohen \& Prusak, 2001). Different types of trust that affect organizational social capital are acknowledged to exist; fragile and resilient trust merit further analysis (Ring \& Van de Ven, 1992; Leana \& Van Buren, 1999). Fragile trust is based on a formal and contractual basis and does not survive beyond the transaction (Leana \& Van Buren, 1999). On the other hand, resilient trust is based on much stronger and durable links between the organization and its members (Leana \& Van Buren, 1999). According to Leana and Van Buren (1999, p. 543):

Organizations strong in social capital will exhibit resilient trust, even among individuals connected generally rather than personally. Organizations weak in social capital, conversely, will be characterized by fragile trust (if any), even among individuals who directly and frequently interact.

\section{The Cognitive Dimension}

Cognitive social capital refers to the capacity of an organization to share the same vision, mission, and goals among members. Leana and Van Buren (1999) refer to cognitive social capital as the "willingness and ability to define collective goals that are then enacted collectively" (Leana \& Van Buren 1999, 542). The sharing of similar goals can happen either by sharing language and codes, by sharing same narratives, or by a combination of them (Nahapiet \& Ghoshal, 1998). Shared language and codes as well as narratives are the components of cognitive social capital. Language is a primary tool for exchange in social interactions and relations. Codes help to create a common language that facilitates communication itself, and the capacity to understand each other. Therefore, shared language and codes "may provide a common conceptual apparatus for evaluating the likely benefits of exchange" (Nahapiet \& Ghoshal, 1998, 
p. 254). Shared narratives, such as "myths, stories, and metaphors also provide powerful means in communities for creating, exchanging, and preserving rich sets of meanings" (Nahapiet \& Ghoshal, 1998, p. 254).

This chapter has reviewed the literature on social capital in general and organizational social capital in particular. The chapter started by highlighting the central theories of organizational social capital: neo-capitalist theory, social network theory, and organizational culture theory. The chapter has then described three types of social capital: individual social capital, community social capital, and organizational social capital. Taking into consideration both the contributions within the public administration literature and those from other field of studies. The analysis of both stream of literature highlighted how social capital is still more developed in fields outside the public administration or public management debate. The next chapter analyzes the relationship between the concept of organizational social capital and performance information use. 


\section{Chapter 4 Research Questions and Hypothesis}

This chapter constitutes the first part of the core of the dissertation. By reviewing both the literatures on performance information use and organizational social capital, this chapter highlights the gap in the literature and proposes two main research questions. Furthermore, by providing further insight into the literature of organizational social capital and performance information use, it offers the theoretical explanations of how the former and the latter are linked. The chapter also delivers the hypotheses that will be tested in the dissertation's empirical section.

\section{Research questions}

As stated in Chapter 1, the main goal of this dissertation is to relate organizational social capital and performance information use. Although, as seen in the literature review, several drivers of performance information use have been identified, the concept of organizational social capital has not yet been explored. Therefore, given the gap in the literature, two main research questions have been identified:

1. Does organizational social capital foster departmental performance information use?

2. Does organizational social capital affect routine and nonroutine performance information in similar ways, or does it increase the use of only one type of information at the expense of the other?

\section{Organizational Social Capital and Performance Information Use: Hypotheses}

\section{Nonroutine performance information}

The link between organizational social capital and performance information use is analyzed as follows: first the importance of informal feedback in decision making is analyzed; second, the drivers that lead to use of nonroutine performance information 
are discussed; finally the link between organizational social capital and nonroutine performance information use is proposed.

The importance of informal feedbacks, as highlighted in Chapter 2, has been studied long before that performance management had become a new trend in the public sector. Mintzberg (1973), Ouchi (1979), and Kotter (1990) have previously studied the significance of this type of performance information that seems to be so important for managerial decision making. One of the role of managers described by Mintzberg (1973) is informational from collecting information from many sources to assess organizational performance, from facilitating the flow of information within an organization and in particular between subordinates, to inform stakeholder about organizational performance and the achievement of goals and objectives. As portrayed here, managers have this role of information traders within an organization. As noted above, Mintzberg (1973) points out that most of this information is informal in nature. Managers would base their decision more likely on nonroutine performance information that comes both from inside (see also Kroll, 2013; MacRae \& Wilde, 1985; Weiss, 1981) and outside (see also Kroll, 2013; Suchman, 1995) the organization rather than routine performance information originated by performance management systems (Mintzeberg, 1973). This is due to the fact that that kind of information is more accessible and immediate to managers than reports and data that requires longer time to be processed and analyzed (Mintzeberg, 1973).

The importance of clan behavior has been analyzed primarily by Ouchi (1979). He states that organizations that behave like a "clan"-with a strong focus on the socialization of the group, same ethics and morale, and same behaviors - are more likely to use informal information systems that "grow up as a natural by-product of 
social interaction" (Ouchi, 1979, p. 839). More recently, Simon (1995) noted how informal information systems generated by interactions among members of an organization are crucial for managerial decision making. Similarly, Oh et al. (2004) analyzed how group ties among members of an organization support the sharing of informal information and, even more interestingly, they describe how these ties are important when a member of the group is in need of information.

Members of organizations with a high level of organizational social capital tend to have strong ties, trust, and shared goals among each other. Therefore, they tend to have a behavior similar to those described by Ouchi (1979), Simon (1995), and Oh et al. (2004). These organizations are more likely to rely on informal information systems and informal feedback, which leads us to our first hypothesis:

H1: Departments with high levels of organizational social capital are more likely to use nonroutine performance information.

\section{Nonroutine performance information and routine performance information}

In the previous section, it was hypothesized that departments with a higher level of organizational social capital are more likely to use nonroutine performance information. Although this hypothesis is supported by theoretical argumentation, routine performance information must also be taken into consideration. Otherwise, it would be unclear why public administrations have spent significant resources in adopting and implementing formal information systems in the past 30 years. Therefore, it is plausible to think that managers use nonroutine performance information in addition to using routine performance information. This study aims to determine if managers use routine and nonroutine performance information in similar ways, if 
routine and nonroutine performance information complement each other, or if the use of one type can substitute the use of the other.

From a theoretical perspective, only scant research exists to explain the use of routine performance information alongside the use of nonroutine performance information. However, Kroll (2013) notes that managers of local public administrations that consider nonroutine performance information in their decision making process will be more likely to also use routine performance information. By extension of the argumentation in the previous section, it is hypothesized that organizational social capital will foster routine performance information use and not just use of informal feedback. Thus, the second hypothesis is proposed:

H2: Departments with high levels of organizational social capital are more likely to use nonroutine performance information as well as routine performance information.

As discussed in Chapter 3, organizational social capital is composed of three distinct yet interrelated dimensions: structural social capital, relational social capital, and cognitive social capital. To more effectively analyze the link between organizational social capital and performance information use, the sub-hypotheses of $\mathrm{H} 2$ are proposed by considering each dimension separately.

\section{The Structural Dimension}

The "configurations of linkages between people and units" (p. 244) constitute the structural dimension of organizational social capital (Nahapiet \& Ghoshal, 1998). Network ties and network configuration are the two major components of the structural dimension of organizational social capital. Network ties and network configuration are 
acknowledged to have positive effects at the organizational level (Andrews, 2011; Granovetter, 1973; Jacobs, 1965; Nahapiet \& Ghoshal, 1998). Andrews (2011) finds that the amelioration of the working condition as well as the amelioration of both individual and organizational performance are possible due to spillover effects generated by both formal and informal collaboration and coordination and interaction between colleagues, units, and departments. Nahapiet and Ghoshal (1998) state that network ties within an organization provide access to information. Furthermore, once information is made available, the configuration of networks constitutes the channels by which information is transmitted within an organization (Nahapiet \& Ghoshal, 1998).

Similarly, Granovetter (1973) and Jacobs (1965) state that density, connectivity, and hierarchy (i.e., network configuration and network ties) are all associated with the concept of flexibility and ease of information exchange within an organization. Furthermore, different studies show how effective internal communication is responsible for a strong organizational focus on results (i.e., Moynihan \& Pandey, 2006). Therefore, the structural dimension of organizational social capital (i.e., collaboration, coordination, interaction between members of an organization) not only makes information available, but also facilitates information exchange among the members of an organization. Therefore, if the supply of performance information is guaranteed by high levels of organizational social capital, managers will more likely be using the information that is available to them.

H2a: Departments with high levels of structural social capital are more likely to use nonroutine performance information as well as routine performance information. 


\section{The Relational Dimension}

Trust can be defined as the "positive expectations individuals have about the intent and behaviors of multiple organizational members based on organizational roles, relationships, experiences, and interdependencies" (Kath et al., 2010). According to Diffie-Couch (1984), relationships would not be able to survive without trust. Job satisfaction, productivity, organizational commitment, decreased absenteeism, and turnover are all positive effects of organizational trust (Driscoll, 1978; Hopkins \& Weathington 2006; Perry \& Mankin, 2007). According to Putnam (1993), trust “enables participants to act together more effectively to pursue shared objectives" (p. 56). Putnam, with that definition, not only defines the concept of trust but also states one of the positive organizational effects of trust that is acknowledged by other authors. Similarly, Coleman (1988), explains that higher level of trustworthiness and extensive trust within the members of an organization lead to higher levels of achievement of goals and objectives. Organizations need information to achieve their goals and objectives and information itself is by no means a fundamental basis for action (Coleman, 1988). However, acquiring information could be highly costly and difficult, especially for “difficult-to-measure programs" (Coleman, 1988; Wholey, 1999, p- 291).

However, trust is not only associated with higher levels of productivity and achievement — as Coleman (1988) and Putnam (1993) point out—but it is also associated with the ease of information exchange between different actors. Andrews (2011) states that a higher level of trust is associated with easier interaction and easier exchanges of information. Similarly, high levels of trust between organizational leaders and members may permit the transfer of sensitive information (Coleman, 1988). Furthermore, it has been observed that the more managers trust their employees, the 
more they are willing to share information with them (Dansereau et al., 1975; Gomez \& Benson, 2001).

A third positive organizational effect is that with higher levels of trust among the members of an organizations, managers are more likely to trust the quality of the information upon which they base their decisions (Dirks \& Ferrin, 2001). This is due to the fact that managers that trust their subordinates consider the data and reports provided as accurate and reliable - with no additional need to verify the information provided.

Therefore, relational social capital conceptualized as trust has multiple effects. On the one hand, it fosters productivity and goal achievement (Coleman, 1988; Putnam, 1993). On the other, it fosters the ease of exchange of information (Andrews, 2011; Coleman, 1988) and managers' trust in the quality and accuracy of the information that they are using. Therefore, performance information use in public administration is fostered by the need to use performance information to measure organizational achievements and the ease of sharing information that managers can trust. Finally, trust not only facilitates sharing of official performance information, but as Bunt et al. (2005) and Kroll (2013) show, also facilitates sharing of other types of performance information including "nonroutine feedback."

H2b: Departments with high levels of relational social capital are more likely to use nonroutine performance information as well as routine performance information.

\section{The Cognitive Dimension}

As stated before, cognitive social capital refers to the ability and willingness to define shared goals that are enacted collectively by the organization. The concept of 
shared goals differs from the concept of group goals. A shared goal "can be pursued independently as a personally or individually held goal. What makes it shared is simply that other in-group members are also experiencing that same goal" (Shteynberg \& Galinsky, 2011, p. 1292). In an experimental study, Shteynberg and Galinsky (2011) found that "participants pursued goals more intensely when they were aware that similar others were experiencing the same individual goal" (p. 1293). Moreover, the authors discovered that when goals are shared and "experienced by similar others" (p. 1293 ) people adopt and produce a "more goal-congruent behaviour" (p. 1293). As Shteynberg and Galinsky (2011) show in their analysis, "the increased convergence of individual goals may make collective action to meet those goals more likely" (p. 1294). Job-goal commitment, job-goal specificity, and mission specificity, as well as strategic planning capacity can enhance organizational performance (Su Sung \& Lee, 2012).

The literature on strategic planning (i.e., Barzelay \& Campbell, 2003; Kim, 2002; Olsen \& Eadie, 1982) suggests that organizations need strategic goals, a mission, and a vision to measure performance. Furthermore, if the majority of people agree on a particular goal, it will be easier for the organization - and the employees that are supposed to achieve those goals - to define indicators that are capable of measuring the defined goal and that are widely accepted by each employee, thus fostering the use of performance information.

Following a behavioral analysis on motivation and group identification in pursuing shared goals by Fishbach et al. (2011), two different types of individuals in an organization exist: those who identify less with their group and/or organization and those who identify highly with their group and/or organization (Fishbach et al., 2011). Those who belong to the first group are more concerned about the value of the shared 
goal, and if they find the goal to be valuable, they will more likely contribute to its achievement. In this scenario, "because information on the group's completed actions signals value, the focus on accumulated contributions increases investment more than the focus on remaining contributions to complete the goal" (Fishbach et al., 2011, p. 530). Those who belong to the second group, on the other hand, are more concerned about whether more action or effort is needed to achieve the goal and, if the need for goal progress exists, they will more likely contribute to its achievement. In this scenario, "because information on required actions signals a need for progress, the focus on remaining contributions increases investment more than the focus on accumulated contributions" (Fishbach et al., 2011, p. 530). In both scenarios, performance information is needed to evaluate goal achievement.

The previous literature on cognitive social capital (Leana \& Van Buren, 1999; Nahapiet \& Ghoshal, 1998) and on the behavioral and psychology literature (Fishbach et al., 2011; Shteynberg \& Galinsky, 2011), supports the idea that sharing common goals within an organization will enhance performance information use. Performance information is fundamental for public managers to determine whether the organization is headed in the right direction - toward the achievement of the defined goals - or whether corrective actions are needed. Furthermore and more importantly, as indicated in previous analyses, performance information could be used by managers as a motivational factor for the organizations to move toward the achievement of organizational goals. Making public sector employees aware of their contribution toward the achievement of organizational goals will increase their effort and commitment in the organization (Fishbach et al., 2011). Therefore, having an 
organization that shares the same goals (i.e., having an organization with cognitive social capital) will enhance managers' ability to use performance information.

H2c: Departments with high levels of cognitive social capital are more likely to use nonroutine performance information as well as routine performance information.

This chapter has highlighted the gap in the literature and proposed two main research questions. Furthermore, by providing further insight into the literature of organizational social capital and performance information use, it has offered the theoretical explanations of how the former and the latter are linked. The chapter has also delivered the hypotheses that will be tested in the dissertation's empirical section. 


\section{Chapter 5: Quantitative Research Design and Methods}

The aim of this chapter is to present the quantitative research design and methods of the investigation that has been used to answer the two proposed research questions. The first section presents the unit of analysis of this study, Florida county governments, along with a brief digression into the history of the State of Florida and some facts regarding Florida counties. The second section introduces the survey instrument and describes how variables have been operationalized in the analysis. The following section describes the pilot test study that was conducted to enhance the validity and reliability of the survey instrument. The fourth section illustrates the response rate achieved for the survey. Estimation routines and limitations are then introduced. The chapter concludes by describing the factor analyses performed to construct the main indexes used in the analysis.

\section{Unit of Analysis}

In this research proposal, the unit of analysis is State of Florida County Governments. The first question to be answered here is why Florida? There are three categories of rationale for this decision: geographical and socio-economic, political, and administrative. First, the State of Florida ranks fourth in the United States in population behind California, Texas, and New York. Florida has experienced a rapid and significant increase in its population, growing from 9.75 million in 1980 to 18.8 million in $2010^{1}$. Population increase, along with other factors (i.e., lack of state income tax and generally low taxes, lucrative homestead exemptions, and cheap land for suburban development) have made Florida one of the fastest growing states especially in the service and real estate sectors of the economy (Kolo \& Watson, 1992), thus

\footnotetext{
${ }^{1}$ U.S. Census, April $1{ }^{\text {st }} 2010$.
} 
making Florida's large size worthy of examination. Also considering the fact that this booming in population lessens the likelihood of having a long established level of community social capital.

The State of Florida has also been chosen for political reasons. Florida is considered a swing state, although still leaning slightly Republican. In the last five Presidential elections, Florida electoral votes have been assigned three times to a Democratic candidate (1996, 2008, and 2012) and two times to a Republican candidate (2000 and 2004), making Florida one of the ultimate battleground states. Political and ideological variation within Florida is also an interesting factor to be taken into consideration. South Florida and metropolitan areas historically are more liberalsupporting Democratic candidates - and Northern Florida and more rural areas tend to be more conservative-supporting Republican candidates (Griset, 2002).

The final set of reasons is administrative. First, by restricting the analysis to Florida counties, other potential influences on performance information use - such as the legal framework and state level obligations - are held constant (as in Andrews et al., 2009). Second, the State of Florida has a relatively small number, compared to other states, of overlapping special districts that provide services also supplied by counties and/or municipalities (Wu \& Hendrick, 2009). Finally, studying the State of Florida allows researchers to take into consideration different levels of professionalism among public managers and civil servants: from high professionalism in more dynamic organizations to low professionalism in more conservative ones.

The second question to be answered is why county governments? According to the Constitution ${ }^{2}$ of the State of Florida, counties are political subdivisions of State

\footnotetext{
${ }^{2}$ Constitution of the State of Florida, as revised in 1968 and subsequently amended in November 2010.
} 
territory. There are 67 counties in the State of Florida. Counties have powers and duties related to various public issues and are also responsible for the delivery of public services such as: (a) hospitals, ambulance service, and health and welfare programs; (b) parks, nature preserves, playgrounds, recreation areas, libraries, museums, historical commissions, and other recreation and cultural facilities and programs; (c) land development; (d) zoning and business regulations; (e) housing, slum clearance, community redevelopment, conservation, flood and beach erosion control, air pollution control, and drainage; and (f) waste and sewage collection and disposal, water, and alternative water supplies.

Therefore, counties are the level of government that provides basic services to their citizens, making them worthy of examination and that is emphasized a lot by the State government. Performance management systems among Florida counties are very diverse, with more advanced systems developed especially in metropolitan counties and more rudimental systems developed in rural counties. The differences are accentuated due to the fact that the Florida Statutes do not provide performance management Statewide requirements that every county has to follow.

\section{Historical and geographical overview of the State of Florida}

According to a majority of historians, Florida was discovered and named by the Spanish explorer Juan Ponce de León in 1513. His expedition, which included more than 200 people, first landed in the area that would later be named the City of St. Augustine after one month at sea-sailing from the Spanish colony of Puerto Rico (Allman, 2013). During his return voyage, he stopped in the area that is now modern Jupiter, where he encountered indigenous people and charted Florida's East Coast. He then continued toward Dry Tortuga in the Florida Keys and headed north to explore 
and chart Florida's West Coast until reaching the harbor of what is today Port Charlotte, FL (Allman, 2013). While most of the written history focuses on Juan Ponce de León's explorations, other explorers like Gaspar Corte-Real Panfilo de Narvaez, Álvar Núñez Cabeza de Vaca, Hernando De Soto, Don Luis Velasco made voyages towards the Florida Peninsula (Allman, 2013). In 1570, Florida became a province of the Royal District of New Spain (Mexico). The Governors of Spanish Florida were appointed by the Spanish crown and served five years if they came from Europe and three years if they came from another colony.

In 1763, Florida became a possession of England. The English divided the Florida peninsula into two distinct colonies East and West Florida (Allman, 2013). In contrast to Spanish colonizers, the British attempted to develop Florida as a trade platform and to increase Florida's population especially by recruiting Greek, Italian, and Minorcans. At the start of the American Revolution in 1775, British East and West Florida remained loyal to their Motherland.

With the Treaty of Paris of 1783 , Florida did not become part of the newly born United States of America but was returned to the Spanish Crown. With Thomas Jefferson's Louisiana Purchase from Napoleon in 1803, Florida became even more isolated from the rest of the Spanish Empire. The War of 1812 between England - an ally of Spain - and the United States placed Florida in a difficult position. General Andrew Jackson invaded Florida without Federal authorization and occupied the town of Pensacola. Finally in 1821, the Spanish Crown yielded Florida to the United States of America, understanding that they would have been unable to defend against an American invasion, especially considering that Spanish South American colonies were demanding independence from their Motherland. 
The Territory of Florida was subsequently annexed to the United States of America and General Andrew Jackson became the first Governor of the new Territory. The structure of the government in the Territory of Florida was very basic. The President of the United States of America appointed a three-year Governor, who was assigned a small portion of Federal money. People elected a Territorial Council, which had limited powers over the Territorial Militia. Soon Florida became very similar to other Southern States. Many Georgians and Alabamians moved to Northern and Central Florida to start cotton plantations and slavery became a major share of the Florida economy. The Territory of Florida did not possess any slaves. Slaves were private property of land owners. A second fact that characterized Florida were the Seminole Wars. The First Seminole War was from 1816 to 1819, the Second Seminole War from 1835 to 1842 , and the Third Seminole War from 1855 to 1858 . At the end the Seminole Wars, and because of the Indian Removal Act of 1830, only a few hundred Seminoles were left in the State. In 1845 , Florida became the $27^{\text {th }}$ State of the United States of America.

In 1861, Florida seceded from the Union and joined the Confederate States of America. Florida offered the highest percentage of soldiers in the Confederacy and also suffered the highest percentage of casualties among the Confederate States. Although most battles between the Union and the Confederacy occurred in the northern part of the Confederacy, a few major battles occurred in the State of Florida as well. During Reconstruction, the aims of the Republican Party in Florida were twofold. First, to guarantee political and economic power to former slaves; second, to guarantee the transition from an agricultural economy to a more diversified economy. Both attempts failed. By the end of Reconstruction (1876), southern Democrats regained political and 
economic power. The result was limiting Black-American voting rights, passing of the "Pig Laws," the presence of the Ku Klux Klan, and the restoration of Florida as a conservative, agrarian, Southern State.

The end of the $19^{\text {th }}$ century was dominated by railroad development: William D. Chipley in the Panhandle; Henry B. Plant in the Gulf Coast; and Henry F. Flagler in the Atlantic Coast. Not only did these individuals develop the railroad system, but they also built hotels, roads, and villages. Railroads were fundamental not just for the development of tourism in Florida but also for Florida's economic development. Agricultural goods and Florida sugar could be shipped to Northern markets easily and rapidly.

The 1920s saw the Great Florida Land Boom, with hundreds of thousands of Americans moving for vacation, or permanently, to Florida — transforming Florida's image forever. In the 1920s, the conservative state government of Florida financed a state-wide project to improve the transportation system and public services to favor this boom of visitors. Similarly, in 1924, the Florida Legislature passed a bill that would prevent the collection of a state income and inheritance tax. However, the real estate bubble burst in 1926 and the Great Depression of 1929 hit Florida's economic boom even more harshly. The New Deal, in Florida, was concentrated on lowering the unemployment rate, increasing salaries, and improving working conditions. During World War II, Florida played a major role in the military and civil aviation system. In the four decades after the war ended, Florida experienced record population and economic growth as well as social changes.

In the 1950s, Florida emerged more as an urban society and tourism replaced agriculture as Florida's major industry. Highway projects, such as the Sunshine Skyway 
Bridge and the Florida Turnpike, reduced the role of the railroad industry. The 1960s were a time of social change for Florida, with the civil rights movement transforming the lives of Black Americans, the election of the first Republican Governor since the Reconstruction Era, and a new Constitution, approved in 1968, that transferred powers and responsibilities in the delivery of public services and public programs to counties and cities. All of these changes were possible thanks to a power switch in the State Legislature from rural areas to urban areas.

In the 1970s, Florida experienced continued rapid growth in its population and tourist industry. Walt Disney opened the first theme park in Orlando, setting the basis for a new tourist boom. In the 1980s, Florida had to cope with Northern style problems such as poverty, crime, drugs, population boom, etc. Florida entered the twenty-first century with its old economic roots of tourism and agriculture geared for new challenges, but with a more balanced and diverse economic base. Today, Florida remains a vibrant and booming state in the Union, though not without its problemslike any other state or country.

\section{Overview of the State of Florida County Governments}

When Florida became a Territory of the United States of America, only two counties existed: Escambia and St. Johns. All of the current 67 Florida Counties were created from these two. The last county created in Florida was Gilchrist County in 1925. Table 1 provides a comprehensive list of the 67 Florida Counties in alphabetical order. For each county, the table indicates the County seat, the year it was established, population density and overall population, and county area in square miles.

Population figures are based on data from the 2010 United States Census. The population of Florida was $18,801,310$ in 2010 , an increase of $17.6 \%$ from 2000 . Current 
estimates for 2015 show an overall population of 19.9 million for the State of Florida. The U.S. Census Bureau reported that in 2015, Florida has passed the State of New York in terms of population, making it the third most populous state in the Union after California and Texas. Average population of Florida counties is 280,616 inhabitants. Miami-Dade County is the most populous county with 2,662,874 inhabitants, while Liberty County is the least populous with 8,365 inhabitants. In terms of size, the average land area is 805 square miles. Palm Beach County is the largest county in the State with a land area of 2,034 square miles while Union County is the smallest with a land area of 240 square miles.

Table 1: List of Florida Counties and County Facts

\begin{tabular}{|c|c|c|c|c|c|}
\hline County & County Seat & Established & Density & Population & Area \\
\hline Alachua & Gainesville & 1824 & 285.31 & 249,365 & 874 sq. mi \\
\hline Baker & Macclenny & 1861 & 46.42 & 27,154 & 585 sq. mi \\
\hline Bay & Panama City & 1913 & 222.32 & 169,856 & 764 sq. mi \\
\hline Bradford & Starke & 1858 & 96.43 & 28,255 & 293 sq. mi \\
\hline Brevard & Titusville & 1844 & 533.95 & 543,566 & 1,018 sq. mi \\
\hline Broward & $\begin{array}{l}\text { Fort } \\
\text { Lauderdale }\end{array}$ & 1915 & 1472.43 & $1,780,172$ & 1,209 sq. mi \\
\hline Calhoun & Blountstown & 1838 & 26.01 & 14,750 & 567 sq. mi \\
\hline Charlotte & Punta Gorda & 1921 & 231.28 & 160,511 & 694 sq. mi \\
\hline Citrus & Inverness & 1887 & 239.78 & 140,031 & 584 sq. mi \\
\hline Clay & $\begin{array}{l}\text { Green Cove } \\
\text { Springs }\end{array}$ & 1858 & 320.08 & 192,370 & 601 sq. mi \\
\hline Collier & East Naples & 1923 & 161.96 & 328,134 & 2,026 sq. mi \\
\hline Columbia & Lake City & 1832 & 84.67 & 67,485 & 797 sq. mi \\
\hline DeSoto & Arcadia & 1887 & 54.78 & 34,894 & 637 sq. mi \\
\hline Dixie & Cross City & 1921 & 23.42 & 16,486 & 704 sq. mi \\
\hline Duval & Jacksonville & 1822 & 1124.95 & 870,709 & 774 sq. mi \\
\hline Escambia & Pensacola & 1821 & 450.47 & 299,114 & 664 sq. mi \\
\hline Flagler & Bunnell & 1917 & 200.78 & 97,376 & 485 sq. mi \\
\hline Franklin & Apalachicola & 1832 & 21.72 & 11,596 & 534 sq. mi \\
\hline Gadsden & Quincy & 1823 & 89.44 & 46,151 & 516 sq. mi \\
\hline Gilchrist & Trenton & 1925 & 48.72 & 17,004 & 349 sq. mi \\
\hline Glades & Moore Haven & 1921 & 16.32 & 12,635 & 774 sq. mi \\
\hline Gulf & Port St. Joe & 1925 & 28.04 & 15,844 & 565 sq. mi \\
\hline Hamilton & Jasper & 1827 & 28.49 & 14,671 & 515 sq. mi \\
\hline
\end{tabular}




\begin{tabular}{|c|c|c|c|c|c|}
\hline Hardee & Wauchula & 1921 & 43.78 & 27,887 & 637 sq. mi \\
\hline Hendry & LaBelle & 1923 & 33.9 & 39,089 & 1,153 sq. mi \\
\hline Hernando & Brooksville & 1843 & 362.12 & 173,094 & 478 sq. mi \\
\hline Highlands & Sebring & 1921 & 95.94 & 98,630 & 1,028 sq. mi \\
\hline Hillsborough & Tampa & 1834 & 1206.26 & $1,267,775$ & 1,051 sq. $\mathrm{mi}$ \\
\hline Holmes & Bonifay & 1848 & 41.23 & 19,873 & 482 sq. $\mathrm{mi}$ \\
\hline Indian River & Vero Beach & 1925 & 276.13 & 138,894 & 503 sq. mi \\
\hline Jackson & Marianna & 1822 & 53.81 & 49,292 & 916 sq. mi \\
\hline Jefferson & Monticello & 1827 & 24.51 & 14,658 & 598 sq. mi \\
\hline Lafayette & Mayo & 1856 & 16.47 & 8,942 & 543 sq. mi \\
\hline Lake & Tavares & 1887 & 315.86 & 301,019 & 953 sq. mi \\
\hline Lee & Fort Myers & 1887 & 785.24 & 631,330 & 804 sq. mi \\
\hline Leon & Tallahassee & 1824 & 416.75 & 277,971 & 667 sq. mi \\
\hline Levy & Bronson & 1845 & 35.92 & 40,156 & 1,118 sq. mi \\
\hline Liberty & Bristol & 1855 & 9.94 & 8,314 & 836 sq. mi \\
\hline Madison & Madison & 1827 & 27.62 & 19,115 & 692 sq. mi \\
\hline Manatee & Bradenton & 1855 & 441.49 & 327,142 & 741 sq. mi \\
\hline Marion & Ocala & 1844 & 210.59 & 332,529 & 1,579 sq. mi \\
\hline Martin & Stuart & 1925 & 265.28 & 147,495 & 556 sq. mi \\
\hline Miami-Dade & Miami & 1836 & 1313.5 & $2,662,874$ & 1,946 sq. mi \\
\hline Monroe & Key West & 1823 & 74.1 & 73,873 & 997 sq. mi \\
\hline Nassau & $\begin{array}{l}\text { Fernandina } \\
\text { Beach }\end{array}$ & 1824 & 113.8 & 74,195 & 652 sq. mi \\
\hline Okaloosa & Crestview & 1915 & 196.03 & 183,482 & 936 sq. mi \\
\hline Okeechobee & Okeechobee & 1917 & 51.86 & 40,140 & 774 sq. mi \\
\hline Orange & Orlando & 1824 & 1287.56 & $1,169,107$ & 908 sq. mi \\
\hline Osceola & Kissimmee & 1887 & 208.9 & 276,163 & 1,322 sq. mi \\
\hline Palm Beach & $\begin{array}{ll}\text { West } & \text { Palm } \\
\text { Beach } & \\
\end{array}$ & 1909 & 656.43 & $1,335,187$ & 2,034 sq. mi \\
\hline Pasco & Dade City & 1887 & 626.12 & 466,457 & 745 sq. mi \\
\hline Pinellas & Clearwater & 1912 & 3276.42 & 917,398 & 280 sq. mi \\
\hline Polk & Bartow & 1861 & 325.06 & 609,492 & 1,875 sq. mi \\
\hline Putnam & Palatka & 1849 & 102.55 & 74,041 & 722 sq. mi \\
\hline St. Johns & St. Augustine & 1821 & 321.55 & 195,823 & 609 sq. mi \\
\hline St. Lucie & Fort Pierce & 1905 & 490.17 & 280,379 & 572 sq. mi \\
\hline Santa Rosa & Milton & 1842 & 151.68 & 154,104 & 1,016 sq. mi \\
\hline Sarasota & Sarasota & 1921 & 668.2 & 382,213 & 572 sq. mi \\
\hline Seminole & Sanford & 1913 & 1380.1 & 425,071 & 308 sq. mi \\
\hline Sumter & Bushnell & 1853 & 179.04 & 97,756 & 546 sq. mi \\
\hline Suwannee & Live Oak & 1858 & 61.01 & 41,972 & 688 sq. mi \\
\hline Taylor & Perry & 1856 & 21.78 & 22,691 & 1,042 sq. $\mathrm{mi}$ \\
\hline Union & Lake Butler & 1921 & 64.12 & 15,388 & 240 sq. mi \\
\hline Volusia & DeLand & 1854 & 447.38 & 494,804 & 1,106 sq. mi \\
\hline
\end{tabular}




\begin{tabular}{|l|l|l|l|l|l|}
\hline Wakulla & $\begin{array}{l}\text { Crawfordvill } \\
\mathrm{e}\end{array}$ & 1843 & 51.03 & 30,978 & 607 sq. mi \\
\hline Walton & $\begin{array}{l}\text { DeFuniak } \\
\text { Springs }\end{array}$ & 1824 & 52.73 & 55,793 & 1,058 sq. $\mathrm{mi}$ \\
\hline Washington & Chipley & 1825 & 42.99 & 24,935 & 580 sq. $\mathrm{mi}$ \\
\hline
\end{tabular}

\section{District plan}

For the purpose of elections, counties have liberty in how they establish districts. In particular, three types of district plans exist in Florida: at-large, single member, and mixed (http://www.fl-counties.com). In the at-large district plan, commissioners are elected in county-wide balloting, but are required to reside in a district. The following counties adopted the at-large system: Alachua, Baker, Bay, Charlotte, Citrus, Clay, DeSoto, Dixie, Flagler, Gilchrist, Glades, Hardee, Hernando, Highlands, Holmes, Indian River, Lafayette, Lake, Lee, Levy, Liberty, Marion, Martin, Monroe, Nassau, Okaloosa, Okeechobee, Osceola, Pasco, Polk, Putnam, St. Johns, St. Lucie, Santa Rosa, Sarasota, Seminole, Suwannee, Wakulla, Walton, and Washington.

In the single member system, each district elects its own county commissioner to represent that district. The following counties adopted the single member system: Bradford, Brevard, Broward, Calhoun, Collier, Columbia, Escambia, Franklin, Gadsden, Gulf, Hamilton, Hendry, Jackson, Jefferson, Madison, Miami-Dade, Palm Beach, Sumter, Taylor, and Union.

The mixed system is a combination of the previous two. Some commissioners are elected from voters within the district and other commissioners are elected on a county-wide ballot. The following counties adopted the mixed system: Duval, Hillsborough, Leon, Manatee, Orange, Pinellas, and Volusia. 


\section{Charter Status}

In the new Constitution of Florida adopted in 1968, counties had the power to adopt charters to administer their territory. Charters are a type of county constitution that defines powers, duties, and privileges for the county that adopts it. The new constitution allowed the creation of charter counties to free the state legislature from dealing with local problems that needed local solutions. As of today, 20 of the 67 Florida counties have adopted a charter: Alachua (1987), Brevard (1994), Broward (1975), Charlotte (1986), Clay (1991), Columbia (2002), Duval (1968), Hillsborough (1983), Lee (1996), Leon (2002), Miami-Dade (1957), Orange (1987), Osceola (1992),

Palm Beach (1985), Pinellas (1980), Polk (1998), Sarasota (1971), Seminole (1989), Volusia (1971), and Wakulla (2008).

\section{Form of Government}

Florida counties can choose between three forms of government, which are also established in other states in the Union: the traditional commission form, the commission-administrator or manager form, and the commission or council-executive form (Jewett, 2010). According to Jewett (2010), the policy implementation process is what mainly differentiates these three forms of county government. While, in all three forms, the board of county commissioners is responsible for policy adoption, the implementation process is entrusted to different entities. In the traditional commission form, the board of county commissioners is responsible for implementing policies. In the commission-administrator or manager form, the administrator or manager selected by the board of county commissioners manages the implementation process. In the last form, an elected official - the county mayor-is responsible for the policy implementation process. 
These counties have chosen the traditional commission form: Calhoun, Franklin, Hamilton, Jefferson, Lafayette, Levy, Liberty, Madison, Suwannee, and Union. Most Florida counties have adopted a county administrator: Baker (1990), Broward (1975), Charlotte (1986), Citrus (1999), DeSoto (1987), Escambia (1985), Flagler (1995), Gadsen (1989), Gilchrist (2004), Gulf (1993), Hendry (1978), Hernando (1983), Highlands (1991), Hillsborough (1983), Holmes (2006), Indian River (1990), Jackson (1984), Leon (2002), Manatee (1991), Marion (1983), Martin (1981), Monroe (1977), Okaloosa (1993), Okeechobee (1992), Palm Beach (1985), Pasco (1974), Pinellas (1980), Putnam (1990), Santa Rosa (1989), Sarasota (1971), St. Johns (1990), St. Lucie (1959), Sumter (1983), Taylor (2003), Wakulla (2008), Walton (1984), and Washington (1991). Although the term administrator and manager can be used interchangeably in Florida (Jewett, 2010), these counties have a county manager: Alachua (1987), Bay (1987), Bradford (1993), Brevard (1994), Clay (1991), Collier (1993), Columbia (2002), Dixie (N/A), Glades (1995), Hardee (2001), Lake (1990), Lee (1996), Nassau (1986), Osceola (1992), Polk (1998), Seminole (1989), and Volusia (1971). Finally, only three counties have adopted the council-executive form: Duval (1968), Miami-Dade (2007), and Orange (1986).

\section{Survey Instrument: Multiple informant Survey}

The two proposed research questions can be answered quantitatively with a multiple-informant survey (Enticott, Boyne, \& Walker, 2009). This type of survey is advantageous for several reasons. First, it allows researchers to survey multiple respondents within each organization. Respondents usually belong to different echelons in the organization. Each level in the organization views organizational level variables (i.e., organizational social capital) in a different way (Payne \& Mansfield, 1973). Payne 
and Mansfield (1973) note that only using one score per organization to measure an organizational level variable "may be misleading" (p. 519) and found—based on their analysis on hierarchical position and perception of organizational climate - that persons higher in the organizational hierarchy tend to perceive organizational climate differently from persons in lower positions. This supports the argument that organizational level variables are better measured when different echelons within an organization are taken into consideration.

Second, it allows researchers to aggregate individual level responses at the organizational level (Andrews, 2010, 2011; Leana \& Pil, 2006). In particular, Andrews (2011) collected data from senior and middle managers and aggregated them to create an organizational level variable by adding the two scores together and dividing them by two. Similarly, Leana and Pil (2006), in a study on school performance and community and organizational social capital, constructed organizational level variables by aggregating school teachers' individual level responses. In contrast to Andrews $(2010,2011)$, the authors also tested if such aggregation may be justified empirically. To do so, they "generated intraclass correlation coefficients $[\ldots]$ using ANOVA on the individual-level data with the school as independent variable and the social capital construct as dependent variable" (p. 358). A positive significant coefficient on the ANOVA test signifies convergence within the organization (see Kenny \& LaVoie, 1985).

Third, instead of focusing on performance information use as an individual level variable, the aggregation at the departmental level allows for an innovative contribution to the literature on performance information use. As discussed in the next section, the survey for the present study was completed online. Four follow-ups were necessary to 
achieve a response rate between $30-35 \%$, as in other surveys administered in the public sector. Statistical analysis was conducted using Stata 14.

Because organizational social capital is an organizational variable and multipleinformant surveys allow for the aggregation of responses for every organization or suborganization, data was collected and aggregated at departmental level. Eight departments from each county were surveyed. Following Lowi (1964), the eight departments were chosen according to his classic typology of public policy: regulation, distribution, redistribution, and constituent, which could also be used to control for variation across departments. Table 2 categorizes county departments that could be surveyed according to Lowi's (1964) typology. Departments may change across counties due to county government size and internal organization; therefore, it was impossible to choose the same departments for each of the 67 Florida counties. In choosing the departments, each of the four typologies proposed by Lowi have been equally represented.

Table 2: Department categorization according to Lowi's typology

\begin{tabular}{|c|c|c|c|}
\hline Regulatory: & Distributive: & Redistributive: & Constituent: \\
\hline $\begin{array}{l}\text { Formulate } \\
\text { implement rules } \\
\text { imposing obligations } \\
\text { on individuals and } \\
\text { providing sanction } \\
\text { for non- } \\
\text { conformance. }\end{array}$ & $\begin{array}{l}\text { Distribute tangible } \\
\text { benefits and } \\
\text { intangible ones } \\
\text { (i.e., distributive } \\
\text { public goods). }\end{array}$ & $\begin{array}{l}\text { Redistributive } \\
\text { benefits to one } \\
\text { group of people } \\
\text { from another group } \\
\text { of people. }\end{array}$ & $\begin{array}{l}\text { Carry out } \\
\text { residual tasks } \\
\text { that do not fit } \\
\text { among the } \\
\text { other three: } \\
\text { serving } \\
\text { government in } \\
\text { general }\end{array}$ \\
\hline $\begin{array}{l}\text { Elections } \\
\text { Office of the } \\
\text { Property Appraiser } \\
\text { Department of } \\
\text { Regulatory and } \\
\text { Economic } \\
\text { Resources }\end{array}$ & $\begin{array}{l}\text { Police } \\
\text { Water and Sewer } \\
\text { Library services } \\
\text { Fire rescue } \\
\text { Judicial } \\
\text { administration }\end{array}$ & $\begin{array}{l}\text { Public Housing } \\
\text { Homeless trust } \\
\text { Community and } \\
\text { Human Services }\end{array}$ & $\begin{array}{l}\text { Internal } \\
\text { service } \\
\text { department } \\
\text { Management } \\
\text { and budget } \\
\text { Human } \\
\text { resources }\end{array}$ \\
\hline
\end{tabular}


In this way, eight departments for each of the 67 Florida counties for a total of 513 cases were surveyed (assuming a response rate of $30-35 \%$, the sample size will be about 165 departments). Department heads, middle managers, and any other figure with a supervisor role from each department were surveyed. Querying different tiers of public employees will overcome the sample bias which can occur when surveying only one tier of public employees (Andrews et al., 2009). It was difficult to quantify how many employees would be surveyed given the heterogeneity in size of Florida county government (from a few hundred employees in rural counties to more than 32,000 employees in Miami-Dade County). Given this heterogeneity, the aim was to obtain at least two responses per department.

Moreover, to increase the face validity of the survey, a pilot test was conducted on a department of Miami-Dade County to obtain recommendations and improve the overall reliability of the survey. Because of convenience, the chosen department was the Miami-Dade County Parks, Recreation and Open Spaces Department. Also, validity was enhanced by using, whenever possible, measures that have been previously used and tested in previous research-described in greater detail in the next section.

\section{Operationalization of the dependent variables}

This section will discuss how to measure performance information use. The question of how to measure routine and nonroutine performance information use will be discussed separately. According to Kroll (2013), routine performance information is that which is regularly collected, based on ex-ante indicators, often quantitative, and formally noted in reports that follow a management-for-results logic. To measure routine performance information use, the literature suggests several methods. Moynihan and Lavertu (2012), in evaluating performance information use under the 
GPRA and PART frameworks, measured "the extent to which respondents reported using performance information for a particular set of activities" (p. 595). The set of activities chosen were: setting program priorities, allocating resources, identifying program problems to be addressed, taking corrective action to solve program problems, adopting new program approaches or changing work processes, refining program performance measures, setting new or revising existing performance goals, setting individual job expectations, and rewarding government employees (Moynihan \& Lavertu, 2012).

In another study, Moynihan and Ingraham (2004) used two different measures of performance information use. The first measure attempts to capture senior executive policy-making decisions and is based on the question: "To what extent do you agree with the following statement about the use of performance-information in your state? Performance information is frequently used by executive branch officials in decisionmaking." (p. 434). The second measure captures decisions relating to agency activities made by lower level managers and is based on the question: "To what extent do you agree with the following statement about the use of performance information in your state? Performance information is frequently used to direct agency activities." (p. 434). Respondents answered both questions using a 5-point Likert-type scale $(1=$ strongly disagree, $2=$ disagree, $3=$ neutral, $4=$ agree, $5=$ strongly agree). The correlation between the two dependent variables was .499. That correlation is a sign of "consistency between use of performance information in different decisions, but also suggests that each decision type is distinct enough to be worth investigating separately" (p. 435). 
Moynihan and Pandey (2010) measured performance information use using this particular question: "I regularly use performance information to make decisions." Respondents answered the question using a 6-point Likert-type scale ( 1 = strongly disagree, $6=$ strongly agree). The same measure is also used by Moynihan, Pandey, and Wright (2012) in a study on performance information use and transformational leadership. The common denominator of these methods is that respondents were asked directly to evaluate their attitude toward performance information use. One limitation of this approach is that performance information use is a self-reported measure. As reported in the full survey in the appendix section, respondents were asked three questions about routine performance information. The first block of questions attempts to capture the extent to which routine performance information is used by each single respondent for a broad and common set of activities that county public managers are charged with executing.

According to Kroll (2013), nonroutine performance information is the kind of information that is ad hoc, often not actively pursued but passively received, often qualitative, and gathered through various media, including documents, written inquiries, formal meetings, and informal talks. Measuring this type of performance information may be more difficult than routine performance information. Kroll (2013) differentiates between nonroutine performance information that is internally produced and that which is externally produced. Again, asking respondents about the use of these particular types of performance information is inherently subject to the following limitation: it is a self-reported measure.

Finally, to increase the internal validity of the model, it was necessary to control for other potential factors that could affect a priori routine and nonroutine performance 
information use such as organizational culture, informal control systems, and stakeholder orientation (Kroll, 2013). For a complete list of these variables, please refer to the full survey in the appendix. In particular, the following control variables were included in the survey: system maturity (Moynihan \& Pandey, 2010); leadership commitment to results (Moynihan \& Lavertu, 2012); developmental culture (Kroll, 2013); citizens' demand of performance information (Moynihan \& Ingraham, 2004); and peer exchange and benchmarking (Kroll, 2013).

\section{Operationalization of the main independent variable}

The aim of this section is to review how previous researchers have measured organizational social capital and its components. As stated above, the concept of social capital is not clearly and unequivocally established for two main reasons: first, there is no agreed-upon definition of what constitutes social capital, and second, no measure is able to capture the different facets of social capital (Fukuyama, 2005). The same difficulties also apply to the concept of organizational social capital. A comprehensive index, so far, does not exist. However, organizational social capital and its three components have been measured using proxies in studies by Andrews $(2010,2011)$ and Leana and Pil (2006). These measures are presented in Table 3.

Andrews $(2010 ; 2011)$ developed two studies on the effects of organizational social capital on public administration performance in local government bodies in England. He developed three indexes, one for each of the three dimensions of organizational social capital, based on measures that were derived from a large-scale electronic survey of managers in English local governments (2010).

The structural dimension of organizational social capital was measured by asking public managers the extent to which "coordination and joint-working" and 
"cross departmental and cross-cutting working" were important within their organizations (Andrews, 2010, 2011). According to Andrews (2011), "these measures represent a reasonable proxy for the frequency with which actors are likely to have interacted across functional boundaries" (p. 943).

The relational dimension of social capital was assessed by asking whether "there is a high level of trust between top management and staff" and if "there is a high level of trust between top-management and politicians" (Andrews, 2010; Andrews, 2011, p. 643). According to Grootaert and Bastelaer (2001), who aimed to develop an index for social capital and organizational social capital, measuring trust (relational social capital) "requires asking respondents about their expectations and experiences with behaviour requiring trust" (p. 37).

Finally, Andrews (2011) measured the cognitive dimension of social capital using the following indicators: "Mission, values and objectives are clearly and widely owned and understood by all staff" and the extent to which the organization concentrated on achieving its "mission, values and objectives."

Andrews' $(2010,2011)$ main limitation is that he adapted his organizational social capital measure from an existing survey. From these measures, Andrews (2011) created a social capital index with a principal component analysis that accounted for 60 percent of the variance in the data. All the factor loadings of this index were over 0.5 , meaning that they are good predictors of the explained variance. A similar result was found in a study by Leana and Pil (2006). All three dimensions of organizational social capital have been treated as a single factor. 
Table 3: Measures of Organizational Social Capital ${ }^{3}$

\begin{tabular}{lll}
\hline Structural Dimension & Relational Dimension & Cognitive Dimension \\
\hline \multicolumn{1}{c}{ Andrew's } & (2010, 2011) Measures (All Items) \\
$\begin{array}{l}\text { Coordination and joint } \\
\text { working with other } \\
\text { departments is a major part } \\
\text { of our approach to the } \\
\text { organization of services. }\end{array}$ & $\begin{array}{l}\text { There is a high level of } \\
\text { management and staff. }\end{array}$ & $\begin{array}{l}\text { The authority's mission, } \\
\text { values and objectives } \\
\text { are clearly and widely } \\
\text { Cross-departmental/cross- } \\
\text { cutting working is important } \\
\text { in driving service }\end{array}$ \\
$\begin{array}{l}\text { thust between officers } \\
\text { improvement. }\end{array}$ & $\begin{array}{l}\text { and politicians. } \\
\text { by all staff in the } \\
\text { service. }\end{array}$ \\
& & $\begin{array}{l}\text { The authority } \\
\text { concentrates on } \\
\text { achieving its mission, } \\
\text { values and objectives. }\end{array}$ \\
\hline
\end{tabular}

\section{Leana's and Pil's (2006) Measures (All Items)}

Teachers engage in open and honest communication with one another.

Teachers at this school have no hidden agendas or issues.

Teachers share and accept constructive criticism without making it personal.

Teachers discuss personal issues if they affect job performance.

Teachers willingly share information with one another.

Teachers at this school keep each other informed at all times
I can rely on the teachers I work with in this school.

Teachers in this school are usually considerate of one another's feelings.

Teachers have confidence in one another in this school.

Teachers in this school show a great deal of integrity.

There is no "team spirit" among teachers in this school (reversed).

Overall, teachers at this school are trustworthy.
Teachers share the same ambitions and vision for the school.

Teachers enthusiastically pursue collective goals and mission.

There is a commonality of purpose among teachers at this school.

Teachers at this school are committed to the goals of the school.

Teachers view themselves as partners in charting the school direction.

Everyone is in total agreement on our school's vision.

The questions proposed in the present study are based on the work by Andrews (2010, 2011) and Leana and Pil (2006). For a complete list of the questions used to

\footnotetext{
${ }^{3}$ Leana and Pil refer to the first dimension as "information sharing," which is not fully in line with the definition of "structural social capital" utilized here and in previous work.
} 
measure organizational social capital for the purpose of this study, please refer to the full survey in Appendix A.

In addition to the measures proposed by Andrews $(2010,2011)$ that have been included in the questionnaire, based on the review of the literature and based on the theoretical background that constitute the foundation of organizational social capital, six different questions to measure the main independent variable were added to the questionnaire. Table 4 shows the additional measures of organizational social capital added to the questionnaire.

\section{Table 4: Additional Measures of Organizational Social Capital}

\begin{tabular}{lll}
\hline Structural Dimension & Relational Dimension & Cognitive Dimension \\
\hline $\begin{array}{l}\text { Collaboration as well as } \\
\text { interaction among } \\
\text { colleagues, units, and other } \\
\text { departments is well } \\
\text { developed. }\end{array}$ & $\begin{array}{l}\text { There is a high level of } \\
\text { trust between top } \\
\text { management and staff. }\end{array}$ & $\begin{array}{l}\text { Departmental goals are } \\
\text { shared by all the } \\
\text { members. }\end{array}$ \\
$\begin{array}{l}\text { Information is easily } \\
\text { shared. }\end{array}$ & $\begin{array}{l}\text { There is a high level of } \\
\text { respect for the } \\
\text { leadership. }\end{array}$ & $\begin{array}{l}\text { Every member } \\
\text { contributes to achieving } \\
\text { departmental goals. }\end{array}$ \\
\hline
\end{tabular}

Following the literature, the first additional question to measure the structural dimension of social capital (i.e., "Collaboration as well as interaction among colleagues, units, and other departments is well developed.") is designed to measure network ties and network configuration, which constitute the backbone of this dimension. According to Andrews (2011), formal and informal collaboration and coordination as well as interaction between colleagues, units, and departments creates spillover effects that can ameliorate working conditions and individual and organizational performance. 
If network ties and network configurations are well developed, information should be shared more easily within the organization (Granovetter, 1973; Jacobs, 1965). The second additional question that measures the structural dimension of social capital (i.e., "Information is easily shared.") is designed to measure the ease and flexibility of information sharing.

Following the literature, the first additional question that measures the relational dimension of social capital (i.e., "There is a high level of trust between top management and staff.") was adapted from Andrews $(2010,2011)$. This item measures the level of trust within members of a department, which is the main component of relational social capital. Trust is critical to information sharing; the transfer of sensitive information is only possible when a high level of trust exists between people.

The second additional question that measures the relational dimension of social capital (i.e., "There is a high level of respect for the leadership.") was adapted from Leana and Pil (2006) and the FedView Point survey. This item measures the level of a different facet of trust between the members of a department.

Following the literature, the first additional question that measures the cognitive dimension of social capital (i.e., "Departmental goals are shared by all the members.") was adapted from Andrews $(2010,2011)$. The item measures the level of goal sharing within a department.

A second additional question measures the cognitive dimension of social capital (i.e., "Every member contributes to achieving departmental goals."). This measure helps to quantify employees' individual contributions (Fishbach et al., 2011) toward the achievement of shared goals. 


\section{Operationalization of the control variables}

Control variables were included in the analysis. Two types of control variables were included: organizational level control variables and variables that control for individual characteristics of the respondents. Peer exchange, developmental culture, citizens' demand of performance information, and resources belong to the first group of control variables. Individual characteristics of the respondents include supervisory status, length of stay in the department, and age group.

- $\quad$ Peer exchange. This variable was measured by using the following question: "My department regularly exchanges information with professional staff from other counties who work in the same field." This question has been previously employed by Kroll (2013) and Ammons and Rivenbark (2008). The possible answers provided ranged from $1=$ Strongly disagree to $5=$ Strongly agree. This variable was added because, if managers are open to exchanging information with peers, they will be more likely to use performance information (Kroll, 2013)

- Developmental culture. The first item used to measure the control variable developmental culture is "My department is dynamic and entrepreneurial. People are willing to stick their necks out and take risks." The second item is "The glue that holds my department together is a commitment to innovation and development." The third item is "The staff shows great readiness to meet new challenges." These items were used previously by Moynihan and Pandey (2010) and Kroll (2013). The possible answers provided ranged from 1 $=$ Strongly disagree to $5=$ Strongly agree. This variable was included because 
developmental culture has been found to have a positive effect on performance information use (Moynihan \& Pandey, 2010)

- $\quad$ Citizens' demand of performance information. This variable was measured using the following question: "Citizens demand performance information." This question has been previously employed by Moynihan and Ingraham (2004) and it is considered a driver of performance information use. Therefore, it must be included in the analysis as a control. The possible answers provided ranged from $1=$ Strongly disagree to $5=$ Strongly agree .

- $\quad$ Resources. This variable was measured using the following question: "In my department, there are sufficient resources (e.g., people, materials, budget) to get the job done." This question has not been previously used, aside from the Federal Viewpoint Survey. The possible answers provided ranged from $1=$ Strongly disagree to $5=$ Strongly agree. Performance management is an extensive task that requires many resources, both financial and human. Controlling for the availability of resources is necessary to determine if departments that have more resources are more likely to use performance information in their decision making process.

- $\quad$ Supervisor status. This variable was measured using the following question: "What is your supervisory status?" The possible answers provided were $1=$ Departmental head, $2=$ Middle management, $3=$ Supervisor, and $4=$ Other.

- $\quad$ Length of stay. This variable was measured using the following question: "How long have you been working in your current department?" The 
possible answers provided were $1=$ Less than 1 year, $2=1$ to 5 years, $3=6$ to 10 years, $4=11$ to 15 years, $5=15$ to 20 years, and $6=$ more than 20 years.

- $\quad$ Age group. This variable was measured using the following question: "What is your age group?" The possible answers provided were $1=$ 25 and under, $2=26-29,3=30-39,4=40-49,5=50-59$, and $6=60$ or older.

\section{Pilot Study}

In social science research, pilot studies can be used in two different ways (Van Teijlingen, \& Hundley, 2002). Feasibility studies are "small scale version[s], or trial run[s], done in preparation for the major study" (Polit et al., 2001: 467). However, pilot studies are also used to pre-test a particular research instrument (Baker, 1994, p. 182). One of the advantages of conducting a pilot study is that it can help researchers understand the validity and reliability of their research instrument prior to conducting the major study. More importantly, pilot testing allows researchers to understand whether the questionnaire is able to provide the information needed to complete the study (Peat et al., 2002). In particular, pilot studies in survey research can be used to "check to see if there are any ambiguities or if the respondents have any difficulty in responding” (De Vaus, 1993, p. 54). Similarly, Fink and Kosekoff (1985) affirm that a survey instrument needs to be revised if respondents fail to answer questions, if they provide multiple answers to the same question, or if they provide written comments to the proposed questions. Peat et al. (2002) state that "all surveys must be pilot tested before put into practice" (p. 7). Peat et al. (2002) provide a useful step-by-step guide to conducting a meaningful pilot study to improve the internal validity of a questionnaire which was used in order to conduct my two pilot studies. 
The first draft of the questionnaire adopted to answer the proposed research questions was developed during the months of January and February of 2015. The survey was composed of 71 questions and 4 additional experimental survey questions. The majority of the survey questions were measured using a 5-point Likert-type scale (e.g., $1=$ strongly disagree, $5=$ strongly agree; or $1=$ not important, $5=$ extremely important). However, demographic questions such as race, education, length of stay in the county government, length of stay in the current department, and age group were measured using a 6-point Likert-type scale. The respondents were also asked to provide the name of their department in an open-ended question.

The first draft of the survey was organized around several thematic blocks of homogeneous questions. The first three blocks of questions were designed to ask respondents about their use of routine performance information while the fourth block of questions concerned the use of nonroutine performance information. The following three blocks focused on measuring the level of organizational social capital in their organizations. These initial seven blocks were designed to operationalize the main dependent and independent variables in the analysis, routine and nonroutine performance information use, and organizational social capital. The following blocks aimed to capture organizational level variables such as performance measurement system maturity, leadership, organizational culture, citizens' demand of performance information, organizational resources, and benchmarking.

Individual level variables were also included such as public service motivation, intrinsic and extrinsic motivation, and job satisfaction. The final blocks were demographic, individual level questions such as gender, race, education, length of stay in the county government, length of stay in the current department, and age group. 
Most, if not all, of the survey questions included in the first draft were derived from the literature and therefore previously tested and deemed valid and reliable in other studies.

To increase the face validity of the survey instrument, a first pilot test was conducted; the following list of individuals were asked to take the survey and provide feedback: three members of the dissertation committee, namely Dr. Rosenbaum, Dr. Kroll, and Dr. Ganapati, and the Chair of the Public Administration Department at Florida International University and the Director of the Metropolitan Center-an applied research and training institute that provides policy solutions to public, private and non-profit organizations in South Florida. Different from the protocol used by Peat et al. (2002), the survey was distributed via paper or Microsoft Word file format instead of using an online Qualtrics version of the survey. The rationale for this decision is that it was necessary to have a first round of feedback from the academic world and from professors that had previously used this instrument for data collection and that were familiar with the world of local public managers and employees in the context of Florida.

Following Peat et al. (2002), the respondents were asked to identify and discard all ambiguities, difficult and unnecessary questions, to evaluate the response time and decide whether it was reasonable, and assess whether each question garnered an adequate range of responses. The main result of the first pilot study was a substantial cut in the number of proposed survey questions. In particular, two out of four respondents considered 71 questions to be an excessive number of questions to ask public managers in an online survey. According to them, such a high number of questions would have discouraged managers from participating in the survey due to 
time limitations, and therefore, the excessive length would have reduced and impacted the overall response rate.

Consequently, a second draft of the survey was composed of 54 survey questions and 5 experimental survey questions. The second draft was reorganized around 8 blocks of homogeneous questions. The first block of questions were designed to ask respondents about their use of routine performance information while the second block of questions focused on the use of nonroutine performance information. Two blocks of questions from the previous version of the questionnaire, regarding the use of performance information, were deleted. While questions regarding the use of nonroutine performance information remained the same, the original three blocks of questions regarding level of organizational social capital were combined into a single block.

In addition to the original questions borrowed from the literature (Andrews, 2010 and 2011), in the second draft of the questionnaire 6 more questions that were considered more appropriate to measure the concept of organizational social capital were added. The rationale behind this decision came from a careful review of the literature and a review of the theoretical background of organizational social capital. Most of the questions that were cut between the first and second draft of the questionnaire focused on the organizational and individual level characteristics of the respondents.

Organizational level variables were also reorganized in two homogeneous blocks: organizational culture and work related questions. Of the original 21 questions in the first draft, only 12 appeared in the second draft. Similarly, of the 9 demographic questions in first draft, only 4 appeared in the second draft. However, an additional 
open-ended question (i.e., "Number of employees reporting directly to you") was added as a result of the first pilot study, bringing the overall number of questions in the demographic block to five. Finally, the original four experimental survey questions that centered on the use of routine performance information in a budgetary decision-making process were replaced with five experimental research questions centered on the use of routine and nonroutine performance information in the performance appraisal process of a county employee.

The second pilot study was conducted with the staff of Miami-Dade County Parks, Recreation and Open Spaces Department to obtain a second round of recommendations and improve the overall reliability of the survey. The Miami-Dade County Parks Department is responsible for managing the third largest county park system in the United States, consisting of 270 parks and 13,573 acres of land. It is one of the most unique park and recreation systems in the world (http://www.miamidade.gov/parks/about-parks.asp). The park system also offers outstanding attractions including (http://www.miamidade.gov/parks/about-parksmore.asp):

- Fruit and Spice Park: The only tropical botanical garden of its kind in the United States and a gardener's and horticulturalist's dream destination. The 35-acre park boasts more than 500 varieties of exotic and tropical fruits, vegetables, nuts, spices and herbs.

- Zoo Miami: A 740-acre cageless zoo that showcases more than 900 animals belonging to more than 250 species. It has excelled in the successful breeding of rare and endangered animals. 
- Deering Estate at Cutler: A historic 444-acre bayfront park with nature preserves, archaeological sites, an off-shore island, and an education center, museum on South Florida Ecology, and house tours of a restored 1922 Stone Mansion.

- Crandon Golf Course: On Key Biscayne and Audubon certified, it is one of South Florida's premier golf courses in a pristine natural setting with breathtaking views and wildlife.

- Crandon Tennis Center: The Crandon Park Tennis Center and Stadium is home to the Sony Open Tennis Tournament, a 12-day tennis tournament featuring the top 96 men and women tennis players in the world.

- EcoAdventures: Naturalist guided tours through South Florida's unique and exciting network of parks, beaches, wildlife-landscapes, and wetlands, including the Everglades.

- Arts and culture are also celebrated in Miami-Dade County Parks facilities, creating a positive and inspiring environment for the presentation and development of the arts and to use the arts to bring together people of diverse cultures, generations, and walks of life.

The respondents were asked to complete the online Qualtrics version of the second draft of the survey prior to the scheduled meetings. The pilot study took place in two distinct instances. First at Zoo Miami, two separate interviews were conducted. The first interview was with the Director of Zoo Miami and with the assistant Director of Operations. Both interviewees had previously completed the online version of the survey. A paper copy of the survey was provided to the interviewee in both interviews. In addition to these two interviews, a focus group was conducted in July 2015 with six 
managers from the Miami-Dade County Parks, Recreation and Open Spaces Department, including the Chief of the contract management and procurement division.

The pilot study was carried out following the Peat et al. (2002) step-by-step guide. Subjects were asked to identify ambiguities and discard unnecessary and difficult questions. The respondents reworded some of the terminology used in the survey. In particular, they asked to replace the expression "civil servant" with "county employees." According to them, the term "civil servants" refers to employees of the Federal Government and county employees do not refers to themselves in such a way. A second example of rewording involved some of the questions that measured organizational social capital, which were developed for the U.K. context. For example, the term "joint working" was replaced with the expression "co-ordination and working with other departments," the expression "cross cutting working" was replaced with the expression "cross-departmental working," and the word "officer" was changed to "county management." Thirdly, both interviews and the focus group revealed the necessity to eliminate a redundant question on performance related pay. Pay for performance was measured by asking two separate questions: "My pay varies widely. It consists of a fixed salary part and a performance-related part" and "My pay does not vary. I receive a fixed salary." All the participants indicated that the second question was misleading and confusing when taking the first one into consideration. Therefore, they suggested to remove it from the survey. Finally, both interviews and the focus group assessed that the time taken to complete the questionnaire was reasonable and assessed that each question garnered an adequate range of responses. The time taken to answer the survey in its final draft was on average 8 minutes. 
After conducting the second pilot study, the final draft of the survey was crafted by taking into consideration the comments and suggestions about rewording and ambiguities indicated by the managers. The final version of the survey is attached in Appendix A. The survey was endorsed by the Florida City and County Management Association (FCCMA) Board of Directors during its August 12 Board Meeting. The endorsement of the survey has been fundamental to achieving a satisfactory response rate. The endorsement letter is attached in Appendix B. The survey was finally lunched using Qualtrics on September $9^{\text {th }}, 2015$. After the first request to participate in the study, four subsequent reminders were sent to the population every two weeks during the months of September, October, and beginning of November to achieve the desired response rate.

\section{Response rate}

As stated in the previous section, data collection was concluded after four waves of reminders had been sent to the population of the study. Data collection formally closed in the first week of November 2015. Before describing the estimation routine employed for the analysis of data, a digression must be made on the different response rates achieved.

\section{County level response rate}

We will first consider the response rate at the county level. Fifty-seven out of the 67 Florida counties have in some way participated in the study. For a complete list of respondents and non-respondents, please see

Table 5 below. The sample is representative of the population of counties. According to the 2010 Census, $45 \%$ of Florida Counties are rural and the remaining urban. In the sample $42 \%$ per cent of counties are rural and the remaining urban. Regarding the 
demographics of the non-responding counties, most are small counties in terms of population. Calhoun, Columbia, Liberty, Okeechobee, Union, and Wakulla are mostly rural counties. Calhoun, Liberty, and Wakulla are located in the Florida Panhandle, while Columbia and Union are situated in Northern Florida and Okeechobee in SouthCentral Florida.

Table 5: List of Counties' respondents and non-respondents

\begin{tabular}{|l|l|l|l|}
\hline \multicolumn{3}{|c|}{ Respondents } & Non-respondents \\
\hline Alachua & Gulf & Nassau & Calhoun \\
\hline Baker & Hamilton & Orange & Columbia \\
\hline Bay & Hardee & Osceola & Hillsborough \\
\hline Bradford & Hendry & Palm Beach & Lake \\
\hline Brevard & Hernando & Pasco & Liberty \\
\hline Broward & Highlands & Pinellas & Martin \\
\hline Charlotte & Holmes & Polk & Okaloosa \\
\hline Citrus & Indian River & Putnam & Okeechobee \\
\hline Clay & Jackson & St. Johns & Union \\
\hline Collier & Jefferson & St. Lucie & Wakulla \\
\hline DeSoto & Lafayette & Santa Rosa & \\
\hline Dixie & Lee & Sarasota & \\
\hline Duval & Leon & Seminole & \\
\hline Escambia & Levy & Sumter & \\
\hline Flagler & Madison & Suwannee & \\
\hline Franklin & Manatee & Taylor & \\
\hline Gadsden & Marion & Volusia & \\
\hline Gilchrist & Miami-Dade & Walton & \\
\hline Glades & Monroe & Washington & \\
\hline
\end{tabular}

Lake, Martin, and Okaloosa can be considered medium sized counties in terms of population. Okaloosa County is located in the Florida Panhandle, Lake County is situated in Central Florida, and Martin County is located in South-Central Florida. Finally, Hillsborough County, situated on the Florida Gulf Coast, is a large sized county with over a million inhabitants. In terms of districting, Calhoun, Columbia, and Union have adopted a single member system. Lake, Liberty, Martin, Okaloosa, Okeechobee, 
and Wakulla have adopted an at-large system, while the only mixed system is Hillsborough. Columbia, Hillsborough, and Wakulla are also the only three counties that have Charter status. Besides Wakulla and Okaloosa, which deliberately decided to not participate in the survey, there is no apparent explanation for why the other eight counties decided to not participate, though fear of sharing county information and lack of personnel may have been factors.

\section{Individual level response rate}

This section will discuss the individual level response rate. Unfortunately, this information is impossible to calculate. The way the survey was distributed makes it impossible to calculate the individual response rate. Given the multiple-informant nature of the survey, the survey was sent to the heads of the departments selected asking them two things: to share the invitation email with middle managers and any other individuals with a supervisory role in their department, so that they could participate in the survey; and to participate themselves in the survey. Therefore, it is only known how many department heads were asked to respond to the survey. Based on this method of distribution, it is not possible to ascertain how many middle managers and other individuals with a supervisory role received the survey. The following information is known: a total of 513 department heads were asked to participate in the survey; a total of 449 responses were received when the survey closed in November 2015; 127 of the 449 respondents identified themselves as department heads, equal to $28.29 \%$ of respondents; 79 respondents self-identified as middle managers, equal to $17.59 \%$ of respondents; supervisors accounted for $6.01 \%$ of respondents, which are 27 out of 449 respondents; 19 respondents (4.23 percent) self-identified as other individual with supervisory role, while 197 respondents (43.88 percent) did not indicate any supervisory status. 
Regarding the demographics of the individual response rate, the following facts were determined. On average, respondents have been working in their current department for six to ten years. The median of county managers' length of stay in their current department is also equal to six to ten years. However, the mode is slightly lower: from one to five years. Regarding the age group of the respondents, the mean, median, and mode of this indicator show that county managers are between 50 and 59 years old.

The number of county employees who report to the managers who responded to the survey varies substantially. On average, a county manager oversees 112 county employees. However, if we examine the median and mode, the numbers are quite different. The median number of employees overseen by a county manager in the State of Florida is 7 , while the mode is 4 . The average number is skewed to the right because of the presence of outliers. The maximum number of county employees overseen is 884 in the Miami-Dade County Internal Services Department. After all, most managers in Florida counties oversee few employees. Finally, most respondents came from a Parks and Recreation or equivalent department. For more information regarding descriptive statistics, please see Table 9 .

\section{Departmental level response rate}

The final response rate that we will examine is the departmental level response rate. As explained in the next section, the present analysis has been conducted at the departmental level. Therefore, the response rate that is most important to assessing survey quality is the departmental level response rate. The research literature identifies a high response rate as a measure of accuracy in survey results (Babbie, 1990; Backstrom \& Hursh, 1963; Parker \& Rea, 1997). 
However, more recent studies indicate that low response rate does not affect the accuracy of survey results and that expenses made to achieve a higher response rate are not justified by higher levels of survey accuracy. Following this path, Visser et al. (1996) demonstrated that survey research with lower response rates (close to 20\%) yielded more accurate estimations than surveys with higher response rates (close to 60\%). Similarly, Keeter et al. (2006) first administered a 5-day survey following the methodology of the Pew Research Center, which yielded a 25\% response rate. Second, they conducted another survey following more strict procedures and over a longer time span, which yielded a response rate of $50 \%$. By comparing the results of the two surveys, in 77 out of 84 comparisons, the differences in the two surveys were statistically indistinguishable. Finally, Holbrook et al. (2005) evaluated the demographic representativeness of a sample in survey research with a low response rate. They analyzed 81 national surveys with response rates ranging from 5\% to 54\%. The results of their study showed that demographic representativeness in surveys with a low response rate is equal to those with a high response rate.

The departmental response rate achieved in the present analysis is $32.36 \%$, which is considered adequate in the public administration literature. In particular, 166 out of the 513 engaged departments participated of survey. Thus, an average of 2.91 departments per county participated in the survey, which is a good number in terms of representativeness. More in details, in the population, $45.22 \%$ of the departments belonged to the distributive category, $20.67 \%$ to the regulative one, $18.32 \%$ to the constituent one, and $15.79 \%$ to the redistributive category. In the sample, $45 \%$ of the departments belonged to the distributive category, $20 \%$ were regulative, $25 \%$ belonged to the constituent category, while $10 \%$ to the redistributive. Overall the sample 
represents the population quite well. The departmental response rate has been calculated by aggregating individual level responses to departmental level. Following Andrews $(2010,2011)$, the aggregation was calculate by summing the respondents for each department and dividing that by the number of departmental respondents. Departments that had only one respondent were excluded from the analysis because they are representative of only one echelon, and the scope of multiple informant surveys is to capture variation in different echelons of an organization.

\section{Construction of the main dependent and independent variables}

Factor analysis is a multivariate statistical technique that not only test items' convergent validity, which is how highly similar items are correlated, but also how different these items are from other somewhat related constructs (Harman, 1976; Thompson, 2004). It serves two main purposes (Harman, 1976; Thompson, 2004). First, it is used for data reduction by combining several items into one or more factors. Secondly, it is used to classify variables by detecting structure in the relationships between one another. It can also be used as a remedying method for multicollinearity (Gujarati \& Porter, 2009). Although the term factor analysis was first introduced by Thurstone (1931), this technique originated from a study by Spearman (1904). From a statistical and procedural point of view, a factor analysis "assumes that there are [multiple] underlying factors whereby each observed variables is a linear function of

these factors together with a residual variate" (Yong \& Pearce, 2013, p. 81). The contribution of each single item in the analysis to the construction of the factor is called factor loading. A larger factor loading means that the item has contributed more in the construction of the factor itself (Harman, 1976). In factor analysis, Eigenvalues are used to determine the right amount of factors. Factors with Eigenvalues greater than 1 are 
considered significant. After estimating the factors, the researcher needs to interpret the factor or factors and assign them names.

To construct the two main dependent variables (i.e., routine and nonroutine performance information use) and the main independent variable (organizational social capital), a factor analysis was performed using the "pcf" option, which specifies that the principal-component factor method is to be used to analyze the correlation matrix. The Promax method (Cureton, 1976) was used in the rotation of the correlation matrix. The next three sections will outline the results of the factor analysis conducted.

\section{Construction of the dependent variable Routine PI Use}

As shown in Table 6, the eight items used in the survey to measure the use of routine performance information all load on a single factor (Factor 1) that is labelled in the analysis as Routine Performance Information. The Eigenvalue of Factor 1 is 4.529, which is greater than 1 and therefore significant. The Eigenvalue of all the other factors was lower than 1 and therefore discarded from the analysis. Furthermore, the Cronbach's alpha, which measures the internal reliability of the index, is $87.8 \%$, which means that all the items are highly correlated to each other and measure the same underlying concept.

This result is interesting because it conflicts with a previous study by Moynihan et al. (2012) in which two different factors emerged from the factor analysis. The first factor, which they labelled political performance information use, comprised the following items: communicate program successes to stakeholders, advocate for resources to support program needs, and explain the value of programs to the public. The second item, labelled purposeful use of performance information, comprised the remaining five items. 
Table 6: Routine Performance Information Use Factor Analysis

\begin{tabular}{lll}
\hline Item & Factor 1 & Uniqueness \\
\hline Communicate program successes to stakeholders. & .754 & .432 \\
Advocate for resources to support program needs. & .811 & .342 \\
Explain the value of programs to the public. & .667 & .555 \\
Make decisions. & .804 & .354 \\
Think of new approaches for doing old things. & .787 & .380 \\
Set priorities. & .784 & .386 \\
Identify problems that need attention. & .779 & .392 \\
Rewarding government employees that the & .609 & .629 \\
respondent manages or supervises. & & \\
\hline EIGENVALUE & $\mathbf{4 . 5 2 9}$ & \\
\hline Cronbach's alpha & $\mathbf{. 8 7 8}$ & \\
\hline
\end{tabular}

\section{Construction of the dependent variable Nonroutine PI Use}

As shown in Table 7, the eight items used in the survey to measure the use of nonroutine performance information load on two different factors: Factor 1, which is labelled in the analysis as External Nonroutine Performance Information—or following Kroll (2013) as Outsider Feedback — and Factor 2, which is labelled in the analysis as Internal Nonroutine Performance Information—or following Kroll (2013) as Insider Talks. The Eigenvalue of Factor 1 is 3.919, which is greater than 1 and therefore significant. The Eigenvalue of Factor 2 is 1.059 , which is slightly above the 1 threshold and therefore still significant. Furthermore, the Cronbach's alpha of the first factor is $85.9 \%$, which means that all the items are highly correlated to each other and measure the same underlying concept.

The Cronbach's alpha of the second factor, is $67 \%$, which is slightly lower than the threshold for a good, reliable scale of $70 \%$, but can still be considered acceptable 
(Nunnally, 1978). Nunnally (1978) states that: "what a satisfactory level of reliability is depends on how a measure is being used. In the early stages of research [...] one saves time and energy by working with instruments that have only modest reliability, for which purpose reliabilities of .70 or higher will suffice [...]. In contrast to the standards in basic research, in many applied settings a reliability of .80 is not nearly high enough" (p. 245). Other scholars have criticized Nunnally (1978). In particular, Lance et al. (2006) demonstrated that the cutoff point of 70\% is a myth. Furthermore, Loewenthal (1996) notes that a Cronbach's alpha between 60 and $70 \%$ can be considered acceptable. For these reasons, the variable Internal Nonroutine Performance Information Use can be considered acceptable and utilized in the analysis.

\section{Table 7: Nonroutine Performance Information Use Factor Analysis}

\begin{tabular}{llll}
\hline Item & Factor 1 & Factor 2 & Uniqueness \\
\hline Formal meetings with county employees. & & .840 & .350 \\
Informal talks with county employees. & & .870 & .309 \\
Written feedback from local politicians. & .627 & .388 \\
Written feedback from interest & .512 & & .497 \\
$\quad$ groups/customers. & .646 & & .462 \\
Local media. & .937 & & .256 \\
Formal meeting with politicians. & .888 & & .471 \\
Informal talks with politicians. & .715 & & \\
Talks with interest groups, citizens, media. & & & \\
\hline EIGENVALUE & $\mathbf{3 . 9 1 9}$ & $\mathbf{1 . 0 5 9}$ & \\
\hline Cronbach's alpha & $\mathbf{. 8 5 9}$ & $\mathbf{. 6 7 0}$ & \\
\hline
\end{tabular}

This result is interesting because it confirms a previous study by Kroll (2013) that identified the emergence of the two types of nonroutine performance information: outsider feedback and internal talks. 


\section{Construction of the independent variable Organizational Social Capital}

As shown in Table 8 Table 7 , the six items used in the survey to measure organizational social capital load on two different factors: Factor 1, which is labelled in the analysis as the Trust and Value component or Relational-Cognitive Social Capital (RCSC); and Factor 2, which is labelled in the analysis as the Network component or Structural Social Capital (SSC). The Eigenvalue of Factor 1 is 2.709, which is greater than 1 and therefore significant. The Eigenvalue of Factor 2 is 1.299 , which is above the 1 threshold and therefore significant. Furthermore, the Cronbach's alpha of the first factor is $78.8 \%$, which means that all the items are highly correlated to each other and measure the same underlying concept.

The Cronbach's alpha of the second factor is 67.1, which is slightly lower than the threshold for a good reliable scale of $70 \%$, but can still be considered acceptable based on the arguments noted in the previous section. Moreover, both Cronbach's alphas are higher than the Cronbach's alpha of the Organizational Social Capital Index in Andrew (2010), which was 61\% and Andrew (2011), which was 64.3\%.

This result is interesting because it conflicts with previous studies by Andrews $(2010,2011)$ in which all the six items used to measure organizational social capital are loaded on one single factor.

Table 8: Organizational Social Capital Factor Analysis

\begin{tabular}{llll}
\hline Item & Factor 1 & Factor 2 & Uniqueness \\
\hline $\begin{array}{l}\text { SSC: coordination and working with other } \\
\text { departments is a major part of our }\end{array}$ & .871 & .297 \\
approach to the organization of services. & & &
\end{tabular}


SSC: cross-departmental working is

important in driving service improvement.

RSC: there is a high level of trust between $\quad .689$

top management and staff

RSC: there is a high level of trust between $\quad .556$ county management and politicians

CSC: the department's mission, values and $\quad .923$

objectives are clearly and widely

understood and owned by all staff in the

service.

CSC: the department concentrates on achieving its mission, values and objectives.

\begin{tabular}{lcc}
\hline EIGENVALUE & 2.709 & 1.299 \\
\hline Cronbach's alpha & .788 & .671 \\
\hline
\end{tabular}

\section{Construction of other independent variables}

The only control variable that needed to be constructed and that was not readily usable was developmental culture. Because the three items have previously been widely used in the literature to measure this concept (see Moynihan \& Pandey, 2010; Kroll, 2013), no factor analysis was performed. The developmental culture variable was created by averaging the responses of all three items. Cronbach's alpha for this scale is $77 \%$.

\section{Estimation Routine}

As previously stated, the analysis performed in this study is at the departmental level. Therefore, departmental level dependent and independent variables have been created by aggregating individual level responses at the departmental level. Regarding the estimation procedure, Ordinary Least Square (OLS) analysis with cluster-robust standard errors was conducted. Standard errors were clustered at the county level. The 
usual OLS assumption is that standard errors are independently and identically distributed. However, due to the way the analysis was designed, standard errors clustered might have been clustered at the departmental or organizational level. The reason for this is that observations within groups might be correlated in some unknown ways, thus violating the aforementioned OLS assumption. If clustered errors are present, the OLS estimations are still considered to be unbiased but the estimation of standard errors might be incorrect, thus leading to errors of Type I, rejecting a true null hypothesis, or Type II, failing to reject a false null hypothesis.

With the cluster-robust option, one assumes that the observations are independent across clusters but not necessarily within the clusters. Higher number of clusters results in greater accuracy in the estimation of standard errors. In particular, Kézdi (2004) states that 50 clusters can be considered an acceptable number that allows for the estimation of standard errors in a very accurate fashion. In the analysis, 166 clusters/departments are used in the estimation routine. Descriptive statistics of the main variables of interest in the analysis are reported in Table 9. Developmental culture, peer exchange, resources, and citizens' demand of performance information were all measured on Likert-type scales ranging from 1 to 5 . The mean of all these variables is above the middle of the range (2.5), which means that Florida County Government Departments perform reasonably well on these variables. Table 10 is the correlation matrix of the all the variables adopted in the analysis. As the table shows, there are no highly correlated variables (above 0.7 ) in the analysis.

Table 9: Descriptive Statistics

\begin{tabular}{lllll}
\hline Variable & Mean & Std. Dev. & Min & Max \\
\hline Routine PI Use & $-4.74 \mathrm{e}-10$ & 1 & -3.088 & 2.331
\end{tabular}




\begin{tabular}{lllll} 
Nonroutine PI Use - External & $-1.44 \mathrm{e}-10$ & 1 & -3.512 & 1.989 \\
Nonroutine PI Use - Internal & $-3.13 \mathrm{e}-09$ & 1 & -2.852 & 1.902 \\
Relational-Cognitive SC & $-5.13 \mathrm{e}-09$ & 1 & -3.014 & 1.916 \\
Structural SC & $-5.35 \mathrm{e}-09$ & 1 & -3.695 & 1.680 \\
Developmental Culture & 3.572 & .565 & 2 & 4.778 \\
Peer Exchange & 3.766 & .689 & 2 & 5 \\
Resources & 2.885 & .821 & 1 & 4 \\
Citizens' Demand of PI & 2.940 & .758 & 1 & 4.5 \\
Supervisory Role & 1.746 & .757 & 1 & 4 \\
Length of Stay & 3.394 & 1.169 & 1 & 6 \\
Age & 4.693 & .575 & 3 & 6 \\
\hline
\end{tabular}


Table 10: Correlation Matrix

\begin{tabular}{|c|c|c|c|c|c|c|c|c|c|c|c|}
\hline & $\begin{array}{l}\text { Routine } \\
\text { PI Use }\end{array}$ & $\begin{array}{l}\text { NR PI } \\
\text { Use } \\
\text { Extern. }\end{array}$ & $\begin{array}{l}\text { NR PI } \\
\text { Use - } \\
\text { Internal }\end{array}$ & $\mathrm{RCSC}$ & $\mathrm{SSC}$ & $\begin{array}{l}\text { Dev. } \\
\text { Cultur } \\
\text { e }\end{array}$ & $\begin{array}{l}\text { Peer } \\
\text { Exch. }\end{array}$ & Res. & $\begin{array}{l}\text { Citizens' } \\
\text { Dem. }\end{array}$ & $\begin{array}{l}\text { Superv. } \\
\text { role }\end{array}$ & $\begin{array}{l}\text { Length } \\
\text { of Stay }\end{array}$ \\
\hline \multicolumn{12}{|l|}{ Routine PI Use } \\
\hline $\begin{array}{l}\text { Nonroutine PI Use - } \\
\text { External }\end{array}$ & 0.204 & 1.000 & & & & & & & & & \\
\hline $\begin{array}{l}\text { Nonroutine PI Use - } \\
\text { Internal }\end{array}$ & 0.319 & 0.479 & 1.000 & & & & & & & & \\
\hline $\begin{array}{l}\text { Relational-Cognitive } \\
\text { SC }\end{array}$ & 0.297 & 0.166 & 0.174 & 1.000 & & & & & & & \\
\hline Structural SC & 0.223 & 0.214 & 0.158 & 0.306 & 1.000 & & & & & & \\
\hline Developmental Culture & 0.267 & 0.198 & 0.221 & 0.618 & 0.262 & 1.000 & & & & & \\
\hline Peer Exchange & 0.347 & 0.190 & 0.232 & 0.278 & 0.202 & 0.474 & 1.000 & & & & \\
\hline Resources & 0.012 & 0.038 & 0.075 & 0.357 & 0.204 & 0.325 & 0.177 & 1.000 & & & \\
\hline Citizens' Demand of PI & 0.156 & 0.276 & 0.228 & 0.046 & 0.004 & 0.025 & 0.078 & 0.088 & 1.000 & & \\
\hline Supervisory Role & -0.129 & 0.012 & -0.161 & -0.162 & -0.043 & -0.048 & -0.067 & 0.128 & 0.065 & 1.000 & \\
\hline Length of Stay & -0.0179 & 0.1068 & 0.0072 & 0.1031 & 0.0650 & 0.0703 & -0.011 & 0.039 & 0.069 & -0.030 & 1.000 \\
\hline Age & -0.177 & -0.072 & -0.152 & -0.104 & -0.137 & -0.074 & -0.110 & -0.097 & -0.0855 & -0.1124 & 0.2110 \\
\hline
\end{tabular}




\section{Limitations of the study}

\section{Reverse causality/endogeneity}

From a methodological perspective, the present study has two main limitations: reverse causality/endogeneity and common source bias. In this dissertation, it is hypothesized that organizational social capital has a positive effect on performance information use. Reverse causality occurs if performance information use has an effect on organizational social capital. Research on this possible effect is not yet well developed, but performance information use and more generally performance management could crowd out organizational social capital. Two arguments, described below, support the directional relationship of the original hypothesis: organizational social capital affects performance information use.

The first argument is time. Organizational social capital, as well as community social capital, develops over time (Leana \& Van Buren, 1999; Nahapiet \& Ghoshal, 1998). It cannot be created overnight. Following organizational culture theory (Pettigrew, 1979; Schein, 1992), organizational social capital cannot be adopted and implemented in an organization as a managerial tool; rather, it is something that the organization possesses and that can only be fostered. Similarly, organizational social capital cannot be quickly removed from an organization. On the other hand, a performance measurement and management system is a tool that can be adopted rather quickly in an organization, although its implementation might be more time- and resource-consuming. Furthermore, it is something that an organization can dismantle easily. More importantly, performance measurement and management systems have only been adopted and implemented in local public administrations recently, while, given the advanced age of the people working for Florida county governments (on average 50 to 59 years old), organizational social capital has been created and nurtured 
on an earlier and over a longer period of time. Therefore, to establish causality, given the aforementioned characteristics of organizational social capital and of performance management systems, from a temporal point of view, organizational social capital antecedes the adoption and implementation of performance measurement and the management system-making the direction of the relationship that which was hypothesized.

The second argument that supports the hypothesized relationship concerns the way survey questions about performance information use and organizational social capital had been asked to respondents. Routine performance information use was measured by asking department heads, middle managers, and supervisors to evaluate their individual use of performance information ("I use performance information to..."), while organizational social capital was measured by asking the same individuals to evaluate the perception they had of the level of social capital in their departments. Managers cannot directly impact the level of organizational social capital. It is outside of their direct control, while performance information use is within their control. Therefore, the former can affect the latter but not the other way around.

\section{Common source bias}

Finally, the problem of common source bias must be addressed. Common source bias "is a biasing of results (which could be in the form of false positives from hypothesis tests) that is caused by two variables exhibiting related measurement error owing to a common method, such as a single survey" (Favero \& Bullock, 2014, p. 1). Both the literature and statistical procedures can be used to support the argument that common source bias is not a problem in this study. Starting with the literature, a study by Meier and O'Toole (2013) shows that the common source bias potential of 
performance information use items is lower than that of other items. The explanation is that there seems to be greater social desirability to report higher levels of organizational performance than high levels of performance information use, because high performance can be extrinsically rewarded and high levels of performance information use cannot.

From a statistical point of view, two methods can be used to test for common source bias. Meier and O'Toole (2013) suggest use of both objective and subjective measures (e.g., objective vs. subjective performance or objective vs. subjective turnover, etc.), and estimate the relationships between the variables in the data set (like organizational social capital or performance information use) and the objective and subjective measures. Larger differences between the correlation of performance information use and the objective measure on the one hand, and the correlation of performance information use and the subjective measure on the other, result in higher common source bias potential. This method does not help address the problem, but it can indicate whether there is problem or not. Unfortunately, this kind of statistical procedure cannot be performed in the present study because no objective measures of performance information use, let alone organizational social capital, exist.

A second statistical procedure that can be used to support the idea that common source bias is not a problem in the present study is Harman's single-factor test. The test requires that all the variables being tested, dependent and independent, are placed in a factor analysis. The emergence of a single factor that explains more than $50 \%$ of the variance in the data could be a sign of common source bias. The result of Harman's single-factor test show that the common source bias may not be considered a problem in the data. The first factor explains only $26.4 \%$ of the total variance in the data. 
In conclusion, by taking into consideration both the literature (Meier \& O'Toole, 2013) and the result of the Harman's single-factor test, one can affirm that common source bias is not a problem in this study.

This chapter has presented the quantitative research design and methods of investigation used to answer the two proposed research questions. The first section presented the unit of analysis of this study, Florida county governments. The second one introduced the survey instrument, and described how variables have been operationalized in the analysis. The following section described the pilot test and the following section illustrated the response rate achieved for the survey. Estimation routines and the factor analyses performed to construct the main indexes used in the analysis. The chapter concluded by describing the methodological limitations of the study. 


\section{Chapter 6 - Results}

The aim of this chapter is to present the statistical results of the analysis performed using Stata 14. This chapter contains two sections. The first section describes the results related to the first dependent variable, nonroutine performance information use; the second section describes the results related to the second dependent variable, routine performance information use. The first main finding partially supports the hypothesis that organizational social capital is positively associated with nonroutine performance information use-outsider feedback. Finally, there is no support for nonroutine performance information use-insider talks. The second main finding supports the hypothesis that organizational social capital is positively associated with routine performance information use. The chapter concludes by analyzing the substitution effect between routine and nonroutine performance information.

\section{Nonroutine Performance Information Use}

\section{Outsider Feedback}

Table 11 presents the estimation results of three OLS regression models with nonroutine performance information-outsider feedback as the dependent variable. Overall, the models fit the data sufficiently well, with $\mathrm{R}^{2}$ values between .15 and .20 , which indicates that the models can explain roughly between 15 and $20 \%$ of the variation of nonroutine performance information. Three different models were tested. The first model assumes a linear relationship between OSC and nonroutine performance information use, while the other two models assume a non-linear relationship between the two variables.

In Model 1, the OLS regression results partially support the hypothesis that organizational social capital is positively associated with nonroutine performance 
information use. The coefficient of the relational-cognitive dimension of social capital and the coefficient of the structural dimension of social capital exhibit expected signs, but only the second one is statistically significant. Other factors being held equal, departments with a higher value of structural social capital tend to have a higher usage of nonroutine performance information - outsider feedback. Departments that tend to work in coordination and collaboration with other departments also tend to have higher usage of outsider feedback in their decision-making process.

Among the control variables, only Citizens' Demand of Performance Information shows a statistically significant sign in Model 1. The coefficient of Citizens' Demand of Performance Information is statistically positive. Departments that tend to regularly provide performance information to their citizens, tend also to have higher usage of nonroutine performance information in their decision-making process, holding other factors constant.

In Model 2, the relational-cognitive social capital squared term has been introduced in the analysis to test for a non-linear relationship between this dimension of social capital and performance information use. Before adding the squared term, the main independent variable has been centered by subtracting the mean of the independent variable from each value. The new variable represents the linear term, which will then be squared to create the squared term. As an added benefit, centering the independent variable reduces the correlation between the linear and quadratic terms. The OLS regression results support the evidence of a curvilinear relationship between relational-cognitive social capital and nonroutine performance information useoutsider feedback. Both the linear and quadratic coefficient of the relational-cognitive dimension of social capital are statistically significant. Because both the linear and 
quadratic terms are statically positive, increases in low levels of social capital foster the use of outsider feedback, while increases at higher levels of the variable foster at a higher rate the use of nonroutine performance information. Among the control variables, only Citizens' Demand of Performance Information shows a statistically significant and positive sign in Model 2.

Table 11: Estimation results. DV: Nonroutine PI Use-Outsider Feedback

\begin{tabular}{llll}
\hline Variables & Model 1 & Model 2 & Model 3 \\
\hline Relational-Cognitive SC & $.041(.105)$ & $.268^{* *}(.111)$ & \\
Structural SC & $.164^{* *}(.076)$ & & $.237^{* *}(.084)$ \\
$\begin{array}{l}\text { Relational-Cognitive SC } \\
\text { squared term) }\end{array}$ & $.146^{* * *}(.050)$ & \\
Structural SC (squared term) & & & $.083(.058)$ \\
Developmental Culture & $.149(.136)$ & $.125(.136)$ & $.152(.123)$ \\
Peer Exchange & $.118(.116)$ & $.139(.113)$ & $.103(.112)$ \\
Resources & $-.083(.066)$ & $-.110(.065)$ & $-.069(.069)$ \\
Citizens' Demand of PI & $.261 * *(.070)$ & $.271^{* * *}(.067)$ & $.262^{* * *}(.070)$ \\
Supervisory Role & $.036(.069)$ & $.065(.071)$ & $.005(.074)$ \\
Length of Stay & $.051(.052)$ & $.069(.051)$ & $.054(.053)$ \\
Age & $-.034(.101)$ & $-.062(.092)$ & $-.051(.101)$ \\
Constant & $-1.63 * *(.764)$ & $-1.70 * *(.075)$ & $-1.56 * *(.667)$ \\
\hline Observations & 161 & 161 & 161 \\
\hline R Squared & 0.160 & 0.186 & 0.169 \\
\hline
\end{tabular}

Note: Regression coefficients marked with an asterisk were statistically significant at $* \mathrm{p}<0.10 ; * * \mathrm{p}<0.05 ; * * * \mathrm{p}<0.01$

Similarly, in Model 3 the structural social capital squared term has been introduced in the analysis to test for a non-linear relationship between this dimension of social capital and performance information use. The OLS regression results do not support the existence of a curvilinear relationship between structural social capital and 
nonroutine performance information use. While the linear term exhibits a statistically significant and positive sign, the quadratic coefficient of the structural dimension of social capital is not statistically significant. Once again, among the control variables, only Citizens' Demand of Performance Information shows a statistically significant and positive sign in Model 3. To conclude this subsection, given the described results, the second model seems to explain better the departmental level use of nonroutine performance information — outsider feedback in Florida county governments.

\section{Insider Talks}

Table 12 presents the estimation results of three OLS regression models with nonroutine performance information —insider talks as the dependent variable. Overall, the models fit the data sufficiently well, with $\mathrm{R}^{2}$ values above .15 , which indicates that the models can explain roughly more than $15 \%$ of the variation of nonroutine performance information. Three different models were tested. The first model assumes a linear relationship between OSC and nonroutine performance information use, while the other two models assume a non-linear relationship between the two variables.

In Model 1, the OLS regression results do not support the hypothesis that organizational social capital is positively associated with nonroutine performance information use-internal talks. The coefficient of the relational-cognitive dimension of social capital and the coefficient of the structural dimension of social capital are not statistically significant.

Among the control variables, Citizens' Demand of Performance Information and Supervisory Role show a statistically significant sign in Model 1. The coefficient of Citizens' Demand of Performance Information is statistically positive. Departments that tend to regularly provide performance information to their citizens, tend also to 
have higher usage of nonroutine performance information deriving from internal talks in their decision-making process, holding other factors constant. The negative sign of the coefficient of Supervisory Role suggests that departments that tend to have less individuals in a supervisory role, also tend to have higher usage of routine performance information.

In Model 2, the relational-cognitive social capital squared term has been introduced in the analysis to test for a non-linear relationship between this dimension of social capital and performance information use. The OLS regression results do not support the evidence of a curvilinear relationship between relational-cognitive social capital and nonroutine performance information use-insider talks. Both the linear and quadratic coefficient of the relational-cognitive dimension of social capital are not statistically significant. Similar to Model 1, among the control variables, Citizens' Demand of Performance Information and Supervisory Role show a statistically significant sign in Model 2. The coefficient of Citizens' Demand of Performance Information is statistically positive, while the coefficient of the second control variable is negative.

Likewise, in Model 3 the structural social capital squared term has been introduced in the analysis to test for a non-linear relationship between this dimension of social capital and performance information use. The OLS regression results do not support the existence of a curvilinear relationship between structural social capital and nonroutine performance information use. Both the linear and quadratic coefficient of the relational-cognitive dimension of social capital are not statistically significant. Once again, among the control variables, Citizens' Demand of Performance Information and 
Supervisory Role show a statistically significant and respectively positive and negative signs in Model 3.

To conclude this subsection, given the described results, organizational social capital does not have any effect on the use of nonroutine performance informationinsider talks.

Table 12: Estimation results. DV: Nonroutine PI Use-Insider Talks

\begin{tabular}{llll}
\hline Variables & Model 1 & Model 2 & Model 3 \\
\hline Relational-Cognitive SC & $-.013(.117)$ & $.012(.161)$ & \\
Structural SC & $.080(.088)$ & & $.084(.107)$ \\
Relational-Cognitive SC & & $.007(.077)$ & \\
(squared term) & & & $.006(.067)$ \\
Structural SC (squared term) & & $.198(.132)$ & $.182(.118)$ \\
Developmental Culture & $.194(.133)$ & $.162(.135)$ & $.152(.129)$ \\
Peer Exchange & $.152(.132)$ & $.162)$ & $-.009(.079)$ \\
Resources & $-.008(.082)$ & $-.003(.081)$ & $.218 * * *(.078)$ \\
Citizens' Demand of PI & $.219 * * *(.078)$ & $.217 * * *(.078)$ & $-.198 * *(.095)$ \\
Supervisory Role & $-199 *(.101)$ & $-.200 *(.105)$ & $.001(.051)$ \\
Length of Stay & $.001(.052)$ & $.005(.052)$ & $-.156(.107)$ \\
Age & $-.156(.109)$ & $-.168(.109)$ & $-868(.655)$ \\
Constant & $-.913(.672)$ & $-944(.683)$ & 161 \\
\hline Observations & 161 & 0.156 & \\
\hline R Squared & 0.161 & & \\
\hline
\end{tabular}

Note: Regression coefficients marked with an asterisk were statistically significant at $* \mathrm{p}<0.10 ; * * \mathrm{p}<0.05 ; * * * \mathrm{p}<0.01$ 


\section{Routine Performance Information Use}

In Model 2, the relational-cognitive social capital squared term has been introduced in the analysis to test for a non-linear relationship between this dimension of social capital and performance information use. The OLS regression results do not support the existence of a non-linear relationship between organizational social capital and routine performance information use. While the linear term exhibits a statistically significant and positive sign, the quadratic coefficient of the relational-cognitive dimension of social capital is not statistically significant. Among the control variables, Peer Exchange and Age still show statistically significant sign in Model 2. The coefficient of Peer Exchange is statistically positive, while the coefficient of Age is statistically negative - therefore, mirroring the results of Model 1.

Table 13 presents the estimation results of three OLS regression models with routine performance information as the dependent variables. Overall, the models fit the data sufficiently well, with $\mathrm{R}^{2}$ values around .20 , which indicates that the models can explain roughly $20 \%$ of the variation of routine performance information. Three different models were tested. The first model assumes a linear relationship between organizational social capital and routine performance information use, while the other two models assume a non-linear relationship between the two variables.

In Model 1, the OLS regression results support the hypothesis that organizational social capital is positively associated with routine performance information use. The coefficient of the relational-cognitive dimension of social capital and the coefficient of the structural dimension of social capital exhibit expected signs and are statistically significant. Other factors being held equal, departments with a higher value of relational-cognitive social capital tend to have higher usage of routine 
performance information. Similarly, other factors being held equal, departments with a higher value of structural social capital tend to have higher usage of nonroutine performance information. In terms of magnitude, the association between the relationalcognitive dimensions of social capital is greater than that between the structural dimensions of social capital. The coefficient of the relational-cognitive dimension of social capital is .191, while the coefficient of the structural dimension of social capital is .144.

Among the control variables, Peer Exchange, Resources, and Age show statistically significant signs in Model 1. The coefficient of Peer Exchange is statistically positive. Departments that tend to regularly exchange information with professional staff from other counties who work in the same field, tend also to have higher usage of routine performance information in their decision-making process, holding other factors constant. These departments seem to be more likely to use performance information for benchmarking purposes, thus making the use of performance information more likely to occur in their daily decision-making process.

The coefficient of Resources is statistically negative. Departments that tend to have sufficient resources (e.g., people, materials, budget) to complete projects, also tend to have lower usage of routine performance information in their decision-making process, holding other factors constant. The negative sign of the coefficient of Age group suggests that departments that tend to have younger management, also tend to have higher usage of routine performance information. Younger managers, that were trained after the New Public Management (NPM) movement reshaped approaches to managing public administrations and that were trained in programs that embraced NPM theories and practices, are more likely to the use of performance information. 
In Model 2, the relational-cognitive social capital squared term has been introduced in the analysis to test for a non-linear relationship between this dimension of social capital and performance information use. The OLS regression results do not support the existence of a non-linear relationship between organizational social capital and routine performance information use. While the linear term exhibits a statistically significant and positive sign, the quadratic coefficient of the relational-cognitive dimension of social capital is not statistically significant. Among the control variables, Peer Exchange and Age still show statistically significant sign in Model 2. The coefficient of Peer Exchange is statistically positive, while the coefficient of Age is statistically negative - therefore, mirroring the results of Model 1.

Table 13: Estimation results. DV: Routine Performance Information Use

\begin{tabular}{llll}
\hline Variables & Model 1 & Model 2 & Model 3 \\
\hline Relational-Cognitive SC & $.191^{*}(.091)$ & $.215^{*}(.106)$ & \\
Structural SC & $.144^{*}(.064)$ & & $.186^{* *}(.082)$ \\
$\begin{array}{l}\text { Relational-Cognitive SC } \\
\text { squared term) }\end{array}$ & & $-.002(.055)$ & \\
Structural SC (squared term) & & & $.026(.064)$ \\
Developmental Culture & $.052(.123)$ & $.066(.123)$ & $.190(.123)$ \\
Peer Exchange & $.270^{* *}(.096)$ & $.272 * * *$ & $.243 * *(.100)$ \\
& & $(.096)$ & \\
Resources & $-.128^{*}(.068)$ & $.115(.066)$ & $.097(.068)$ \\
Citizens' Demand of PI & $.141(.096)$ & $.138(.097)$ & $.145(.097)$ \\
Supervisory Role & $-.097(.080)$ & $-.103(.082)$ & $-.140 *(.075)$ \\
Length of Stay & $-.025(.038)$ & $-.020(.040)$ & $-.019(.038)$ \\
Age & $-.144^{*}(.079)$ & $-.159 *(.076)$ & $-.168 *(.083)$ \\
Constant & $-.352(.643)$ & $-.438(.636)$ & $-.787(.622)$ \\
\hline Observations & 165 & 165 & 165 \\
\hline
\end{tabular}




\begin{tabular}{llll}
\hline R Squared & 0.215 & 0.197 & 0.196
\end{tabular}

Note: Regression coefficients marked with an asterisk were statistically significant at $* \mathrm{p}<0.10 ; * * \mathrm{p}<0.05 ; * * * \mathrm{p}<0.01$

Similarly, in Model 3 the structural social capital squared term has been introduced in the analysis to test for a non-linear relationship between this dimension of social capital and performance information use. Structural social capital has been centered as well, following the procedure previously described. The OLS regression results do not support the existence of a non-linear relationship between structural social capital and routine performance information use. While the linear term exhibits a statistically significant and positive sign, the quadratic coefficient of the structural dimension of social capital is not statistically significant. Among the control variables, Peer Exchange, Age, and Supervisory Role show statistically significant sign in Model 2. The coefficient of Peer Exchange is statistically positive, while the coefficient of Age is statistically negative. The negative sign of the coefficient of Supervisory Role suggests that departments that tend to have fewer individuals in a supervisory role, tend also to have higher usage of routine performance information. Department heads and middle managers are held accountable for their department performance by the county manager, board of county commissioners, and external stakeholders; therefore, they tend to use more routine performance information. This is not the case for supervisors that feel less external pressure, therefore tending to use less performance information in their decision-making process.

To conclude this section, given the described results, the first model seems to better explain departmental level use of routine performance information in Florida county governments. 


\section{The substitution effect}

This section presents results of the second research question: "Does organizational social capital affect routine and nonroutine performance information in similar ways, or does it increase the use of only one type of information at the expense of the other?" The aim of the second research question is to measure the substitution effect that organizational social capital might generate between nonroutine and routine performance information. To answer this second research question, the following statistical approaches are performed. For an initial and preliminary understanding of this effect, the correlation between the main dependent variables was analyzed. The sign and absolute value of the Pearson coefficient defines the direction and magnitude of the relationship between two variables. A positive correlation means that when one variable increases (or decreases), the other variable also increases (or decreases). A negative correlation means that when one variable increases (or decreases), the other variable decreases (or increases). A Pearson coefficient close to 0 indicates a weak relationship, while a coefficient close to -1 or +1 indicates, respectively, a strong negative relationship or a strong positive relationship.

As shown in Table 10, the correlation coefficient between the relational and cognitive dimension of social capital and routine performance information use is 0.30 , while it drops to 0.174 with nonroutine performance information-internal (insider talks) and to 0.166 with nonroutine performance information-external (outsider feedback). Though all positive, the relational and cognitive dimension of organizational social capital seem to have a stronger relationship with routine performance information use rather than nonroutine performance information use. In terms of structural social capital, the correlation coefficient with routine performance information is equal to 
0.223 and equal to 0.214 with nonroutine performance information-external (outsider feedback). The correlation coefficient drops to 0.174 with nonroutine performance information —internal (insider talks).

From this preliminary analysis, one can cautiously conclude that, first, trust and shared goals (the relational and cognitive dimension) are more likely to favor the use of routine performance information rather than the use of nonroutine performance information. Second, connections and interactions (the structural dimension) are important to fostering both routine performance information use and nonroutine performance information-external (outsider feedback) but not as important to fostering nonroutine performance information —internal (insider talks).

A different way to measure this effect is to consider the results from six different models, as reported in Table 14. The characteristic of these models is that in all of them, it is controlled for another type of performance information use that differs from the one used for the dependent variable.

Table 14: Substitution effect modelling

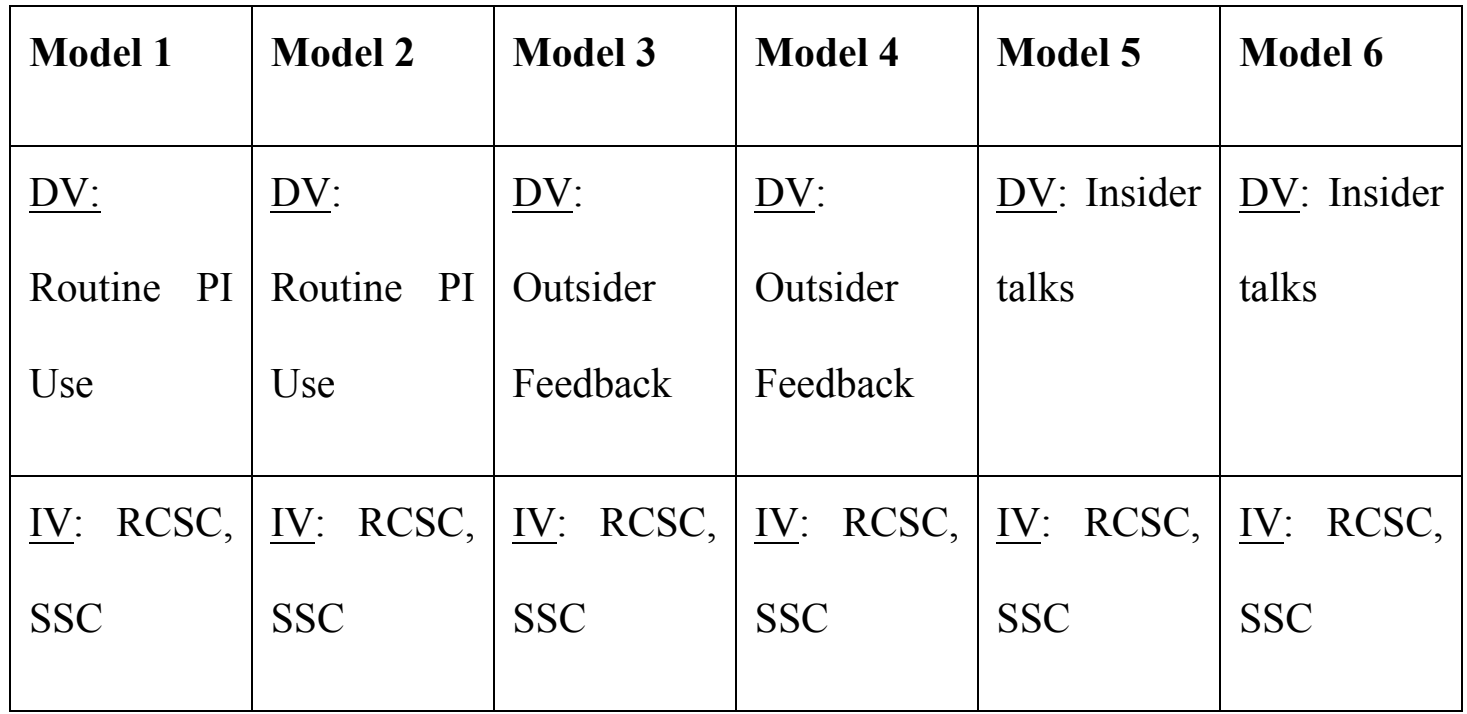




\begin{tabular}{|l|l|l|l|l|l|}
\hline C1: & $\underline{\mathrm{C} 1}:$ Insider & $\underline{\mathrm{C} 1}$ : Routine & $\underline{\mathrm{C} 1}$ : Insider & $\underline{\mathrm{C} 1}$ : Routine & $\underline{\mathrm{C} 1}:$ \\
Outsider & talks & PI Use & talks & PI Use & Outsider \\
Feedback & & & & & Feedback \\
\hline Controls & Controls & Controls & Controls & Controls & Controls \\
\hline
\end{tabular}

The results of the analysis, grouped two models at the time, are reported in Table 15, Table 16, and Table 17.

Table 15 presents results of the first and second model. Routine performance information use is the dependent variable and organizational social capital is the main independent variable, while nonroutine performance information use-outsider feedback and nonroutine performance information use-insider talks are the main variables to control for the hypothesized substitution effect. In Model 1, the relational and cognitive dimension of social capital shows a statistically significant and positive sign, as previously shown in the previous section of this chapter. Other factors being held equal, departments with a higher value of relational-cognitive social capital tend to have higher usage of routine performance information. However, in Model 1, outsider feedback is not statistically significant. Similarly, peer exchange shows a statistically significant and positive sign, while resources and age are statistically significant but negative.

Table 15: Estimation results. DV: Routine Performance Information Use

\begin{tabular}{lll}
\hline Variables & Model 1 & Model 2 \\
\hline Relational-Cognitive SC & $.194^{* *}(.093)$ & $.199^{* *}(.083)$ \\
Structural SC & $.103(.067)$ & $.100(.062)$ \\
Outsider Feedback & $.066(.074)$ &
\end{tabular}


Insider Talks

Developmental Culture

$.033(.119)$

Peer Exchange

$.031 * * *(.098)$

Resources

Citizens' Demand of PI

Supervisory Role

Length of Stay

Age

Constant

Observations

R-squared
$.177 * * *(.076)$

$.008(.108)$

$.294 * * *(.098)$

$-.130 * *(.064)$

$.096(.096)$

$-.052(.080)$

$-.017(.036)$

$-.119(.074)$

-.419 (.603)

In Model 2, nonroutine performance information-insider talks show a statistically significant and positive sign. Other factors being held equal, departments with higher value of relational-cognitive social capital tend to have higher usage of routine performance information. Similarly, other factors being held equal, departments with higher usage of insider talks tend to have higher usage of routine performance information as well. In terms of magnitude, the association between the relationalcognitive dimensions of social capital is greater than that between insider talks. Similar to the previous models, peer exchange shows a statistically significant and positive sign, while resources is statistically significant but negative. Overall, the models fit the data sufficiently well, with $\mathrm{R}^{2}$ values around above .20 , which indicates that the models can explain more than $20 \%$ of the variation of routine performance information.

Table 16 presents the results of the third and fourth models. Nonroutine performance information use-outsider feedback is the dependent variable and organizational social capital is the main independent variable, while routine 
performance information use and nonroutine performance information use-insider talks are the main variables to control for the hypothesized substitution effect. In Model 3 , the structural dimension of social capital shows a statistically significant and positive sign, as previously shown in the first section of this chapter. Other factors being held equal, departments with a higher value of structural social capital tend to have higher usage of nonroutine performance information—outsider feedback. However, in Model 3, routine performance information use is not statistically significant. Similarly, citizens' demand for performance information shows a statistically significant and positive sign.

In Model 4, nonroutine performance information-insider talks shows a statistically significant and positive sign. Other factors being held equal, departments with higher usage of insider talks tend to have higher usage of nonroutine performance information-outsider feedback as well. None of the dimensions of organizational social capital appears to be statistically significant. Similar to the previous models, citizens' demand for performance information shows a statistically significant and positive sign. Overall, the models fit the data sufficiently well, with $\mathrm{R}^{2}$ values around above .20 for Model 3 and above 0.30 for Model 4, which indicate that the models can explain, respectively, more than 20 and $30 \%$ of the variation of routine performance information.

Table 16: Estimation results. DV: Nonroutine PI Use - Outsider Feedback

\begin{tabular}{lll}
\hline Variables & Model 3 & Model 4 \\
\hline Relational-Cognitive SC & $.027(.104)$ & $.047(.118)$ \\
Structural SC & $.156^{*}(.077)$ & $.131(.075)$ \\
Routine PI Use & $.074(.085)$ &
\end{tabular}


Insider Talks

Developmental Culture

Peer Exchange

Resources

Citizens' Demand of PI

Supervisory Role

Length of Stay

$$
\text { Age }
$$

Constant
$.146(.137)$

$.095(.113)$

$-.074(.068)$

$.252 * *(.065)$

$.042(.070)$

$.052(.052)$

$-.024(.101)$

$-1.592 * *(.767)$
$.412 * * *(.099)$

$.069(.138)$

$.055(.115)$

$-.080(.066)$

$.171 * *(.065)$

$.118(.076)$

$.051(.046)$

$.030(.078)$

$-1.259 * *(.712)$

Observations

161

161

R-squared

0.234

0.306

Table 17 shows the results of the fifth and sixth models. Nonroutine performance information use-insider talks is the dependent variable and organizational social capital is the main independent variable, while routine performance information use and nonroutine performance information use-outsider feedback are the main variables to control for the hypothesized substitution effect. In Model 5, routine performance information use is statistically significant. Other factors being held equal, departments with higher usage of routine performance information tend to have higher usage of nonroutine performance information-insider talks. However, in Model 5, both the relational and cognitive dimension of social capital as well as the structural dimension do not show statistically significant signs, as previously shown in the third section of this chapter. Citizens' demand for performance information shows a statistically significant and positive sign, while Supervisory Role is statistically significant but negative. 
In Model 6, nonroutine performance information-external feedback shows a statistically significant and positive sign. Other factors being held equal, departments with higher usage of outsider feedback tend to have higher usage of nonroutine performance information-insider talks as well. However, in Model 6, both the relational and cognitive dimension of social capital as well as the structural dimension do not show statistically significant signs, as previously shown in the third section of this chapter. Similar to the previous model, Supervisory Role shows a statistically significant and negative positive sign. Overall, the models fit the data sufficiently well, with $\mathrm{R}^{2}$ values around above .20 , which indicates that the models can explain more than $20 \%$ of the variation of routine performance information.

Table 17: Estimation results. DV: Nonroutine PI Use-Insider Tallks

\begin{tabular}{lll}
\hline Variables & Model 5 & Model 6 \\
\hline Relational-Cognitive SC & $-.052(.105)$ & $-.030(.128)$ \\
Structural SC & $.057(.089)$ & $.011(.084)$ \\
Routine PI Use & $.201 * *(.085)$ & $.421^{* * *}(.108)$ \\
Outsider feedback & & $.131(.134)$ \\
Developmental Culture & $.185(.125)$ & $.102(.128)$ \\
Peer Exchange & $.087(.132)$ & $.027(.079)$ \\
Resources & $.018(.082)$ & $.109(.083)$ \\
Citizens' Demand of PI & $.192 * * *(.077)$ & $-.214 * *(.101)$ \\
Supervisory Role & $-.182 * *(.103)$ & $-.021(.044)$ \\
Length of Stay & $.004(.051)$ & $-.141(.090)$ \\
Age & $-.126(.106)$ & $-.225(.637)$ \\
Constant & $-.796(.671)$ & 161 \\
\hline Observations & 161 & \\
\hline
\end{tabular}




\begin{tabular}{lll}
\hline R-squared & 0.192 & 0.307
\end{tabular}

In summary, other factors being held equal, departments with a higher level of relational and cognitive social capital tend to use more routine performance information (.194) while controlling for nonroutine performance information-outsider feedback and (.199) while controlling for nonroutine performance information-insider talks. Other factors being held equal, departments with a higher level of structural social capital tend to have higher usage of nonroutine performance information - outsider feedback (.156) while controlling for routine performance information.

\section{Summary of Results}

The chapter has presented the results of quantitative analysis of survey data. The main results are that all the dimension of organizational social capital are relevant for routine performance information use while only the structural dimension is relevant for nonroutine performance information use - outsider feedback. The results also show that benchmarking and citizen's demand for performance information are important factors that favor managerial usage of performance data. Among the different types of performance information available, more likely managers seem to use more routine performance information in organization with a high level of relational and cognitive social capital while they seem to use more nonroutine performance informationoutsider feedback in organizations with a high level of structural social capital. 


\section{Chapter 7 Complementary Qualitative Research Design}

The aim of this chapter is to present the comparative case study that was conducted to gather contextual information to support the results of the quantitative analysis. The first section presents the purpose of a comparative case study analysis and the selection process of the two cases. The second section introduces the methods of investigation used in this part of the analysis. For each of the two cases, County A and County B, a contextual description is provided and then the main results regarding both performance information use and organizational social capital are presented. The chapter concludes by summarizing in a comparative way the main results of the qualitative analysis.

\section{Purpose and selection of cases}

Mixed-methods approaches allow researchers to study complicated research questions and to gather a greater abundance of and more distinct assortment of information than would be possible with only one method of investigation (Yin, 2009). In particular, "mixed methods research forces the methods to share the same research questions, to collect complementary data, and to conduct counterpart analyses" (p. 63). According to Yin (2009), the mixed-methods approach adopted in this analysis is a case study within a survey. The central investigation relied on the use of quantitative methods as described in Chapter 5 and Chapter 6, while the case study here "may help to investigate the conditions within one of the entities being surveyed" (p. 63).

A complementary case study research design has also been chosen as appropriate for better understanding and identifying the relationship between organizational social capital and performance information use and how the former affects the use of routine and nonroutine performance information, and for searching 
for insights behind the scenes. Given the nature of a case study within a survey, this case study shares the same research questions presented in Chapter 4. In terms of unit of analysis, two Florida counties have been chosen with similar charter status, form of government, districting plan, budget, and demographics.

The sites have been chosen for comparability along those dimensions, but based on the results of the survey, with one significant difference: one site, County A, showed evidence of having higher level of organizational social capital, whereas the second site, County B, presents a low level of social capital. To guarantee anonymity of the results, the actual names of the two chosen counties will not be displayed. County A shows high levels of routine and nonroutine performance information and above average level of relational-cognitive and structural organizational social capital. On the other hand, County B shows below average level of both performance information use and organizational social capital. In particular, the County A score, in terms of routine and nonroutine performance information use, is within the $75^{\text {th }}$ percentile. In terms of organizational social capital, the relational dimension is within the $95^{\text {th }}$ percentile and the structural dimension is within the $90^{\text {th }}$ percentile. The County B score, in terms of routine and nonroutine performance information use, is within the $10^{\text {th }}$ percentile. In terms of organizational social capital, the relational dimension is within the $10^{\text {th }}$ percentile and the structural dimension is within the $25^{\text {th }}$ percentile.

Charter status, form of government, district planning, and demographics were used to select two comparable counties. In terms of charter status: both counties have adopted a charter. They both became charter counties in the 1980s. A second similarity is that both counties have adopted a county administrator form of government along with the introduction of their county charter. In terms of electoral structure (district 
planning), the two counties differ slightly: County A has adopted the single member plan, while County B has adopted the mixed system. To some degree, the two counties are not so different in terms of district planning because in the mixed system, some county commissioners are elected and represent a specific district (as in the single member system) and some county commissioners are selected via county-wide elections (as in the at-large system).

In terms of budget size both counties are very comparable. In terms of demographics, both counties have a comparable population. County A has slightly more than one million inhabitants, while County B has slightly less than one million inhabitants. This is an important factor because it means that both counties have to serve and provide public services to a substantial numbers of citizens - further increasing the similarity between the two counties in that they are comparable in terms of number of departments, county employees, and extension and variety of services provided to citizens. Finally, both counties were created at the beginning of the $20^{\text {th }}$ century-an important factor to consider with regard to organizational social capital, which is generally created over a long period of time.

\section{Methods of investigation}

Following Yin (2009), the specific design of this case study within a survey is an embedded multi-case design. It is a multi-case design because two contexts are studied: County A and County B. It is considered an embedded case study because both the county governments and the different departments within each are analyzed. In terms of external validity, or analytical generalizability, the aim is to "generalize a particular set of results to some broader theory" (Yin, 2009, p. 43). The embedded multi-case design offers a better basis for generalizing results than a single case study 
(Yin, 2009). Replication is guaranteed by studying two different contexts and by studying several departments within each context. Construct validity and reliability will be discussed during the data collection phase of the research and internal validity will be presented during the data analysis phase of the investigation.

Semi-structured interviews with department heads and focus groups with middle managers and civil servants have been conducted in each site. A total of five interviews and a total of three focus groups have conducted in both sites. One semistructured interview with the Department Head of each of the following departments: Fire Rescue (County A), Purchasing Department (County A), Planning Department (County B) Volunteer Program (County B), and Communication Department (County B). The three focus groups were conducted in the Fire Rescue Department (County A), Purchasing Department (County A), and Planning Department (County B). People were engage first by sending an email invitation. A mail invitation was also used in order to capture more senior manage that still prefer more formal way of communication.

Using both semi-structured interviews and focus groups helped to achieve a better understanding, including possible explanations for, of the results of the quantitative analysis, thus increasing construct validity and reliability of the study. In particular, both data and methodological triangulation were used to increase the construct validity of the entire study. First, a mixed-methods approach aims to favor the different methodological approaches in answering the research question(s). Second, data triangulation has been guaranteed by using multiple sources of evidence: survey, semi-structured interviews, and focus groups. In terms of the reliability of the case study, it was guaranteed by developing the case study protocols, which helped in the data collection process in each of the cases analyzed. The case study questions for semi- 
structured interviews and focus groups were developed after the survey was completed and based on the results of the survey instrument. For a complete list of questions adopted in the semi-structured interviews and focus groups, please refer to Appendix $\mathrm{D}$ and $\mathrm{C}$.

Semi-structured interviews or "guided conversations" (Yin, 2009, p. 106) aim to gain deeper understanding of how department heads use routine and nonroutine performance information to make decisions or whether their decisions are based on other factors. Moreover, they seek insight on the three organizational social capital components. Although there was an overlapping between survey questions and interviews questions, the latter have been "essential sources of case study information" (p. 106). The term "guided conversation" seems to be more appropriate in case study interviews because on one side, it allows for the gathering of direct and specific answers to research questions. On the other side, these answers are collected in a "friendly" and "nonthreatening" (p. 107) way that places the respondent at ease, thereby facilitating collaboration in the interview process. A complete list of the questions used is available in Appendix C.

Likewise, focus groups with county employees/middle managers aimed to gain better insight on the three organizational social capital components. In focus groups, researchers interview a small group of people and learn — through conversation—about the topics of investigation but also about the dynamics among members of the group. Focus groups were used in combination with semi-structured interviews and with the survey instrument to triangulate results of the analysis on organizational social capital — thus increasing the construct validity of the whole research. A complete list of the questions used is available in Appendix D. 
Focus groups and semi-structured interviews were recorded and then transcribed for analysis using the qualitative research software NVivo. Comparative analysis (Glaser \& Strauss, 1967) was used to identify patterns, code data, and categorize findings. Interviews and focus groups were coded using the following nodes for performance management 'measures/measurement' and 'use'. The following nodes were used for information regarding social capital: 'collaboration/connection', 'trust', 'goals', and 'activities to foster social capital'. The data provided detailed descriptions of the how decisions are made within those two counties' departments and their level of social interaction, trust, and shared goals. The next two sections present first an overview of each of analyzed county, and then present results of the qualitative analysis.

\section{County A}

\section{Descriptions}

County A approved the county charter in the 1980s. The Charter allows the Board of County Commissioners to pass local laws in accordance with state general laws and/or the Constitution of the State of Florida. The Board of County Commissioners in County A is composed of seven members elected to four year terms; they are eligible for re-election. A County Mayor is elected by the board as its chair and he/she also serves in a ceremonial capacity for the County. The Board of County Commissioners is responsible for a variety of duties - from law enforcement and disaster relief services to the construction and maintenance of county roads and bridges; from providing social services to the community to environmental protection; from regulating economic activities to providing cultural services to citizens. The Board also appoints a County Administrator who is responsible for the implementation of the policies approved by the Board. The main source of revenue for County A is property tax. The Board approves the County budget and sets the property tax millage rate. There 
is a conspicuous amount of incorporated municipalities within the boundaries of County A. Each incorporated municipality has the freedom to pass and impose policies and ordinances within their boundaries.

The organizational structure of County A can be described as follows. As explained earlier, the electorate elects the Board of County Commissioners along with seven elected state determined officers: Sheriff, State Attorney, Public Defender, Clerk \& Comptroller, Property Appraiser, Tax Collector, and Supervisor of Elections. The Board then nominates the County Administrator along with County Attorney and the Internal Auditor. The following departments report directly to the County Administrator: Airports, Engineering \& Public Works, Facility Development and Operations, Financial Management and Budget, Information Systems Services, Water Resources Manager, Office of Community Revitalization, Planning and Zoning, Tourist Development Council, Office of Small Business Assistance, and Workforce Housing. Three different Assistant County Administrators report to a Deputy County Administrator, who eventually reports to the County Administrator; the Assistant County Administrators manage the remaining departments of County A (e.g., Fire Rescue, Human Resources, Legislative Affairs, Public Affairs, Risk Management, Community Services, Library, Parks and Recreation, Purchasing, Public Safety, Water Utility, etc.). Independent officials, such as the Inspector General and the Commission on Ethics, complete the organizational structure of County A.

According to the County A Charter, the County Administrator is responsible for appointing each department head, with the exception of the County Attorney and the Internal Auditor, who are appointed by the Board of County Commissioners and are independent from the County Administrator. Even if Department heads are appointed 
by the County Administrator, they must receive final approval from the Board of County Commissioners. Simultaneously, the County Administrator has the power to organize each department into sub-organizations, such as divisions and sections, to achieve greater levels of efficiency and to guarantee the effective delivery of public services to citizens.

Following the County A Charter, the management of County employees is regulated by the Merit System Service. The Merit System Service rules regulate all aspects of the management of County employees - from recruitment and selection to probation, from classification and pay administration to disciplinary guidelines, and from benefits to performance review. Some of the rules and procedures defined in the Code appear comprehensive and well detailed. However, other sections appear broadly defined and open to interpretation. One such section concerns the performance review of County employees, which identifies the purpose of performance reviews (assessment, performance improvement, correction, separation...), the types of performance review (annual VS. special review), and who is responsible for the process (usually the immediate supervisor), but nothing more is specified regarding performance related pay, quotas, etc.

In terms of organizational performance, the management team of County A annually publishes a document, titled "Objectives and Performance Measures," that contains each department's objectives for the following fiscal year. For each department, the management team lists a series of objectives and then lists a series of performance measures. Provided for each measure is: the actual value for the previous fiscal year, the estimated value for the current fiscal year, and the project values for the next fiscal year. Each department also lists whether each measure is an output, outcome, 
or efficiency measure. Some performance measures that are listed as outcome appear to be more measures of output than measures of outcome- but the line between the two dimensions of performance can sometimes be blurry. The management team should consider describing the performance of County A by reporting, for the consolidated year, whether the objective was met or not. This would enhance the accountability of the administration and the readability of the entire document.

Two departments from County A agreed to be part of the complementary case study analysis. Again, to maintain and guarantee anonymity, the participants' names will remain anonymous. The two departments that agreed to participate in the case study are the Fire Rescue Department and the Purchasing Department. According to Lowi's (1964) policy categorization, the Fire Rescue Department belongs to the distributive category, while the Purchasing Department belongs to the constituent. The two departments were engaged in the analysis by email. Both were responsive and willing to participate in the study.

The Fire Rescue Department of County A provides fire protection and emergency medical services to the unincorporated parts of County A and several municipalities within the same County that outsourced the service to the County. The Fire Rescue Department is organized as followed: the Fire Rescue Chief is responsible for all the operations and management of the service and he is appointed by the County Administrator. He also supervises four sections: Bureau of Safety Services, Operations (Operations Division, Training and Safety Division, and Emergency Management Division), Finance, and Support Services. A deputy Chief supervises each of the four sections. The Department had a budget of $\$ 350$ million for fiscal year 2015 and a total of 1,500 full time equivalent employees. It had roughly 50 stations in the territory it 
serves and received more than 120,000 emergency and fire emergency calls during FY 2015. The average response time is 6 minutes and 35 seconds.

The second department from County A that participated in the analysis is the Purchasing Department. This department is responsible for the procurement and central warehouse services for the County and it is also responsible for the County's courier and mail services. The Department achieves its mission by following strict regulations such as the Purchasing Code and all State and Federally mandated regulations. The Director of the Department supervises four sections: the Administrative Support Section, the Procurement Section, the Contract Section, and the Purchasing and Systems Support Section, as well as the Purchasing Central Warehouse and the couriers and mailroom.

\section{Results: Performance Measurement and Information use}

\section{Fire Rescue Department}

In terms of performance measurement, County A shows an advanced performance measurement system in both the Fire Rescue Department and the Purchasing Department. Interviews revealed that the Fire Rescue Department has historically tracked performance in terms of response time, which is the timespan between the emergency call and the moment department personnel arrive at the scene. However, recently, nationwide this measure has been challenged; it does not measure performance as well as originally thought. Performance measures of the Emergency Management Services (EMS) now place greater emphasis on survivors. In terms of goals, most are set by national standards and in particular by the National Fire Protection Association. According to the manager: 
the problem is that there are so many of them that fire rescue agencies they have to pick and choose. We do the best to meet the ones we feel they are the most appropriate. We try to meet the response standards for emergency delivery and for time of first alarms and second alarms of unseen fire response. So we do our best to meet that. And then there are various other standards that you have to meet within NFPA, protective gear, the management of protective gear; the fleet etc... The NFPA sets them all out for you so we try to correspond.

The manager continues to state that these goals are annually based and that the performance reports published by the department consider past performance to better manage the performance of subsequent years. In terms of performance improvement, the manager states that:

we are always attempting to improve. For example, response time, that is one we spend a lot of time on throughout of the year. Where can you safely save time on a response standard? That time can be safely saved from the time the alarm is received to the time the truck moves. You don't want to drive faster because that endangers the life of personnel and civilians, so that means you get out of the station faster.

The quality improvement aspect was also confirmed during the focus group by staff members:

Today after this meeting, we have an administrative meeting on dispatch protocol about what type of resources are we sending, to what type of calls, because we reviewed incidents and we know that we can improve. We are always improving our performance whether the Fire Rescue manual or the 
officer development academy. We are always improving staff. We have a broad perspective of how the department runs. Compared to how we were doing ten years ago, we have been improved a lot.

From the conversation, one noted how deeply and consistently the Department has changed throughout the years. In the past, the focus group participants described how the Department aimed to achieve the bare minimum standards:

a lot of professional fire departments, they train on minimum standards and they never get passed to it. We were like that for a long time but now we are doing more relevant training, we are doing more street marks, stuff that is not found in the book that industry is doing... we found it in other departments all over the world and it works. So we started to incorporate that and we no longer do just basic training. It's very proactive compared to the past years.

The change in departmental culture came from the ground up: "that's something different from what you would expect. It came from guys like these that were in field... It is important that it took place, otherwise we would be still in the same spot."

In terms of decision making, the department uses both routine and nonroutine performance information. A staff member stated:

I think in my experience is learning from guys. A man who retires after 40 years, just talking to him and his experience, just passing on that information that can help you. We take stuff like that and we look at how the new guys are performing, trying to find some type of happy medium. The old guys work in different ways; the new guys, they are not as mechanical as the old guys were. 
Another interviewee said:

it is feedback. If there is an incident, we conduct a post-incident accident after actual review and it is based on certain things like response, arrival on site. And then we review all of those things in a not punitive fashion and that's where you get those results. It has taken a while to get results from stuff like that but it reflects in everything whether it's licensing or something else... everything has something we can review.

Another added that:

feedback is good because there's not punishment. People are not afraid to admit their mistakes because they are not going to get in trouble. We all learn on them. So people are not afraid anymore to say they made a mistake. If you go out and you make a mistake in the past you tried to hide it and not tell anybody and then another guy makes the same mistake we keep on repeating that. Now if you make a mistake, it's ok. We can learn from it.

\section{Purchasing Department}

The Purchasing Department in County A also shows a well-developed performance measurement and management system. The interview with the Director and with the Assistant Director highlighted the following. First, for the Purchasing Department, the performance measurement system is:

part of the budget process. We prepare our budget and establish the resources we need for the next fiscal year and in that, a portion of that, we give the Board [of County Commissioners] a snapshot picture of our accomplishments during the current [fiscal] year and what we hope to achieve 
next year. I find it very helpful, especially because you can say we did all of this, and we have this much more to do, and the objectives and the performance measures are into that and it's in the budget book so the public see it and they are open for public opinion, and that is attached to our actual budget.

However, the Director points out how the objectives and goals that the Board of County Commissioners assigns to the department and the goals that the Director establishes for the department may differ:

I honestly believe that my objectives, my personal objectives for this department, always are going to be different from the objectives that the $\mathrm{BCC}$ impose on us because they are a political body. I give you an example of that: before I came here, the most important performance measure for my department was the number of protests that we received for county solicitations from vendors who did not get the supply. Now, I fought that for about three years, trying to put in the heads of the administrators that that is something out of my control. I can have the most perfect bid or solicitation, and you protest anyway because you didn't win. County A is extremely litigious. That's nothing on me. I don't control the specifications that the departments write. Nine times out of 10 , that's what the protest is about. But the Board thinks that protests, that vendors being so upset, they think it's a big thing and they held it against the purchasing department. That's wrong. That's something I will never be able to control. They want that everything we do is very vendor friendly and I get all of that. But in the real world, it's very difficult. What I do when I do my objectives is what the Board of County Commissioners can see, but for me that's not important. What is important for me is the day to day stuff that keep us 
going. It's the goal of getting projects done, and getting things done timely and getting vendors paid. We narrowed down to 9 objectives that we can measure and quantify. They are more specific and to me more important. [...] It's the practical thing that I have to look at. Those are things on my lists that are objectives and goals and that can be a little bit different than the ones from the board.

Interestingly, the Assistant Director pointed out the use of internal feedback for measuring the effectiveness and quality of the job done in the Purchasing Department:

for measuring our performance we look at feedbacks such as whether or not the departments we work with are happy. It's informal, because it's just the feedback from user departments, which we don't solicit through a survey but if the departments are not happy they will reach out to us, and the director and assistant director will pick up the phone and we will hear that our staff isn't doing what they need.

A similar picture was painted in the focus group with middle managers. One middle manager stated:

our performance measures are mostly related to the requisitions that we process through our department. We use reports to show this information and then we report it to our budget once a year. We also report if there is any gap in service that's also done mostly manually. Each section of the procurement provides information if there is any gap and also how many procurements of the buyers they do on a quarterly basis, and that's also reported once a year to the budget. There's also tracking of what the warehouse does. But that's done by 
the warehouse that provides the information and I am not sure what type of reports the warehouse uses. I just get the final numbers and that's put into the final budget." In terms of decision making, the participants all highlighted that "we base our decisions based on internal or external feedback.

\section{Summary}

The main results regarding the performance measurement system and performance information use that emerged from the focus group and interview in the Fire Rescue Department at County A are:

- Both departments seem to have a very well developed and sophisticated performance measurement system that tracks the main indicators set for their sectors. From the interviews and focus groups one can notice how both the management and the county employees really believe in the importance of performance management. This performance culture is a combination of both top-down and bottom-up efforts to better manage and deliver better services to citizens.

- The departments have a proactive attitude toward performance and quality improvement. Not only do they measure what is required, they go beyond the established standards and what local politicians ask them to do. The goals that local politicians assign to the departments might be different from the performance that these departments actually measure and track. This result can be justified by the importance that performance management has assumed in both departments.

- Both routine and nonroutine performance information are used in the departmental decision-making process. Managers understood the 
importance of both formal and informal feedback. The reasons lie both in the sectors they represent and in the managerial willingness to achieve higher results.

- In at least one case, most of the organizational change that occurred in terms of performance management in the department in the past decades was mostly employee driven and with a bottom-up approach that facilitated organizational change in the respective department.

\section{Results: Organizational Social Capital}

In this section, the results from the interviews and focus groups on the level of organizational social capital for County A are provided. Each dimension of organizational social capital will be analyzed separately.

\section{Structural Dimension}

\section{Fire Rescue Department}

The structural dimension of organizational social capital refers to the number of connections and the level of collaboration within a given organization. Even though the department head-herein referred to as Director, Chief, or department head-stated that collaboration could always be better, he pointed out how collaboration within and across departments has improved during the last decade. "Before collaboration was not encouraged. It's more so now. But it could always be improved." In terms of interaction with staff members, the manager points out that: "I make it a point to talk to them constantly. There are one or two that are very busy and we don't talk that much as we would." In explaining which factors made this change possible, the Director lists the following factors: "the management and the leadership in this building." Not only has within-departmental collaboration improved but also interdepartmental interaction: "I have two organizations I participate a lot, and I am very well respected, and I do a great 
job in collaboration and constantly sharing information. We are moving forward as a fairly unified body within the County now."

The focus group with staff members painted a similar picture. A member of the focus group highlighted that staff members collaborate "a lot, but we could do more. We are still getting there." Another participant pointed out that "when we have problems, I'll go to XY, I'll go to YX, I'll go to everybody and say: 'what do you think on these?" Another interjected that collaboration is so important in the department "to the point we have our staff meeting on Tuesday morning, and to get everybody on board, we had that meeting at $6.30 \mathrm{am}$. Because everybody is so busy. The schedule is so tight!"

The collaboration and interaction between staff members and the Chief seems to be very open, fluid, and sincere. "The Chief is sort of like the soul source... He is certainly the leader. But, I believe everybody in here uses him especially when you are going to do something vital." Communication with the Chief is fostered in the Department. To the question asking if they communicate with their leader and vice versa, one focus group member responded "Oh, Yeah... it's an open door policy."

Collaboration with other departments within County A is successful. One focus group member stated:

we have an open book sharing. I get other departments that contact me, I can speak for what I do, about driver stuff, and if the boss says it's ok, I put everything out there. I can meet them face to face and show them stuff. I just had a gentlemen requesting some information and I just put it on a flash drive and send it to him. 
Another added, "We put our videos on the internet." In terms of collaboration on other activities with other departments, a staff member explained:

you do cultural things with other fire departments across the country and across the world. We used to be little kingdoms and traditionally we didn't talk to other organizations and vice versa. That's the way it's been since it started and we never talked to other departments in this County. Over last ten/fifteen years or so I've seen a lot of that dissolved and we have our fire academy department with other 6 departments coming in and actually send people, free of charge, to our classes and that perpetuate training with these people because now we know them. You are not going to have a relationship with people because they are in the department next to you. That means nothing. You got to have some kind of personal relationship. We do a lot of that. I send stuff out for our pride protocol, which is our uniform manual and we actually have a Dropbox, a huge one and you can go in there and pick up our manual; if you want to pick up our files, we don't care.

The Fire Department frequently collaborates with other agencies within and outside the boundaries of County A: "in the last week I had to deal with the Federal Bureau of Investigation (FBI), Drug Enforcement Administration (DEA), and multiple police agencies." Moreover, he stated: "The chief has a monthly meetings with the deputy chiefs of the entire counties and we made radical changes that we never thought would happen here." Another added: "I think public education, the drowning prevention people, parks and recreation, it's not just us but the whole department has reached out and spoken to others." 


\section{Purchasing Department}

The Purchasing Department shows a similar level of structural social capital. In particular, the interviews with the Director and with the Assistant Director pointed out how collaboration has evolved in the department throughout the years. The department is divided into two sections: the contract section and the bid section. There has always been tension between the two sections. "I think each section does better with each other than across sections," stated the Assistant Director. One historical reason for this animosity is that one section was receiving higher pay than the other. The Director, in the last three years, elevated the paygrade in efforts to install an equal and fair pay system across the two sections. The result was that:

in the last three years everybody learned to get along better and share information among the two different groups a lot more. People are more open to voice what their processes are. They use two different types of procurement processes. One manager goes to the other manager and they'll talk about it. Collaboration among the two groups have increased tremendously.

More generally, the Director pointed out that:

we have manager meetings where we meet every couple of weeks and we talk about various issues going around the table and we try to get a consensus and we meet with the buyers once a month. In managers meetings we get a lot of good stuff. We get the issues that come up and we get the issues of a business. How should we approach this globally and how does your side do it? The buyers meeting that's a little more difficult because they don't like to talk about it that much. We give them the information they need, we are open to questions, suggestions anything. Sometimes they talk, sometimes they don't. 
The Director also added that:

we always have open doors and the managers have always open doors and the buyers feel free to enter in the manager's officer and the manager to come to us. We like to keep that hierarchy as it is because then managers don't know what is going on. But they can, they know they can but we'd like them to take that one step.

Collaboration is also very well developed across other departments of County A. The Director of the Department stated that:

we have a very good relationship. We service every single county department. There are four or five central service departments. We strive to keep in contact with them. What's going on, what do you need? Cause the last thing that I want is a department head calling me and screaming at me for something.

One last point to highlight is that the department culture seems to have changed substantially throughout the years. "The Director before me was very military but I don't know how he ran the ship. I know that when I got here, the stuff was very regimented. They were not allowed to think outside the box," the Director expressed.

The picture painted by the Director and Assistant Director was also confirmed in the focus group:

some of us have been working together for many years. We had like twenty to thirty years of experience with each other. There is a large amount of collaboration between internal team members we have here at purchasing and other divisions and also a lot collaboration with the finance department at the 
clerk's office. Anything that happens to the financial system they are all interrelated so there are a lot of discussion, if issues come up we try to get together and come up with a solution we get a lot of feedback from each other, lot of help from each other,

stated a member of the focus group interview. Another middle manager said:

I think we communicate pretty well. We all have different personalities. We are really team players and we focus on talking to each other, share opinion. We really value each other's opinions and learn from each other experience and hopefully implement it on a daily basis. However, that doesn't mean that everybody gets along with each other.

\section{Relational Dimension}

\section{Fire Rescue Department}

The relational dimension of social capital refers to the level of trust and reciprocity within a given organization. The interview with the department head indicated that staff members are not subjected to too much oversight:

I let them go for the most part. They are responsible for their area of expertise. They bring their final product and various stages to me, we discuss it and for the most part I don't interfere in what they do. They manage their own time, they manage their own programs. In the end we evaluate them. We discuss at that point, they make the necessary changes and off we go again.

When questioned about having trust in staff members, the Director replied:

Yeah! I have to be. It goes back to staffing. We have about 1500 people in this department. If I were a micro-manager, nothing would get done. They 
have to be able to run those programs within very broad perimeters. And again, most of it goes back to national standards. What do we have to do to get these 1500 people certified, what do we have to do to get them a college education? What do we have to do keep them functioning?

The Director also explained that to create and foster trust with staff members,

I back them up. We discuss something and if it goes wrong than I am the one who is going to take the hit on it. I am going to back them up if there is a problem. I also talk to them as a human. Not as the boss. I have to feel they trust me and I trust them.

Many activities that are performed to create and foster trust are part of the spirit of camaraderie at the Department:

we do things that add to that like promotion ceremonies when our recruit class graduate. We do various get together throughout the year and most of them through the Union like the Christmas party, they do a summer picnic. We do various things here: we just did a 30th anniversary celebration, a lot of people came. Any time people get together, talk to each other, and have a laugh together all of that goes to build trust. Camaraderie! That's exactly what it does.

A similar picture was also painted in the focus group of staff members. One focus group member stated: "We definitely trust each other! There is a lot of trust here." Another added: "Yes, for the most part. You have to. We've been on the field, we've been in some bad situations in our lives out there. So yeah, we trust each other." A third stated: "All our relationships are based on trust." They also seem to trust in their Chief, as expressed by another member of the focus group: "Absolutely. None of us would be 
here if we didn't. Because we don't have to be here. We can all be out in the field. So if we didn't trust him, I think none of us would be here.

To trust in people, some focus group members pointed out: "Honesty, learn from your own mistakes, dependability." Another one described that "Trust, integrity and do the right thing... You are a servant of the community. You make a mistake and we try to learn from that. But if it's a continuous problem, you'll be out of the department." Interestingly, trust has always been a component of the department: "I think that has kind of been the heart of the department. In this industry I believe, it's brotherhood because we do stuff way more extreme that we would be used to." Another one continued by saying: "One of the cores of our profession is that citizens trust us with their lives and their belongings so live on that. Those are the core values of our department." "The fire service is like no other business. Everybody is here because we love it. When you do something wrong you make this look bad [pointing at its badge]. You make the fire service look bad as a whole. And that is not acceptable."

\section{Purchasing Department}

The Purchasing Department Director pointed out how little she oversees its employees: "I am not a micromanager at all. I don't think I am. There is no micromanagement here. We deal with mostly broader bigger issues. The middle managers have more day to day managerial role." She added: "Everybody has responsibilities and has an amount of authority. So there is some formal as far as in the implementation of solicitation but people work pretty autonomously. We are not helicopter people, if a problem arises they'll come to us."

In terms of trust, the Director stated that she "absolutely" trusts her employees "with no doubt, until they give us reasons for not to." Interestingly, trust seems to 
disappear "when employees lie to me and I find out. If they don't follow my direction when specifically told them to and they don't tell me they didn't do it. And they didn't tell why. The specific reason why." Similarly, the Director trusts middle managers too: "I really do. They are good people. And they do good work. I am very happy and even the one or two that they don't do good work (up to my level), I trust them." The Assistant Director added that "everybody wants to do a good job here. Everybody is willing to share information on how to handle this situation and everybody is very willing to share their knowledge and information."

A similar experience was confirmed in the focus group. One focus group member stated that in most cases, there is trust among members of the department:

in general I'd say that most of us trust each other but not always. There are some people that I don't trust based on personality. If you are dealing with somebody and they are flying off the handle and get upset and start screaming, you may lose respect for that person and not be able to trust if they are going to handle the situation in the future. In general, at least here in purchasing, the trust is there. But it's not going to be there in all circumstances because everybody is different and I think there are individuals in my department that don't trust the upper management for their reasons. I think I see that.

When asked about reasons why some employees might not trust upper management, the middle manager replied:

sometimes people have this phobia towards upper management and won't trust anybody beyond the middle management. I found it to be personal. Because if you don't know them, you don't have a personal relation with them, 
for them it's just a title. I get the comments sometimes, or I overhear the comments 'oh that's management' that again it's their own personal bias because they are looking at the title versus the person.

In terms of activities that foster trust and departmental spirit, the Director explained that "we have employees' incentives. Once of the good thing that the county does is that they give employees' incentive leave and money. So I get \$20 dollars per head and we do extra activities." She added: "we brought a popcorn machine or things like that and they do like it." The Assistant Director added: "for United Way we try to get everybody to donate because it's more about participation than dollar amount. We have activities in the office for the entire time ( 6 weeks), we have lunch, pizza for those who donated." Furthermore, "we also do a holiday party whether it is inside our office or outside. So we have a lot of activities that we do together and people do participate."

Similarly, members of the focus group described that they have a committee that represents the staff, and the Director and Assistant Director sit on that committee and they develop interactive activities for the department—-both during and outside office hours. The committee is called "incentives committee." One participant added that:

last year, we went bowling! That was our Christmas celebration. We actually did something small inside the department and then we went bowling at night. Retirement parties, we have them here and then we also have them outside for socialization just to change the environment. A lot of these activities are put together by this little core group of six people. The director tries to get everybody to participate and tries to make it fun at least once a year. There are years we do monthly activities or quarterly activities. It all depends how the committee decides on that particular year. 


\section{Cognitive Dimension}

Fire Rescue Department

The last dimension of organizational social capital, the cognitive dimension, refers to a department that shares goals among its members and enacts these goals collectively. County A appears to have a fairly high level of cognitive social capital. Goals are shared among the members of the department, but as the Chief points out: "we could do better with the communication of those messages." He continued by saying that to improve goal sharing in the department, "we need a goal setting retreat or something. We need to come together and formulate that. Because right now it's been driven by the standards that are out there." The Department is also able to quantify individual contributions to the achievement of these goals, especially "through statistics and through measures: time or survivability."

These results seem at least partially confirmed by staff members in the focus group. To the question concerning whether goals are shared among members of the department, one responded: "I am going to say: yes, now they are shared." Another member in the focus group stated: "we are trying to. Again, it should be that way but we are not there yet. I am not sure that everybody knows step by step what the goals are, what the outcomes should be. I don't think we are good at that." Following that line of thought, another added: "I think what is common here is that not all the people, from a junior guy to a senior officer, may not have the same perception of what the goals are."

\section{Purchasing Department}

The Purchasing Department appears to have a satisfactory level of cognitive social capital. "My managers know my goals. I am pretty clear with those. We talk about them because I need their input about them. The warehouse knows about their 
goals and they are shared. And the purchasing too," stated the Director of the Department. The Assistant Director added that "staff knows about the gap in service objectives. Both sides know about that. That's our departmental goal. They strive to do that."

Similarly, during the focus group, middle managers discussed that departmental goals and objectives are "given to management and then management can give it to the employees and discuss them. "For example, in the case of service gap they know what the goal is on a monthly basis and they provide the information to their supervisor and then it is given to the secretary and that she gives it to me". She continued, "at the end of the year the budget, it is public record and that info is provided again to each manager and then it's up to them to discuss it with their particular groups."

\section{Summary}

The main results regarding the level of organizational social capital in County A are:

- Both the interviews with the department heads and the focus groups with County employees showed that County A has a very high level of structural and relational social capital: the trust component appears to be fundamental for the Fire Rescue Department. These departments have been established for a long time, they have a strong leadership and sense of mission. All of these factors contributes to foster organizational social capital within their departments. The peculiarity of the Fire Rescue Department as an emergency department require high level of trust that is achieved also through comrade, helping each other in emergency situation, and by the spirit of the Fire Fighters corpse; 
- The analysis also shows that County A has a good level of cognitive social capital, even though goals could be shared more consistently in at least one of the two departments;

- County A performs various activities that have the ultimate goal of fostering organizational social capital. The reasons behind this results are for the Fire Rescue department the role of unions and the comradery spirit among the fire fighters. In the case of the Purchasing Department, the reasons are attributable to the 'incentive committee'.

\section{County B}

\section{Descriptions}

County B approved its County Charter in the 1980s. The Charter allows the Board of County Commissioners to adopt ordinances, approve the budget and set local taxes, and design the administration according to its needs - all in accordance with state general laws and/or the Constitution of the State of Florida. The Board of County Commissioners in County B is composed of seven members elected with a mixed method. The Chair and Vice-Chair of the board is elected by members of the board itself. The County Administrator is appointed — with at least five votes — by the Board of County Commissioners and is responsible for duties such as policy implementation and supervision of all departments and department heads, and he/she also acts as the County Budget Officer. Four Assistant County Managers assist the County Administrator in managing the County government along with a Manager responsible for human resources. Each of the four divisions is composed of two sections, and within each section, departments are located. The County has approved a County Strategic Plan, divided into five strategic macro-goals. Each goal is supported by specific strategies. Departments are free to set their own goals and tasks to achieve the overall, 
County-wide strategic goals. No performance indicators are reported, nor is there any reference to the level of accomplishment of these strategic goals.

Three departments from County B agreed to be part of the complementary case study analysis. Again, to maintain and guarantee anonymity, participants' names will remain anonymous. The three departments that agreed to participate in the case study are the Planning and Zoning Department, the Volunteer Program, and the Communication Department. According to Lowi's (1964) policy categorization, the Planning and Zoning Department belongs to the regulative category, the Volunteer Program and Communication Department belong to the constituent category. The two departments that are constituent in nature allow for comparison with County A's Purchasing Department, while the Planning and Zoning allows for examination of a regulative department. After submitting two rounds of email messages to all the departments in the population, and after submitting a formal letter via USPS, only the Communication Department was willing to participate in the study. The other departments were enrolled by visiting County B departments in person and asking to meet with their department heads. The result of this strategy was very positive, given the fact that the two other departments ultimately agreed to participate in the interviews and focus group. Human contact, rather than digital and virtually anonymous email and postal mail messages, remain a good strategy for engaging participants in a case study analysis.

The Planning Department is responsible for the transportation system of County $\mathrm{B}$, for zoning and the use of County B's unincorporated land, and for designing and implementing projects that will allow long-term sustainability of County resources. Two agencies merged, during the last re-organization, into the Planning Department: 
- County B Planning Council: provides a forum for local governments to cooperate on issues that affect more than one jurisdiction, and to work out any disputes that may arise. It also strives to bring consistency to the planning and regulatory efforts of the 25 local governments.

- Metropolitan Planning Organization (MPO): deals with long-range transportation planning, transportation concurrency, impact fees.

Regarding the merging and the managing of this new department, the Department Head stated: "I am the executive director of two organizations that have been essentially merged under one governing board and the two organizations haven't had a lot of communication or collaboration and we are trying to foster all of that."

The Planning Department also collaborates with the Local Planning Agency that is responsible for recommending changes to the Comprehensive Plan and for making recommendations regarding Future Land Use and the Land Development Code. The Department also coordinates with the Board of County Commissioners (reviews changes to Future Land Use, the Comprehensive Plan, Zoning Map, Land Development Code), the Board of Adjustment (reviews variance requests for setback reductions, lot area reductions, parking requirement reductions), and the Historic Preservation Board (countywide policy to address historical protection and redevelopment issues among local communities). Finally, the Department also collaborates with committees such as the Planning Review Committee (reviews zoning and land use proposals) and the Local Mitigation Strategy (serves as a bridge between local governments' comprehensive growth management plans, the County comprehensive emergency management plan, land development regulations, and relevant ordinances and codes such as those for floodplain management). 
The Volunteer Program depends on volunteers to help provide residents and visitors with the best services possible. The Volunteer Program is intended to provide volunteers to any department of County B to guarantee proper administrative functioning. In 2015, the Volunteer Program provided more than 285,000 volunteer hours, which equates to about $\$ 6.45$ million in return-on-investment throughout all the departments within the County. The largest use was Parks and Conservation resources and the Botanical Garden Extension Services, which is $100 \%$ managed by volunteers. Also, other departments (e.g., communication department and the court house) use volunteers as ambassadors. The Program has more than a 150 position descriptions listed on its website, which volunteers can access to decide where to serve.

Volunteers range from high school students to scouts, retirees, and even active executive CEOs who aim to give back to the community by supporting business plans, performing speeches, or by supporting the County using their skills and experience. In its recent reorganization, the Program lost three staff members. So, at the time of interview, two and a half people constitute the backbone of the Program: the Program Director, another full time person, and a part-time person. Thus, aside from the Director, only one person in the Volunteer Program works strictly in the Volunteer Program. As the Director pointed out during the interview: "I am the one who gets out and try to do the networking but with the reduction of staff has been very hard to do it. It's kind to cut your hands off and tell you to increase your sales."

The Communications Department works with the Board of County Commissioners, County Administrator, and County departments to provide information to citizens about issues, programs, and services via print, video, the Internet, and community outreach programs. In particular, the Department is responsible for press 
releases and news, County events, County publications, media support, live interactive online events, image photo library, emergency management TV support, and graphic/web support for the County departments and appointing authorities. Aside from the Department Head, the Communications Department has three middle managers and three supervisors. The Department's subdivisions are units, and projects are carried out in teams.

\section{Results: Performance Measurement and Information use}

\section{Planning Department}

In terms of performance measurement, in County B, all three departments appear to lack such systems. For example, the focus group conducted in the Planning Department highlighted that "we are in the process of developing a new performance measurement system with the State and Federal government but we haven't got quite there yet. The new system will have set targets." For the Planning Department, "the State sets general goals, for example the State of Florida has 'zero crash goal'. So they have this broader overarching goals. We kind of set ourselves. We have measures for the goals but we are not tracking specific targets." And again, the managers stated that regarding the federal funds that the department receives, the impact of federal money on the outcomes of the program should be tracked; however, again, even if they deem this to be important, they can only indicate, "we are not there yet. We haven't started the process yet."

\section{Volunteer Program}

The Volunteer Program measures its performance with two main indicators. As stated by the Program Head, "we measure the success of the program obviously on numbers of new volunteers that we get in a year and also on the return on the investment." In the interview, no other particular measure of performance was 
highlighted. Even if established, the performance measurement system appears to be very limited in terms of measuring organizational performance.

\section{Communications Department}

Finally, the Department Head of Communications stated that "we are the Communications Department and a lot of what we do is intangible and it is difficult to measure" and also that:

we measure the percentage of publicity, press release that actually get placed in the news and in the media which is close to a $100 \%$ because what we put out at this point, the media use it. It could be either it is an online newspaper, the TV they pick up on the information we put out there. We measure how many of the projects that we start are completed on time and we have social media (Facebook, twitter, Instagram, etc....); we keep track of those numbers from year to year, we can see how they increase. How many set goals and so far we've been exceeding our goals. We also look for those things we can't count in the data, we can't keep... so much of what we do is not measurable.

An example of an unmeasurable activity, as reported by the Department Head, is:

we plan a series of budget meetings, we can count how many people attended but if it's an online meeting for the budget with the Board of County Commissioners and with the County Administrator, if that is streamed online, and we have a blog and people can call in for questions, they can tweet. So we can count how many people are there, how many tweet, and blogged, but we have no idea on how many people we reached in total because of the TV. 
Two other unmeasurable activities were noted: "Another example, if we help a department come up with a communication plan on how to reach citizens, we have no way to measure that." She continues, "We won a grant to help citizens navigate the Affordable Care Act Website, and the best we could do with that was for them to say yes - we had an increase in people coming in for help. Finally, the Director states: "Videos, TV, a lot of what we do we don't know if people see it. Public education, hurricane preparedness...We just don't know..."

\section{Performance Information Use}

The second aspect to consider is the use of performance information in the decision-making process. There appears to be some variation between departments in County B. For example, the head of the Volunteer Program affirms: "I really make the decisions based on needs. Where is the most need? Where do I need to have the people? And sometimes is based on hard numbers." Similarly, as the Communication Department Director explains:

what we do is when we get a lot of projects, we decide on which on to work on first. That is really the biggest decision here as a group. We set priorities and there are different ways that we decide. A lot of times they come to me and as supervisor I'd say which one is more important? If I say that for the Board of County Commissioners or the County Administrator that they need this directly, that usually takes precedence. If it's something that is timely, that is urgent etc... That becomes more urgent. If it is an emergency-hurricane, tornado of course - that goes first and everything else gets pushed aside. After that, it's deadlines. 
However, the Planning Department appears to use more routine performance information in their decision-making process. The managers stated that:

we track crashes, we track congestion related data, and that does provide the analytical evidence that we use when we ask our elected officials, our board to approve something. Or when we take a project to the Florida Department of Transportation (FDOT) and ask them to fund it. A lot of times we are driven by a particular problem based on data that we measured. A lot of times what we will do is that we will fund a study based on the data that shows that is a high crash/high congestion location and that the solution that come out of that study we than ask the FDOT or another partner agency to fund. So it is pretty much a data driven process.

However, this statement seems to conflict with the previous one about the maturity of the departmental performance measurement system; moreover, even if they are trying to implement a new system, this appears to be a work-in-progress.

The Planning Department appears to benchmark its activities with other departments or agencies in the field. "We frequently use case studies from other organizations, we had some conversations with our Transit Agency here on how to prioritize projects that are for the whole network of transportation." It continued with "So we reached out to other similar agencies throughout the Country and we asked them how they did things. We will actually develop some recommendations on how to move forward based on the feedbacks we got." It concluded stating that: "I think it's equal parts: data driven (what our elected official want to see, what's their comfort level, what are their concerns) and also some case studies." 


\section{Summary}

The main results regarding the performance measurement system and performance information use that emerged from the focus group and interviews at County B are:

- The performance measurement systems in County B are not as mature and sophisticated as those in County A. There is not a clear understanding of which indicators are tracked and if these indicators are departmental indicators or are assigned by the County Board. This is due because of the reorganization process that the county has gone through (Planning Department), because the activities performance are mostly intangible or hard to measure (Communication Department), or because the service is too small to have a highly sophisticated performance management system (Volunteer service)

- Decision making is based, to some extent, on performance information (mostly routine performance information) but most decisions are based on personal experience and departmental needs. For all the three departments, this is because of a lack of the performance measurement system and performance indicators. For example in the case of the Planning Department once they will be able to track indicators that will be used in the decision making process as the Executive Director pointed out.

\section{Results: Organizational Social Capital}

In this section, results from the interviews and focus groups on the level of organizational social capital for County B are provided. Each dimension of organizational social capital will be analyzed separately. 


\section{Structural Dimension}

\section{Planning Department and Volunteer Program}

The structural dimension of organizational social capital refers to the number of connections and the level of collaboration within a given organization. Again, the three organizations appear to behave differently. On the one hand, we have the Planning Department, which is composed of two separate organizations that merged after the last reorganization, and now focuses on creating a new departmental culture that fosters collaboration among all members. In the words of the Director:

I am the executive director of two organizations that have been essentially merged under one governing board and the two organizations haven't had a lot of communication or collaboration and we are trying to foster all of that. So we have actually set up three emphasis areas for the next two years that are geographically focused for the county that require the land use and transportation people to collaborate. So that's how we are fostering more interaction. I think that the culture is very welcoming for that interaction. People are excited about and willing to take on these new assignments.

Similarly, the Volunteer Program, due to the reorganization, lost three staff members, which severed existing ties and relationships between members of that office - and ultimately lowered the overall level of structural social capital.

\section{Communication Department}

On the other hand, in the Communications Department: "almost every project that comes in we work on as a team. We have to work on things as a team." Furthermore, "the way it is executed is decided as a group. It's a creative process, you have to do it that way. If it's a bigger project, half of this table would be filled." It concludes saying that: "when we meet with other department directors as well to 
understand what their goals are, we talk about what we can do... So we are very collaborative."

\section{Relational Dimension}

\section{Planning Department}

The relational dimension of social capital refers to the level of trust and reciprocity within a given organization. Once again, the level of trust differs among the studied departments, given that most went through a reorganization process. Once again, the Planning Department appears to struggle the most in terms of trust. The reason for this may be that the new department combined two existing agencies under one, new roof. In terms of trust, the new Executive Director declared: "I might have had a different answer five months ago because I was pretty new. I think that people are still wondering a little how things are really going to change when I get settled." The Director continues, "I think there is close knit organization that we are creating. Again we have two separate organizations that are merging. That is taking some time and that will keep taking some time. Especially because they were not used to collaborating."

\section{Volunteer Program}

The Volunteer Program Director, for example, sufficiently trusts staff members (e.g., "I think they are doing a good job") and other members in the County (e.g., "It depends. We have some that actually say what they are going to do regarding the volunteers, and then those who just say yes to get you out of their offices and nothing never happens").

\section{Communication Department}

The Communications Department appears to have a rather good level of trust. However, even if the Communications Director trusts employees in emergency 
situations, ("During an emergency, we activate and we fill a function in the emergency operation service. So during an emergency the whole department lives at the emergency operation service. I totally trust them. I have to be able to trust them.") she was unable to explain if the same level of trust exists in everyday, non-emergency situations.

\section{Cognitive Dimension}

The last dimension of organizational social capital — the cognitive dimensionrefers to a department that shares goals among its members and enacts these goals collectively. Once again, the Volunteer Program, the Planning Department, and the Communications Department seem to lag behind in terms of cognitive social capital. The situation appears critical in the Volunteer Program: "We had a change in the County Administrator and what are his goals? We don't know. I don't currently know what the new goals are. The only things I know are the benchmarks that I continuously set for myself."

In regard to shared goals, the Department Head of the Planning Department stated: "I think that within the MPO they [goals] are shared, they are known, people are aware of them. We could probably do more to share them and especially for linking them to projects that we are seeking to advance funds." Furthermore, "I don't think they are fully shared within the Planning Council and the MPO. As the two organizations have come together, that is something that hasn't been fully embraced." It concludes "as we embark on this performance based outcome driven planning process, we will clarify and probably focus on three to five key goals and measures that define what we want to achieve for the County to move forward."

\section{Summary}

The main results regarding level of organizational social capital in County B are: 
- The analysis shows how the reorganization process in County B profoundly impacted all three dimensions of social capital. The structural dimension was impacted because existing ties were destroyed in cases where departments were separated, or new ties had to be established in cases where new departments were created. Creating ties and new relationship takes time.

- Regarding trust, it is something that is built over time, and the reorganization impacted trust. Finally, because the County had changed multiple County Administrators over the past few years, the organizational goals were not clear for most employees. For example the Volunteer Program Directors stated that it is not possible to know what the goals of County Administrator are. It is important not only for managers but also for employees to understand which direction the administration has.

\section{Comparative analysis}

In this section, the results of County A and County B are compared to better highlight and understand the differences and/or similarities between the two counties. Table 18 presents, in a comparative fashion, a summary of the main findings of the analysis. The two departments chosen from County A both have adopted and implemented an advanced performance management system that tracks the main indicators set for their sectors. The two departments also have a high usage of both routine and nonroutine performance information. They are proactive toward performance and quality improvement and they measure performance beyond what established by standards or what assigned them by local politicians. In terms of organizational social capital, the two departments show a high level of the structural 
and relational dimension and a medium level for the cognitive dimension. Trust seems the most important factor among the members of both departments. Both departments also conduct activities that have the ultimate goal of fostering organizational social capital.

Table 18: Summary of major findings

\begin{tabular}{|c|c|c|c|c|c|}
\hline & \multicolumn{2}{|l|}{ County A } & \multicolumn{3}{|l|}{ County B } \\
\hline & Fire Rescue & $\begin{array}{l}\text { Purchasin } \\
\text { g }\end{array}$ & Planning & Volunteer & $\begin{array}{l}\text { Communic } \\
\text { ation }\end{array}$ \\
\hline Background & Distributive & Constituent & Regulative & Constituent & Constituent \\
\hline PM system & Advance & Advance & $\begin{array}{l}\text { Under } \\
\text { Developm } \\
\text { ent }\end{array}$ & Basic & $\begin{array}{l}\text { Intermediat } \\
\mathrm{e}\end{array}$ \\
\hline $\begin{array}{l}\text { Routine PI } \\
\text { Use }\end{array}$ & High & High & Medium & $\begin{array}{l}\text { Low- } \\
\text { Medium }\end{array}$ & $\begin{array}{l}\text { Low- } \\
\text { Medium }\end{array}$ \\
\hline $\begin{array}{l}\text { Nonroutine } \\
\text { PI use }\end{array}$ & High & High & $\begin{array}{l}\text { Low- } \\
\text { Medium }\end{array}$ & Medium & Medium \\
\hline Structural & High & High & Low & Low & $\begin{array}{l}\text { Medium- } \\
\text { High }\end{array}$ \\
\hline Relational & High & High & $\begin{array}{l}\text { Low- } \\
\text { Medium }\end{array}$ & $\begin{array}{l}\text { Low- } \\
\text { Medium }\end{array}$ & $\begin{array}{l}\text { Medium- } \\
\text { High }\end{array}$ \\
\hline Cognitive & Medium & Medium & Medium & Low & $\begin{array}{l}\text { Medium- } \\
\text { High }\end{array}$ \\
\hline
\end{tabular}

However, the performance management systems at County B are either: under development, as in the case of the Planning Department; basic, as in the case of the Volunteer Program; or intermediate, as in the case of the Communication Department. The usage of both routine and nonroutine performance information appears to range from low to medium. There is also no clear understating of which indicators are tracked and what are the stakeholder interested in measuring them. In terms of social capital, the Planning Department and the Volunteer Program show a low to medium level for all three dimensions of social capital and the Communication Department indicates a better situation — with medium to high level of social capital. One of the reasons for such a low level of social capital is in the reorganization process that took place in 
County B that had a negative impact on both the structural and relational dimension of social capital. Furthermore, a lack of leadership seems to be the reason for a low level of cognitive social capital as well.

The chapter has presented comparative case study that was conducted to gather contextual information to support the results of the quantitative analysis. Interviews, focus groups, and analysis of secondary data have been used in order to understand how the two differs in terms of organizational social capital and performance information use. More in details, the first section presented the purpose of a comparative case study analysis and the selection process of the two cases. The second section introduced the methods of investigation used in the analysis. For each of the two cases, County A and County B, a contextual description was provided and then the main results regarding both performance information use and organizational social capital were presented. A conclusive summary of the main differences between the counties concludes the chapter. 


\section{Chapter 8 Discussion and policy implications}

The main finding of this study is that evidence exists in support of the hypotheses that organizational social capital is positively associated with performance information use. There is full support in terms of routine performance information and partial support in terms of nonroutine performance information-outsider feedback. There is also evidence for the hypothesized substitution effect between different types of performance information: managers tend to use more routine performance information in organization with a high level of relational and cognitive social capital while they seem to use more nonroutine performance information- outsider feedback in organizations with a high level of structural social capital. This chapter is organized as follows: it will review the work described thus far, it will then discuss results of the quantitative analysis and the qualitative analysis to arrive to a joint discussion. The chapter concludes by providing implications to practitioners on how to create and foster organizational social capital in local public administrations.

In this dissertation, performance information use and organizational social capital are tied together by analyzing and discussing the link between these two conceptsarguing that organizational social capital fosters public managers' use of performance information. From a theoretical point of view, several arguments are proposed to support and test the hypothesis that the structural, relational, and cognitive dimensions of organizational social capital foster routine and nonroutine performance information use. The intended contribution of this dissertation is to provide a comprehensive framework that helps us understand what motivates public managers to use performance information. Previous studies have attempted to analyze organizational and environmental factors (e.g., trust and organizational culture) to explain 
performance information use in the public sector. However, none have utilized such an inclusive framework of analysis. The concept of organizational social capital could be a good predictor for performance information use. First, it provides the infrastructure necessary for information to be available and information to be shared. Second, it allows information flow within the organization and it enhances the validity and reliability of performance information — making this information more usable. Finally, it incentivizes managerial performance information use in learning and steering the organization to achieve those agreed upon goals.

The hypothesized effect was tested by surveying department heads, middle managers, and other individuals with a supervisory role from eight departments in each of the 67 Florida counties. The results show that there is evidence of the hypothesized effects. In particular, there is evidence that supports Hypothesis 1 (only in terms of nonroutine performance information-outsider feedback); there is also evidence that supports Hypotheses 2 and Hypotheses 2a, 2b, and 2c (only in terms of routine performance information and nonroutine performance information-outsider feedback). However, there is no evidence to support the same three hypotheses for the internal component of performance information.

Regarding the second research question, the main findings are that the relational and cognitive dimensions of social capital foster the use of routine performance information while controlling for other types of performance information and the structural component of social capital fosters the use of nonroutine performance information-outsider feedback while controlling for other types of performance information. 
The complementary comparative case studies have been fundamental to creating the context necessary to understand the results of the quantitative analysis. The level of social interaction, trust, and shared goals were analyzed in two similar but simultaneously different counties. The differences, based on the results of the survey, were based on each county's level of organizational social capital and performance information: County A, with high levels of both and County B, with low levels of both. The case study was useful not only in validating the results of the survey, but also in understanding the context and other variables that influenced high level of social capital in one county and low level of social capital in the other. Especially for County B, the absence of clear leadership — capable of sharing goals among all departments — and the multiple reorganizations that the county experienced over the past seven years affected the level of social interaction and trust among and within the different departments.

The results of the analysis will now be discussed, taking into consideration the existing literature and the practitioner's perspective.

\section{Quantitative analysis discussion}

\section{Nonroutine Performance Information Use}

As summarized above, the evidence supports the hypotheses only for nonroutine performance information use- outsider feedback. There is no evidence that suggests the same effect for nonroutine performance information use-insider talks. One will first examine the results for outsider feedback. As presented in Chapter 6, when departments collaborate, coordinate, and interact with each other, this not only makes information available but also fosters performance information use. Departments that are more accustomed to (a) collaborating with each other and (b) working with information originating from other departments are also more likely to use feedback 
from outside sources such as local politicians, interest groups and customers/citizens, and local media. However, and this is a very surprising result, it was found that the effect of the relational and cognitive dimension of social capital on nonroutine performance information use - outsider feedback is curvilinear. Departments with low level relational and cognitive social capital still use outsider feedback in their decisionmaking process, but in high doses, departments will use outsider feedback to an even greater extent.

Another interesting result relates to citizens' demand of performance information. Departments that tend to regularly provide performance information to their citizens also tend to have higher usage of nonroutine performance information in their decision-making process, holding other factors constant. These departments appear to be more comfortable using performance information because citizens demand performance information. These departments are held accountable by citizens not only in the provision of performance information, but they are also held accountable for the organizational performance that they achieve. Because these departments are under citizen scrutiny, they are also more responsive to outsider feedback, deeming it important to improving their organizational performance. This result is in line with previous studies (de Lancer Julnes \& Holzer, 2001; Ho, 2006; Moynihan \& Ingraham, 2004; Poister \& Streib, 1999; Yang \& Hsieh, 2006).

Nonroutine performance information — insider talks is not statistically significant in any of the proposed models. The combination of these two results (i.e., evidence supporting the hypothesized effect on outsider feedback, but no evidence supporting insider talk) is interesting because it contrasts two previous subsets of the research literature. The first subset of literature that contrasts the present results refers to external 
feedback in the management of organizations and in goal setting (see Ivancevich \& McMahon, 1982; Kim \& Hammer, 1976). For example, Ivancevich and McMahon (1982) declared "the superiority of self-generated over externally generated performance oriented feedback" (p. 370). The results of this analysis confirm exactly the opposite: departments with higher level of organizational social capital tend to have higher use of outsider feedback compared to internal feedback.

The second subset of the research literature that contrasts the present results examines the downside of social capital. Most of the literature on social capital and organizational social capital describes its positive effects. However, an area of the literature that is not well developed examines the "dark" side of social capital, and this must be taken into consideration. For example, according to Aldridge, Halpern, and Fitzpatrick (2002), social capital may foster behaviors that could exclude actors or possible incumbents from joining a particular network. On the same path, Morrow (1999) and Szreter (2000) find that different groups and associations with more social capital are more likely to exclude outsiders. Portes (2014) concludes that social capital "may restrict the opportunities of outsiders to a community and may inhibit personal freedom." In this analysis, the results show that organizational social capital fosters nonroutine performance information-outsider feedback, which are generated by people that are "outsiders" from the departmental network of employees and managers. On the other hand, the use of feedback that is internally generated by people who belong to the same departmental network is not statistically significant. This is definitely an area of research worthy of future exploration.

A final explanation could be that as departments become more homogenous, the information being produced and disseminated within these departments may become 
less useful because it may lack novelty, objectivity, and controversy. Groupthink theory can be used to explain this finding. Janis (1982) constructed groupthink theory as a model in which seven antecedents (e.g., group cohesion, group homogeneity, group insulation, low self-esteem, external threat, leadership style, methodological procedure) lead to the symptoms of groupthink (belief in group morality, collective rationalization, illusion of invulnerability, pressure on dissenters, self-appointed mindguards, illusion of unanimity, stereotypes of out-groups, self-censorship). The symptoms of groupthink eventually lead to poor decision making. At the basis of groupthink theory, members of a group seek consensus in their decision making. As Janis and Mann (1977) point out, the search for consensus leads the group to discard other elements that are important in the decision making process-especially when adopting the rational model: incomplete survey of alternatives, incomplete survey of objectives, failure to examine risks of preferred choices, failure to reappraise initially rejected alternatives, poor information search, selective bias in information processing, and failure to work out contingency plans.

The defective decision making that groupthink theory leads to, particularly avoidance in selecting different and unbiased information, can explain why departments with a higher level of organizational social capital, which leads to the creation of strong groups / clans and therefore group thinking, are less likely to use nonroutine performance information — internal feedback. Based on this theory, decision makers do not need this kind of information to arrive at a consensus. This theory could be another explanation for why the result of the analysis was not statistically significant. 


\section{Routine Performance Information Use}

As summarized above, there is evidence that supports the hypothesized effect. Holding other factors constant, departments with higher level of organizational social capital tend to have higher usage of routine performance information. Organizational social capital facilitates social interaction, fosters trust among colleagues within and among departments, and helps identify — to each member of an organization — the goals and mission of the organization itself. The findings suggest that organizational social capital is an important organizational factor for the success of performance management initiatives and practices and deserves more attention from both practitioners (managers) and academics.

Collaboration, coordination, and interaction between members of an organization not only make information available (see, for example, Granovetter, 1973; Jacobs, 1965; Nahapiet \& Goshal, 1998), but once information is available in a department, departmental use of the available information will occur. Similarly, when sufficient levels of trust are present in a department, trust first enables a series of positive organizational outcomes, including greater working effectiveness, goal orientation (Putnam, 1993), and goal achievement (Coleman, 1988). Secondly, trust also facilitates information sharing, as for the structural dimension of social capital, and especially of sensitive information and even negative or uncomfortable information to share (de Bunt, Wittek, \& de Klepper, 2005).

Finally, trust increases the reliability — in the eyes of final users - of performance information that is collected, processed, and submitted by employees to their managers (Dirks \& Ferrin, 2001; Nicolaou et al., 2013); thus, the information is more likely to be used in the decision-making process. Therefore, trust enables organizational and 
individual mechanisms that allow higher departmental use of performance information. A department that shares its goals among its members, and strives to achieve these goals in a collective way (Shteynberg \& Galinsky, 2011), uses routine performance information in decision-making processes because managers want to know if the organization can achieve the defined and shared goals (Barzelay \& Campbell, 2003; Olsen \& Eadie, 1982); this routine performance information can also be used to quantify employees' individual contributions to the achievement of overall organizational goals (Fishbach et al., 2011).

Regarding the first model, an interesting result is that departments that tend to regularly exchange information with professional staff from other counties working in the same field, also tend to have higher usage of routine performance information in their decision-making process. This result is in line with several previous studies. For example, Ammons and Rivenbark (2008), in a study of the 15 municipalities participating in the North Carolina Benchmarking Project, found that "the willingness of officials to embrace comparison with other governments or service producers" ( $p$. 315) will increase the use of performance information in the managerial decisionmaking process. A similar result is suggested by Askim and colleagues (2008) in a nationwide study in Norway on benchmarking practices and organizational learning, defined as "processing of information which changes an entity's range of potential behavior" (p. 300), which can be assimilated to performance information use.

A second interesting result is that departments that tend to have sufficient resources (e.g., people, materials, budget) to complete projects also tend to have lower usage of routine performance information in their decision-making process. This result is interesting because the opposite is expected; that is, we expect that departments that 
tend to have sufficient resources to complete projects also tend to have higher usage of routine performance information in their decision-making process because those departments can (a) spend more money adopting and implementing sophisticated performance measurement systems and/or (b) dedicate more human resources to performance management. Although, the result is antithetical to what is expected, a possible explanation is: departments with sufficient resources (e.g., people, material, and budget) are not interested in achieving higher levels of efficiency, productivity, and effectiveness because they are not incentivized to do so given the nonexistent constraints on their resources. A different explanation could be that performance information is used more by those departments that do not have enough resources as a defense mechanism towards the attached of external or even internal stakeholders.

This argument is supported by several studies (see Bromiley, 1991; George, 2005; Tan \& Peng, 2003). This subset of the research literature does not originate from public administration nor public management, but from the business literature: publicly-held and privately-held firms that do not have enough resources (i.e., financial resources) tend to have better organizational performance than their counterparts with higher levels of resources. Similarly, organizations without enough resources to complete projects tend to use more performance information to understand whether they can achieve higher levels of efficiency and effectiveness.

Finally, the negative sign of the coefficient of Age group suggests that departments that tend to have younger management also tend to have higher usage of routine performance information. The explanation for this result is: younger managers that were (a) trained after the New Public Management movement reshaped how public administrations are managed and (b) trained in programs that embraced NPM theories 
and practices are more likely to use performance information. This result finds support in the literature on managers' age and innovation. For example, Bantel and Jackson (1989) point out that younger managers have been trained more recently and thus their knowledge is fresher. Hambrick and Mason (1984) state that because younger people take more risks than older people, they are also more open to implementing new ideas and tools.

\section{Qualitative analysis discussion}

The comparative case study analysis shows how contextual, organizational, and individual factors can cultivate or depress organizational social capital. As pointed out in the interviews and focus groups, County B-which, based on the results of the survey, has lower level of organizational social capital compared to County Aexperienced in the past seven/eight years organizational restructuring and the absence of leadership, which might have impacted organizational social capital. In summary, some departments in County B were merged and new departments were created as offshoots of existing ones; personnel were moved from one department to another. Merging and creating new departments, as well as moving and detaching personnel, certainly impacted both the structural and relational dimensions of organizational social capital. Moreover, as one participant reported, the goals of the new County Administrator are not adequately shared across the organization, thus impacting the level of the third component of social capital: the cognitive dimension.

Evidence from the literature supports this argument. For the structural and cognitive dimensions of social capital, the literature on reorganization can be taken into consideration. The literature points out how reorganization is usually initiated due to some degree of discontent with the administration and for "apparently non-functional 
reasons" (Thomas, 1993, p. 266). Different reasons can drive reorganization: (a) reorganization is expected from managers (Simon et al., 1991), (b) reorganization can revitalize working conditions to improve performance (Wilson, 1989), and (c) reorganization is a response to perceived problems (Bozeman \& Straussman, 1990). The effects of reorganization can be unpredictable. According to Kaufman (1977, p. 402) "in particular circumstances, identical organizational arrangements may produce diametrically opposite effects while radically different arrangements may produce identical effects." However, Andrews and Boyne (2012), in an extensive literature review on the effects of reorganization, pointed out, among others, the following effects (p. 300):

- "goal displacement as both councilors and officers are distracted from running the existing organization and instead spend their time steering the change process and jockeying for position in the new structure;"

- "excessive leadership turnover as some senior staff take early retirement and others, unsure of their future position in the new organization, seek employment elsewhere, thereby producing a loss of organizational memory and management expertise;"

- "reductions in staff morale as a result of uncertainty about roles and responsibilities;"

Andrews and Boyne (2012) also found that, in the short term, the impact of reorganization is negative-lowering the service level performance of these organizations. 
Although the reasons for reorganization in County B over the past years are unknown, some effects that Andrews and Boyne (2012) noted are in line with what occurred in County B: goals that are not clearly communicated to the organization, the departure of some executives in the organization including the past County Administrator, and the low spirit of some departments due to the effects of reorganization (see the Volunteer Program). Moreover, reorganization in County B resulted in severing the existing linkages and networks between and among different departments.

In terms of trust, and therefore the relational dimension of social capital, a wide range of literature examines trust as a history-based mechanism (Deutsch, 1958; Kramer, 1999; Lindskold, 1978; Pilisuk \& Skolnick, 1968; Solomon, 1960; Susan \& Holmes, 1991). According to Kramer (1999), "trust between two or more interdependent actors thickens or thins as a function of their cumulative interaction" (p. 575). The core of these models is that professional history with a person, and daily interaction with that person, gives actors the necessary information to assess "others' disposition, intentions, and motives" (p. 575). The assessor uses this kind of information as a base to judge the other's trustworthiness and to make predictions of his/her future behavior. When county employees are moved from one department to another, or departments are merged together, the effect is that time is needed for people to rebuild history-based trust.

The literature on distrust can also be used to discuss these results. In particular, the literature on social-categorization can be taken into consideration. According to this subset of the research literature, distrust may emerge as a result of social-categorization of people into different groups. Members that belong to the same group are considered 
more trustworthy than outgroup members (Brewer, 1996). According to these studies, boundaries between groups are not always conspicuous, but they can be based on arbitrary, minimal, and transient criteria (Kramer, 1999). Once again, organizational restructuring may favor the development of mistrust among members of an organization, thus impacting the relational dimension of social capital.

A third and final subset of the research literature can be taken into consideration to support these results: the fragility of trust. According to this subset of the literature (Barber, 1983; Mayerson et al., 1996; Slovic, 1993), it is much easier and faster to destroy trust than to create it. Circumstances that lead to the destruction of trust are perceived more and have a stronger impact on individuals than episodes that create trust. Building trust among people in County B will require more time and more effort given the fragile nature of trust.

\section{Policy implications: how to create and foster OSC}

Creating organizational social capital can be as difficult as measuring it. The question of how to create and foster social capital has amassed some answers regarding community social capital. In direct democracies, like Switzerland for example, positive effects related to using direct democratic rights are acknowledged both at the individual and community levels (Stadelmann-Steffen \& Vatter, 2012). In the United Kingdom, "bridge-building activities intended to increase interpersonal contacts between diverse ethnic, faith and nationality groups have the goal to increase community and social cohesion" (Harris \& Young, 2009, p. 517). Others authors (Putnam, 1995; Brehm \& Rahn, 1997; Alesina \& La Ferrara, 2000; Glaeser et al., 2002) have tried to identify factors associated with the creation of (community) social capital. Rupasingha et al. 
(2006), in an attempt to systemize the existing literature, identify the following factors associated with the production of social capital:

- Ethnic division - the more the society is fragmented, the lower the level of social capital will be (Putnam, 1993).

- Income and income inequality_-greater income inequality will lower the level of social capital (Alesina \& La Ferrara, 2000).

- Education - higher educational attainment will lead to higher levels of community engagement (Putnam, 1993).

- Community attachment - the more the people migrate, the lower the level of social capital will be because of broken interpersonal relations (Schiff, 1992; Glaeser et al., 2000).

- Role of women-according to Putnam (1995), the more women are involved in the workplace and less in family affairs, the lower the level of social capital will be.

- Marriage and family_married men and women have higher level of social capital than non-married ones (Putnam, 1995).

- Age-older people are more civic engaged than younger generations (Putnam, 1995).

- Suburbanization - in small and rural environments, social capital is higher (Putnam, 1995).

- Employment type-different types of employment can affect the level of social capital (Glaeser et al., 2002).

- Homeownership - homeowners are found to have higher level of social capital (Glaeser et al., 2002). 
Although the literature on how to create organizational social capital is not well developed, the existing contributions can be analyzed. According to Sherif et al. (2006), the use of Knowledge Management Systems (KMS) within an organization foster the overall level of organizational social capital "because KMS creates dense and highly connected networks, whose members trust each other and feel obliged to carry out the responsibilities bestowed on them by the network with which they associate" (p. 802). The theme of investments in organizational social capital is addressed specifically by Cohen and Prusak (2001) and by Ellinger et al. (2010). These authors identified three managerial tools that can be used to create and foster organizational social capital: making connections; enabling trust; and, fostering cooperation. However, no specific examples were given. Making connections involves all the activities and behaviors that create and foster connections and create and foster a sense of group identity among members of an organization (Cohen \& Prusak, 2001). Enabling trust "involves behavioral norms and values that give employees reasons to have confidence in the organization, instead of giving them reasons to respond to the organization and its representatives defensively" (Ellinger et al., 2010, p. 573). Finally, fostering cooperation means that the organization pushes its employees to adopt collaborative rather than competitive behaviors (Cohen \& Prusak, 2001).

To understand how to create organizational social capital, another important contribution to consider is a study by Korte and Lin (2013). Examining socialization of newcomers in an organization, they described the typical patterns that newcomers experience when building their structural, relational, and cognitive social capital. Understanding the structure of the established groups and relationships in an organization is important to operate on the structural component of organizational 
social capital. Regarding the relational component of organizational social capital, the authors show the importance of finding a mentor "for the purpose of learning how to accomplish various tasks and how things were done in the organization, as well as facilitating integration into the group" (Korte \& Lin, 2013, p. 418) and the importance of building camaraderie, defined as "a category of activities for the purpose of becoming integrated into the group" (p. 418). Finally, the cognitive dimension of organizational social capital could be developed by: understanding the engineering method, learning the work processes, and learning the culture of the group.

The analysis described above shows how it is possible to create and foster both community and organizational social capital. Two final issues from the analysis must still be addressed: how to operate on organizational social capital in the long run and how to operate in the short term. The former deals with the problem of how to treat the current stock of organizational social capital and how to change it in the long run. The latter focuses more on what tools can be used to operate immediately on organizational social capital. In other words, the first issue revolves around hard organizational components while the second focuses more on soft organizational components. Even if the factors described by Rupasinga et al. (2006), directly affect community social capital, some could be transposed to the organizational level. Income and income inequality could be transposed as the fairness of the pay and reward system. Organizations where the payment system is considered fairer will have higher levels of organizational social capital. Education level could be easily transposed. Organizations with higher educational attainment level will have higher stock of organizational social capital. Finally, community attachment could be transposed as turnover rate. Organizations experiencing lower turnover rate among its employees will experience 
higher level of organizational social capital. Those elements can only be changed in the long run, more slowly affecting the overall level of organizational social capital. In the short term, managers can operate on soft organizational incentives such as those proposed by Cohen and Prusak (2001), Ellinger et al. (2010), and Korte and Lin (2013) as well as on organizational culture (Quinn \& Rohrbaugh, 1983; Zummoto \& Krakower, 1991) to create meaningful incentives for the creation of organizational social capital.

Considering the experience of County A and considering what the literature has previously noted on how to create and foster organizational social capital, it is possible to list the following recommendations that public managers, especially in local governments, could use to foster organizational social capital:

- Define and schedule extra activities in which as many employees as possible will participate. Extra activities can be completed either in the work environment or in a non-work environment. Examples of activities are: Christmas/Holiday parties, retirement ceremonies, award ceremonies, summer retreats, etc....;

- Create, in each department, an "incentives committee" composed of the director and other representative members of the department with the specific scope of organizing activities within the department;

- Define “employees' incentives" in the budget consisting of \$20 for each employee in the department to fund activities inside and outside the department;

- Favor (or at minimum, do not oppose) employee unionization; 
- Favor collaboration between "incentive committee" and union representatives;

- Instill an organizational culture of honesty, integrity, and dependability among the members of the department;

- Instill a culture that does not punish employees for mistakes, but allows the organization itself to learn from these mistakes;

- Clear and strong leadership: employees must know what the organizational goals are and what is expected from them.

- Guarantee fairness among all employees, not just in terms of pay and reward system, but more in the most ample way as possible;

- Provide mentors for new employees joining the organization-with the goal of fostering the three components of organizational social capital such as insertion into existing networks, providing a base for trustbuilding relationships, and explaining the organizational culture and climate. 


\section{Chapter 9 Conclusions and future development}

\section{Lesson learned}

Much of the previous literature on performance information has mainly focused on managerial drivers of performance information use and not enough research focused on sociological factors. To address this gap in the literature, the concept of organizational social capital is used in this dissertation as a potential driver of performance information use. Organizational social capital is a concept that is composed of three different dimensions: the structural dimension, or the level of interaction among members of an organization; the relational dimension, or the level of trust among members of an organization; and the cognitive dimension, or the capacity of an organization to have shared goals and enact this goals collectively (Leana \& Van Buren, 1999; Nahapiet \& Ghoshal 1998).

In this dissertation, it is hypothesized that managers are more likely to use performance information in their decision making process if:

(4) they interact and collaborate with each other and with employees,

(5) they have trust in each other and they trust their employees,

(6) they have shared goals and they enact these goals collectively.

To test these hypotheses, a mixed-methods approach was used. First, a multiple informant survey was submitted to department heads, middle managers and other individuals with a supervisory role from eight departments in all 67 Florida counties. The results of the analysis showed evidence supporting the hypothesized effect. Other factors being held equal, departments with a higher value of organizational social capital tend to have higher usage of routine performance information while departments with a higher level of the structural component tend to use more nonroutine 
performance information-outsider talks. In terms of a substitution effect between routine and nonroutine performance information, other factors being held equal, departments with a higher level of relational and cognitive social capital tend to use more routine performance information while controlling for other types of performance information. Departments with higher levels of structural social capital tend to use more nonroutine performance information-outsider feedback, while controlling for other types of performance information.

The second phase of the analysis employed a mixed-methods approach to better understand the context of the hypothesized effect. Two counties with similar characteristics but with different levels of organizational social capital and performance information use were studied. The results showed that organizational and individual factors such as organizational restructuring and absence of leadership can harm the level of organizational social capital. The results of the two phases of the dissertation are used to provide suggestions and policy implications to public managers to create and foster organizational social capital in local public organizations.

In terms of implication for theory, the present research confirms previous studies that highlight the importance of factors such as collaboration and trust in making information available (see for example Granovetter, 1973; Jacobs, 1965; Nahapiet \& Goshal, 1998) and fostering use of the information (Dirks \& Ferrin, 2001; Nicolaou et al., 2013). Furthermore, the research highlights the importance of benchmarking as a driver of performance information use. Surprisingly, more resources are seemingly not important in making a performance management system work. Interestingly, in terms of nonroutine performance information use, external feedback seem to be preferred over internal feedback, which goes against at least two different avenues of the 
literature: the literature on internally versus externally generated feedback (Ivancevich \& McMahon, 1982; Kim \& Hammer, 1976) and the literature on the negative effects of social capital. However, these results seem to support the literature on groupthink theory (Janis, 1982).

In terms of implications for practitioners, this dissertation first reviews the existing literature on how to create and foster organizational social capital and second, based on interviews and focus group carried out in County A and County B, it provides policy recommendation to managers that want to foster organizational social capital in their organizations not only to foster performance information use but to increase the quality of the workplace.

\section{Future development}

The following venues and opportunities to extend and expand the analysis are anticipated. First, the construct of Public Service Motivation (PSM) can be used as a mediating variable between organizational social capital and performance information use. PSM has been defined as an "individual predisposition to respond to motives grounded primarily or uniquely in public institutions and organizations" (Perry \& Wise, 1990, p. 368) and there is theoretical argumentation for why it can mediate organizational social capital and performance information use. Preliminary results show evidence of the hypothesized mediation effect. The total effect that is mediated by public service motivation is $8 \%$ between the relational and cognitive dimensions of social capital and routine performance information use, and $11 \%$ between the structural dimension of social capital and routine performance information use.

A second venue of expansion regards the measurement of organizational social capital. As mentioned above, for the analysis and results portrayed in this dissertation, 
organizational social capital was measured using the scale adopted by Andrews (2010, 2011). However, this scale might not reflect completely how organizational social capital has been theoretically constructed. Therefore, in crafting the survey, additional questions that are believed to be more appropriate to measure organizational social capital were included. A preliminary factor analysis using the available data from the Florida counties showed how all six items load on a single organizational social capital factor. Further analysis must be done to test the validity, reliability, and sensitivity of such a scale.

A third venue for future research should include the other level of social capitalthe community level — in the analysis as well. Taking into consideration both levels of social capital could also control for factors that influence the working constituency of people that the administration can choose to hire. The analysis could also expand knowledge on social capital in the State of Florida and could be easily transformed into a monograph.

More generally, an interesting area that must be addressed in the performance management literature refers to the quality of decisions that managers make in their organizations. Does performance information really improve the quality of managers' decisions? The literature on performance information has evolved throughout the years, from how to measure performance, to how to manage performance and performance information use, to performance governance. A next step toward better understanding of this managerial tool, which has become so popular within the NPM movement, is to understand whether decisions based on performance information are better decisions than those based on other factors. 


\section{Final remarks}

Regardless of whether NPM has helped contemporary public administrations deliver better services to citizens and be more accountable to stakeholders, NPM has also posed quite a few issues and questions. NPM, and its by-products like performance management, is just a paradigm that gave its contribution in an era of disillusionment and critique toward our commonwealth. Other paradigms have preceded and others will follow. In any event, government should organize and manage in a manner resembling what Cicero, in the Fourth Book of his opera De Res Publica (54 BC), stated: to "secure to the citizens the benefits of an honest and happy life, which is, indeed, the grand object of all political association, and which every government should endeavour to procure for the people by its laws and institutions." 


\section{References}

Aldridge, S., Halpern, D. \& Fitzpatrick, S. (2002). Social capital: A discussion paper. London, England: Performance and Innovation Unitge et al.

Alesina, A., \& La Ferrara, E., (2000). Participation in heterogeneous communities. Quarterly Journal of Economics, 115, 847-904.

Allman, T. D. (2013). Finding Florida: The True History of the Sunshine State. Grove/Atlantic, Inc.

Ammons, D. N. \& Rivenbark, W.C. (2008). Factors influencing the use of performance data to improve municipal services: evidence from the North Carolina benchmarking project. Public Administration Review, 68(2), 304-318.

Ammons, D. N. (2013). Signs of performance measurement progress among prominent city governments. Public Performance \& Management Review, 36(4), 507-528.

Anderfuhren-Biget, S. (2012). Profiles of public service-motivated civil servants: Evidence from a multicultural country. International Journal of Public Administration, 35(1), 5-18, DOI: 10.1080/01900692.2011.635276.

Andrews, R., Boyne, G. A., Law, J., \& Walker, R. M. (2009). Strategy Formulation, Strategy Content and Performance. Public Management Review, 11(1), 1-22.

Andrews, R., \& Boyne, G. (2012). Structural change and public service performance: The impact of the reorganization process in English local government. Public Administration, 90(2), 297-312.

Andrews, R. (2010). Organizational social capital, structure and performance. Human Relations, 63(5), 583-608.

Andrews, R. (2011). Exploring the impact of community and organizational social capital on government performance: Evidence from England. Political Research Quarterly, 64(4), 938-949.

Arrow, K. (2000). Observations on social capital. In: Dasgupta, P., Serageldin, I. (Eds.), Social Capital: A Multifaceted Perspective. The World Bank, Washington, DC.

Askim, J., Johnsen, A., \& Christophersen, K.A. (2008). Factors behind organizational learning from benchmarking: Experiences from Norwegian municipal 
benchmarking networks. Journal of Public Administration Research and Theory, 18, 297-320.

Babbie, E. R. (1990). Survey research methods. Belmont, CA: Wadsworth Pubublishing.

Backstrom, C. H., \& Hursh, G. D. (1963). Survey research. Evanston, Illinois: Northwestern University Press.

Baker, T. L. (1994). Doing Social Research. 2nd Edn. New York: McGraw-Hill Inc.

Bantel, K. A., \& Jackson, S. E. (1989). 'Top Management and Innovations in Banking: Does the Composition of the Top Management Team Make a Difference', Strategic Management Journal, 10(S), 107-124.

Barber, B. (1983). The logic and limits of trust.

Barzelay, M., \& Campbell, C. (2003). Preparing for the future: Strategic planning in the US Air Force Washington DC: Brookings Institution Press.

Bazerman, M. H. (2002). Judgment in managerial decision making (5th ed.). New York: John Wiley \& Sons, Inc.

Becker, G. S. (1964). Human Capital. Chicago : University of Chicago Press.

Becker, G. S., (1965). A theory of the allocation of time. Economic Journal, 75, 493517.

Becker, G. S., 1974. A theory of social interactions. Journal of Political Economy, 82, 1063-1093.

Behn, R. D. (2002). The psychological barriers to performance management: Or why isn't everyone jumping on the performance-management bandwagon? Public Performance \& Management Review, 26(1), 5-25.

Behn, R. D. (2003). Why measure performance? Different purposes require different measures. Public Administration Review, 63(5), 586-606. 
Behn, R. D. (2006). The varieties of CitiStat. Public Administration Review, 66(3), $332-340$.

Berman, E., \& Wang, X. (2000). Performance measurement in U.S. counties: Capacity for reform. Public Administration Review, 60(5), 409-420.

Bourdieu, P. (1990). The Logic of Practice. Cambridge: Polity.

Bourdieu, P., \& Passeron, J. C. (1977). Reproduction in Education, Society, Culture. Beverly Hills: Sage.

Bouckaert, G., \& Halligan, J. (2008). Managing Performances. International Comparison. London: Routledge.

Bozeman, B., \& Straussman, J. D. (1990). Public management strategies: Guidelines for managerial effectiveness. Jossey-Bass.

Brehm, J., \& Rahn, W. (1997). Individual-level evidence for the causes and consequences of social capital. American Journal of Political Science, 41, 9991023.

Brewer, M. B. (1996). In-group favoritism: The subtle side of intergroup discrimination. Codes of conduct: Behavioral research and business ethics, 160-171.

Brewer, G. A. (2003). Building social capital: Civic attitudes and behavior of public servants. Journal of Public Administration Research and Theory, 13, 5-26.

Bromiley, P. (1991). Testing a causal model if corporate risk taking and performance. Academy of Management Journal, 34, 37-59.

Burt, R. S. (1992). Structural holes: The social structure of competition. Cambridge, MA: Harvard University Press.

Caiden, G. E. (1994). Administrative reform - American style. Public Administration Review, 54(2), 123-128.

Cebula, R. J. (1995). Effects of property taxes on the cost of living in the USA: Case study of Florida counties. Applied Economics Letters, 5, 757-758. 
Chen, C.-A., Hsieh, C.-W., \& Chen, D.-Y. (2014). Fostering Public Service Motivation through Workplace Trust: Evidence from Public Managers in Taiwan. Public Administration, 92(4), 954-973.

Cicero, M. T. (54 BC). De Res Publica.

Cigler, A., \& Joslyn, M. K. (2002). The extensiveness of group membership and social capital. The impact on political tolerance attitudes. Political Research Quarterly, 55, 7-25.

Claibourn, M. P., \& Martin, P. S. (2007). The third face of social capital: How membership in voluntary associations improves policy accountability. Political Research Quarterly, 60, 192-201.

Chow, W. S., \& Chan, L. S. (2008). Social network, social trust and shared goals in organizational knowledge sharing. Information \& Management, 45, 458-465.

Coffé, H., \& Geys, B. (2005). Institutional performance and social capital: An application to the local government level. Journal of Urban Affairs, 27, 485502.

Cohen, M. D., March, J. G., \& Olsen, J. P. (1972). A garbage can model of organizational choice. Administrative Science Quarterly, 17(1), 1-25.

Cohen, D., \& Prusak, L. (2001). In good company. How social capital makes organizations work. Boston: Harvard Business School Press.

Coleman, J. S. (1988). Social capital in the creation of human capital. American Journal of Sociology, 94 (Suppl.), S95-S120.

Costanza, R., d'Arge, R., de Groot, R., Farber, S., Grasso, M., Hannon, B., van den Belt, M. (1997). The value of the world's ecosystem services and natural capital. Nature, 387(6630), 253-260.

Cureton, E. E. (1976). Studies of the promax and optres rotations. Multivariate Behavioral Research, 11, 449-460.

DeFilippis, J., (2001). The myth of social capital in community development. Housing Policy Debate, 12, 781-806. 
de Bunt, G., Wittek, G., \& de Klepper, M. (2005). The evolution of intra-organizational trust networks: The case of a German paper factory: An empirical test of six trust mechanism. International Sociology, 20(3), 339-69.

de Lancer Julnes, P., \& Holzer, M. (2001). Promoting the utilization of performance measures in public organizations: An empirical study of factors affecting adoption and implementation. Public Administration Review, 61(6), 693-708.

Deutsch, M. (1958). Trust and suspicion. Journal of conflict resolution, 265-279.

De Vaus, D. A. (1993). Surveys in Social Research (3rd edn.). London: UCL Press.

Diffie-Couch. P. (1984). Building a feeling of trust in the company. Supervisory Management, 29, 31-36.

Dirks K. T., \& Ferrin, D.L. (2001). The role of trust in organizational settings. Organization Science, 12(4), 450-467.

Driscoll, J. W. (1978). Trust and participation in organizational decision making as predictors of satisfaction. Academy of Management Journal, 21(1), 44-56.

Durlauf, S. N. (2002). Bowling alone: a review essay. Journal of Economic Behavior and Organization, 47, 259-273.

Ellinger, A. E., Elmadağ B., Ellinger, A. D, Wang, Y,L., \& Bachrach, D. (2011). Measurement of organizational investments in social capital: The service employee perspective. Journal of Business Research, 64, 572-578.

Enticott, G., Boyne, G. A., \& Walker, R. M. (2009). The use of multiple informants in public administration research: Data aggregation using organizational echelons. Journal of Public Administration Research and Theory, 19(2), 229-253.

Etzioni, A. (1967). Mixed-scanning: A 'Third' approach to decision-making. Public Administration Review, 27(5), 385-392.

Favero, N., \& Bullock, J. B. (2014). How (not) to solve the problem: An evaluation of scholarly responses to common source bias. Journal of Public Administration Research and Theory. 
Fink, A. \& Kosecoff, J. (1985) How to conduct surveys; A step-by-step guide. SAGPublications, INC. Beverly Hills, California.

Fishbach, A., Henderson, M. D., \& Koo, M. (2011). Pursuing goals with others: Group identification and motivation resulting from things done versus things left undone. Journal of Experimental Psychology: General, 140(3), 520.

Fukuyama, F. (1995). Trust: The social virtues and the creation of prosperity. New York: Free Press.

Ganapati, N. E. (2013). Downsides of Social Capital for Women during Disaster Recovery: Towards a More Critical Approach. Administration and Society, 45(1), 72-96.

Ganapati, N. E. (2009). Rising from the rubble: Emergence of place-based social capital in Golcuk, Turkey. International Journal of Mass Emergencies and Disasters, 27(2), 127-166.

George, G. (2005). Slack resources and the performance of privately held firms. Academy of Management Journal, 48(4), 661-676.

Glaeser, E. L., Laibson, D. I., Scheinkman, J. A., Soutter, C. L., (2000). Measuring trust. Quarterly Journal of Economics, 115, 811-846.

Glaeser, E. L., Laibson, D., \& Sacerdote, B. (2002). The economic approach to social capital. Economic Journal, 112, F437-F458.

Gomez, C. \& Benson, R. (2001). The leader-member exchange as a link between managerial trust and employee empowerment. Group \& Organization Management, 26(1), 53-69.

Granovetter, M. (1973). The strength of weak ties. American Journal of Sociology, 78, $1360-1380$.

Griset, P. L. (2002). New sentencing laws follow old patterns: A Florida case study. Journal of Criminal Justice, 30, 287-301.

Grootaert, C., \& Bastelaer, T. (2001). Understanding and measuring social capital: A synthesis of findings and recommendations from the social capital initiative (Social Capital Initiative Working paper 24). Washington, DC: The World Bank. 
Gujarati, D. N., \& Porter, D. (2009). Basic Econometrics. New York: McGraw-Hill International Edition.

Hambrick, D. C., \& Mason, P. A. (1984). Upper Echelons: The Organization as a Reflection of its Top Managers. Academy of Management Review, 9, 193-206.

Harris, M., \& Young, P. (2009). Developing community and social cohesion through grassroots bridge-building: an exploration. Policy \& Politics, 37(4), 517-34.

Hatry, H. P. (2006). Performance measurement: Getting results. The Urban Insitute.

Ho, A.T.K. (2006). Accounting for the value of performance measurement from the perspective of city mayors. Journal of Public Administration Research and Theory, 16, 217-37.

Holzer, M., \& Yang, K. (2004). Performance measurement and improvement: An assessment of the state of the art. International Review of Administrative Sciences, 70(1), 15-31.

Hood, C. (1998). The art of the state: Culture, rhetoric, and public management. Oxford: Clarendon Press.

Hopkins, S. M., and Weathington, L. (2006). The relationship between justice perceptions, trust, and employee attitudes in a downsized organization. The Journal of Psychology, 140, 477-498.

Kadushin, C. (2012). Understanding social networks: Theories, concepts, and findings. OUP USA.

Kamensky, J. M. (1996). Role of "reinventing government" movement in federal management reform. Public Administration Review, 56(3), 247-255.

Kezdi, G. (2004). Robust standard error estimation in fixed-effects panel models. Available at SSRN 596988.

Kenny, D. A., \& LaVoie, L. (1985). Interpersonal relations and group processes. $J$. Personality Soc. Psych, 48(2), 339-348.

Kettl, D. (2005). The global public management revolution. $2^{\text {nd }}$ ed. Washington, D.C.: Brookings Institution Press. 
Kim, J. S., \& Hamner, W. C. (1976). Effect of performance feedback and goal setting on productivity and satisfaction in an organizational setting. Journal of Applied Psychology, 61(1), 48.

Knack, S. (2002). Social Capital and the Quality of Government: Evidence from the States. American Journal of Political Science, 46(4), 772-785.

Kolo, J., \& Watson, R. (1992). Local economic development and growth management in Florida. Economic Development Review, 10(3), 68.

Kramer, R. M. (1999). Trust and distrust in organizations: Emerging perspectives, enduring questions. Annual review of psychology, 50(1), 569-598.

Kreitner, R., \& Kinicki, A. (2001). Organizational behavior. 5th Edition. Burr Ridge, IL: Irwin Mc-Graw Hill.

Kroll, A. (2013). The other type of performance information: Nonroutine feedback, its relevance and use. Public Administration Review, 32(2), 265-276.

Kroll, A. (2012). Why Public Managers Use Performance Information: Concepts, Theory, and Empirical Analysis. Ph.D. Dissertation, University of Potsdam.

Korte, R., \& Lin, S. (2012). Getting on board: Organizational socialization and the contribution of social. Human Relations, 66(3), 407-428.

Kosekoff, J., Fink, A., \& Brook, R. H. (1985). General medical care in the education of internists in a university hospital: an evaluation of the Teaching Hospital Group Practice Program. Annual International Medicine, 102, 250-257.

Kotter, J. (1990). A Force for Change: How leadership differs from management. New York: Free Press.

Kadushin, G. (2012). The social work interview: A guide for human service professionals. Columbia University Press.

Hatry, H. (2006). Performance measurement: Getting results. Washington, D.C: Urban Institute Press.

Harman, H. H. (1976). Modern factor analysis. Chicago, IL: The University of Chicago Press. 
Hendrickson, A. E., \& White, P. O. (1964). Promax: A quick method for rotation to oblique simple structure. The British Journal of Statistical Psychology, 17, 6570 .

Holbrook, A., Krosnick, J., \& Pfent, A. (2007). "The Causes and Consequences of Response Rates in Surveys by the News Media and Government Contractor Survey Research Firms." In James M. Lepkowski, N. Clyde Tucker, J. Michael Brick (Eds.) Advances in telephone survey methodology. New York: Wiley.

Holzer, M., \& Yang, K. (2004). Performance Measurement and Improvement: an Assessment of the State of the Art. International Review of Administrative Sciences, 70(1), 15-31.

Hood, C. (2006). Gaming in target world: The targets approach to managing British public services. Public Administration Review, 66(4), 515-21.

Jackman, R. W., \& Miller, R. A. (1998). Social capital and politics. Annual Review of Political Science, 1, 47-73.

Jacobs, J. (1965). The death and life of great American cities. London: Penguin Books.

Jewett, A. (2010). Florida county government guide. Tallahassee, FL: Florida Association of Counties.

Johnson, H. G. (1960). The Political Economy of Opulence. Canadian Journal of Economics and Political Science, 26, 552-64.

Inkpen, A., \& Tsang, E. (2005), Social capital networks, and knowledge transfer. Academy of Management Review, 30, 146-165.

Ivancevich, J. M., \& McMahon, J. T. (1982). The effects of goal setting, external feedback, and self-generated feedback on outcome variables: A field experiment. Academy of Management Journal, 25(2), 359-372.

Kenny, D. A., \& La Voie, L. (1985). Separating individual and group effects. Journal of Personality and Social Psychology, 48(2), 339.

Keeter, S., Kennedy, C., Dimock, M., Best, J., \& Craighill, P. (2006). Gauging the impact of growing nonresponse on estimates from a national RDD telephone survey. Public Opinion Quarterly, 70(5), 759-779. 
Korte, R., \& Lin, S. (2013). Getting on board: Organizational socialization and the contribution of social capital. Human Relations, 66(3), 407-428.

Kramer, R. M. (1999). Trust and distrust in organizations: Emerging perspectives, enduring questions. Annual Review of Psychology, 50(1), 569-598.

Kroll, A. (2013). The other type of performance information: Nonroutine feedback, its relevance and use. Public Administration Review, 32(2), 265-276.

Kroll, A. (2014). Drivers of performance information use: Systematic literature review and directions for future research. Forthcoming in Public Performance \& Management Review.

Kolo, J., \& Watson, R. (1992). Local economic development and growth management in Florida. Economic Development Review, 10(3), 68-72.

Lance, C. E., Butts, M. M., \& Michels, L. C. (2006). The sources of four commonly reported cutoff criteria: What did they really say? Organizational Research Methods, 9(2), 202-220.

La Porta, R., Lopez-de-Silanes, F., Shleifer, A., Vishny, R. W. (1997). Trust in large organizations. American Economic Review, 87, 333-338.

Lau, A. W., \& Pavett, C. M. (1980). The nature of managerial work: A comparison of public-and private-sector managers. Group \& Organization Management, 5(4), 453-466.

Leana, C. R., \& van Buren, H. J. III. (1999). Organizational social capital and employment practices. The Academy of Management Review, 24(3), 538-555.

Leana, C. R., \& Pil, F. K. (2006). Social capital and organizational performance. Organization Science, 17(3), 353-366.

Lin, N. (1999). Building a network theory of social capital. Connections, 22(1), 28-51.

Lindblom, C. E. (1959). The science of "muddling through". Public Administration Review, 19(2), 79-88.

Lindblom, C. E. (1980). The policy-making process. Englewood Cliffs: Prentice-Hall. 
Lindskold, S. (1978). Trust development, the GRIT proposal, and the effects of conciliatory acts on conflict and cooperation. Psychological Bulletin, 85(4), 772 .

Loewenthal, K. M. (1996). An Introduction to Psychological Tests and Scales. London: UCL Press.

Lowi, T. J. (1964). American business, public policy, case-studies, and political theory. World Politics, 16(04), 677-715.

MacRae, D. \& Wilde J. A. (1985). Policy Analysis for Public Decisions. Lanham, MD: University Press of America.

March, J. G. (1987). Ambiguity and accounting: The elusive link between information and decision making. Accounting, Organizations and Society, 12(2), 153-187.

Marx, K. (1995) (1867, 1885, 1894). Capital: A New Abridgement. Oxford: Oxford University Press.

Marx, K. (1933) (1849). Wage-Labour and Capital. New York: International Publishers Company.

McPherson, M., Smith-Lovin, L., \& Cook, J. M. (2001). Birds of a feather: Homophily in social networks. Annual review of sociology, 415-444.

Meier, K. J., \& O'Toole, L. J. (2003). Public management and educational performance: The impact of managerial networking. Public Administration Review, 63(6), 689-699.

Meier, K. J., \& O’Toole, L. J. (2013). Subjective organizational performance and measurement error: Common source bias and spurious relationships. Journal of Public Administration Research and Theory, 23(2), 429-456.

Meyerson, D., Weick, K. E., \& Kramer, R. M. (1996). Swift trust and temporary groups. Trust in organizations: Frontiers of theory and research, 166, 195.

Mintzberg, H. (1973). The nature of managerial work. New York: Harper \& Row. 
Moon, M. J. (2000). Organizational commitment revisited in new public management: Motivation, organizational culture, sector, and managerial level. Public Performance \& Management Review, 24(2), 177-194.

Morrow, V. (1999). Conceptualising social capital in relation to the well-being of children and young people: A critical review. The Sociological Review, 47, 744765 .

Moynihan, D. P., \& Ingraham, P. W. (2004). Integrative leadership in the public sector: A model of performance-information use. Administration \& Society, 36(4), 427453.

Moynihan, D. P., \& Lavertu, S. (2012). Does involvement in performance management routines encourage performance information use? Evaluating GPRA and PART. Public Administration Review, 72(4), 592-602.

Moynihan, D. P., \& Pandey, S. K. (2010). The big question for performance management: Why do managers use performance information? Journal of Public Administration Research and Theory, 20(4), 849-66.

Moynihan, D. P., \& Pandey, S. K. (2006). Creating desirable organizational characteristics. How organizations create a focus on results and managerial authority. Public Management Review, 8(1), 119-140.

Moynihan, D. P., Pandey, S. K., \& Wright, B. E. (2012). Setting the table: How transformational leadership fosters performance information use. Journal of Public Administration Research and Theory, 22(1), 143-164.

Moynihan, D. P. (2005). Goal-based learning and the future of performance management. Public Administration Review, 65(2), 203-16.

Moynihan, D. P. (2008). Learning under uncertainty: Networks in crisis management. Public Administration Review, 68(2), 350-365.

Moynihan, D. P. (2009). Through a glass, darkly: Understanding the effects of performance regimes. Public Performance \& Management Review, 32(4), 592603.

Moynihan, D. P. (2013a). Advancing the Empirical Study of Performance Management: What we learned from the Program Assessment Rating Tool. American Review of Public Administration, 43(5), 497-515. 
Moynihan, D. P. (2013b). The New Federal Performance System: Implementing the GPRA Modernization Act. IBM Business of Government Research Endowment. http://www.businessofgovernment.org/sites/default/files/The $\% 20 \mathrm{New} \% 20 \mathrm{Fed}$ eral\%20Performance $\% 20$ System.pdf

Nahapiet, J., \& Ghoshal, S. (1998). Social capital, intellectual capital, and the organizational advantage. Academy of Management Review, 23(2), 242-266.

Nicolaou, A. I., Ibrahim, M., \& van Heck, E. (2013). Information quality, trust, and risk perceptions in electronic data exchanges. Decision Support Systems, 54(2), 986-996.

Nunnally, J. (1978). Psychometric methods. New York: McGraw-Hill.

Oh, H., Chung, M. H., \& Labianca, G. (2004). Group social capital and group effectiveness: The role of informal socializing ties. Academy of management journal, 47(6), 860-875.

Olsen, J. B., \& Eadie, D. C. (1982). The game plan: Governance with foresight. Washington, DC: Council of State Planning Agencies.

Osborne, D., \& Gaebler, T. (1993). Reinventing government. London: Addison-Wesley Publications.

Ouchi, W. (1979). A conceptual framework for the design of organizational control mechanisms. Management Science, 25(9), 833-848.

Peat, J., Mellis, C., Williams, K., \& Xuan W. (2002). Health Science Research: A Handbook of Quantitative Methods. London: Sage.

Parker, R. A., \& Rea, L. M. (1997). Designing and conducting survey research. San Francisco, CA: Jossey-Bass.

Payne, R., \& Mansfield, R. (1973). Relationships of perception of organizational climate to organizational structure, context and hierarchical position. Administrative Science Quarterly, 18(4), 515-526.

Perry, R. W. \& Mankin, L. D. (2007). Organizational trust, trust in the executive and work satisfaction. Public Personnel Management, 36, 165-179. 
Perry, J. L., \& Wise, L. R. (1990). The motivational bases of public service. Public Administration Review, 367-373.

Pettigrew, A. M. (1979). On studying organizational cultures. Administrative science quarterly, 570-581.

Pierce, J. C., Lovrich Jr., N. P. \& Moon, C. D. (2002). Social Capital and Government Performance: An Analysis of 20 American Cities. Public Performance \& Management Review, 25(4), 381-397.

Pilisuk, M., \& Skolnick, P. (1968). Inducing trust: a test of the Osgood proposal. Journal of Personality and Social Psychology, 8(2p1), 121.

Poister, T. H. (2010). Performance monitoring. In J. Whoely, H, Hatry, and K Newcomer (Eds.), Handbook of practical program evaluation (p. 98-125), San Francisco: Jossey-Bass.

Poister, T. H., \& Streib, G. (1999). Performance measurement in municipal government: Assessing the state of the practice. Public Administration Review, 59(4), 325-335.

Polit, D. F., Beck, C. T., \& Hungler, B. P. (2001). Essentials of Nursing Research: Methods, Appraisal and Utilization. 5th Ed. Philadelphia: Lippincott Williams \& Wilkins.

Pollitt, C., \& Bouckaert, G. (2002). La riforma del management pubblico. Milano: Università Bocconi Editore.

Portes, A. (1998). Social capital: Its origins and applications in modern sociology. Annual Review of Sociology, 24, 1-25.

Putnam, R. D. (1993). Making democracy work: Civic traditions in modern Italy. Princeton, NJ: Princeton University Press.

Putnam, R. D. (1995). Bowling alone: America's declining social capital. Journal of democracy, 6(1), 65-78.

Putnam, R. D. (2000). Bowling alone. The collapse and revival of American community. New York: Touchstone. 
Quinn, R. E., \& Rohrbaugh, J. (1983). A spatial model of effectiveness criteria: Toward competing values approach to organizational analysis. Management Science, 29(3), 363-77.

Rice, T. W. (2001). Social Capital and Government Performance in Iowa Communities. Journal of Urban Affairs, 23(3-4), 375-389.

Ring, P., \& Van de Ven, A. (1992). Structuring cooperative relationships between organizations. Strategic Management Journal, 13, 483-498.

Rupasingha, A., Goetz, S. J., Freshwater, D. (2006). The production of social capital in US counties. The Journal of Socio-Economics, 35, 83-101.

Schein, E. H. (1992). Organizational Culture and Leadership. San Francisco, CA: Jossey-Bass.

Schiff, M., (1992). Social capital, labor mobility, and welfare: the impact of Uniting States. Rationality and Society 4, 157-175.

Sherif, K., Hoffmanb, J., \& Thomas, B. (2006). Can technology build organizational social capital? The case of a global IT consulting firm. Information \& Management, 43, 795-804.

Shockley-Zalabak, P., Ellis, K., \& Winograd, G. (2000). Organizational trust: What it means, why it matters. Organizational Development Journal, 18, 35-48.

Shteynberg, G., \& Galinsky, A. D. (2011). Implicit coordination: Sharing goals with similar others intensifies goal pursuit. Journal of Experimental Social Psychology, 47(6), 1291-1294.

Schultz, T. W. (1961). Investment in Human Capital. The American Economic Review, 51(1), 1-17.

Simon, H. (1972). Theories of bounded rationality, In: McGuire, C. B. \& Radner, R. (Eds.), Decisions and Organizations. North Holland Publishing Company.

Simon, H. A., Thompson, V.A., \& Smithburg, D. W. (1991). Public Administration. Piscataway, NJ: Transaction Publishers. 
Simons, R. (1995). Levers of control: How managers use innovative control systems to drive strategic renewal. Boston, MA: Harvard Business School Press.

Slovic, P. (1993). Perceived risk, trust, and democracy. Risk analysis, 13(6), 675-682.

Solomon, L. (1960). The influence of some types of power relationships and game strategies upon the development of interpersonal trust. The Journal of Abnormal and Social Psychology, 61(2), 223.

Solow, R. (2000). Notes on social capital and economic performance. In: Dasgupta, P., Serageldin, I. (Eds.), Social Capital: A Multifaceted Perspective. The World Bank, Washington, DC.

Spearman, C. E. (1904). The proof and measurement of association between two things. American Journal of Psychology, 15, 72-101.

Stadelmann-Steffen, I., \& Vatter, A. (2012). Does satisfaction with democracy really increase happiness? Direct democracy and individual satisfaction in Switzerland. Political Behavior, 34, 535-559.

Suchman, M. C. (1995). Managing legitimacy: strategic and institutional approaches. Academy of Management Review, 20(3), 571-610.

Susan, D., \& Holmes, J. G. (1991). The dynamics of interpersonal trust: Resolving uncertainty in the face of risk. Cooperation and prosocial behaviour, 190.

Su Junga, C., \& Lee, G. (2012). Goals, strategic planning, and performance in government agencies. Public Management Review, 15(6), 787-815.

Tantardini, M., Guo, H., \& Ganapati, N. (Forthcoming). Social capital and public administration financial performance: Lessons from Florida. Public Performance and Management Review.

Tan, J., \& Peng, M. (2003). Organizational slack and firm performance during economic transitions: Two studies from an emerging economy. Strategic Management Journal, 24, 1249-1264.

Taylor, J. (2010). Public service motivation, civic attitudes and actions of public, nonprofit and private sector employees. Public Administration, 88(4), 1083-1098. 
Tepe, M. (2015). In Public Servants We Trust? A behavioural experiment on public service motivation and trust among students of public administration, business sciences and law. Public Management Review, 1-31.

Terry, L. D. (1998). Administrative leadership, neo-managerialism, and the public management movement. Public Administration Review, 58(3), 194-200.

Thomas, C. W. (1993). Reorganizing public organizations: Alternatives, objectives, and evidence. Journal of Public Administration Research and Theory, 3(4), 457486.

Thompson, B. (2004). Exploratory and confirmatory factor analysis: Understanding concepts and applications. Washington, D.C.: American Psychological Association.

Thurstone, L. L. (1931). Multiple factor analysis. Psychological Review, 38(5), 406.

Uphoff, N., \& Wijayaratna, C. M. (2000). Demonstrated benefits from social capital: The productivity of farmer organizations. In Gal Oya, Sri Lanka. World Development, 28(11), 1875-1890.

Van de Walle, S., \& Bovaird, T. (2007). Making better use of information to drive improvement in local public services: A report for the Audit Commission. Available at SSRN 1347349.

Van Dooren, W., Bouckaert, G., \& Halligan, J. (2010). Performance management in the public sector. London: Routledge.

Van Dooren, W. (2006). Performance Measurement in the Flemish Public Sector: a supply and demand approach. (Doctoral dissertation, University of Bergen, Norway).

Van Dooren, W., \& Van de Walle, S. (Eds). (2008). Performance information in the public sector. How it is used. Hampshire: Palgrave Macmillan.

Van Teijlingen, E., \& Hundley, V. (2002). The importance of pilot studies. Nursing Standard, 16(40), 33-36.

Visser, P. S., Krosnick, J. A., Marquette, J., \& Curtin, M. (1996). Mail surveys for election forecasting? An evaluation of the Columbus Dispatch poll. Public Opinion Quarterly, 60(2), 181-227. 
Yang, K., \& Hsieh, J.Y. (2006). Managerial effectiveness of government performance measurement: testing a middle-range model. Public Administration Review, 67(5), 861-879.

Yin, R. K. (2009). Case study research: Design and methods. $4^{\text {th }}$ Edition. Thousand Oaks, CA: Sage.

Yong, A. G., \& Pearce, S. (2013). A beginner's guide to factor analysis: Focusing on exploratory factor analysis. Tutorials in Quantitative Methods for Psychology, 9(2), 79-94.

Wang, X. (2002). Assessing performance measurement impact. A study of US local governments. Public Performance Management Review, 26(1), 26-43.

Wasserman, S., \& Faust, K. (1994). Social network analysis: Methods and applications (Vol. 8). Cambridge university press.

Weiss, C. (1981). Use of Social Science Research in Organizations: The Constrained Repertoire Theory. In Organization and the Human Services, Herman Stein (Eds.), 180-204. Philadelphia: Temple University Press.

Williams, K., \& Durrance, J. C. (2008). Social networks and social capital: Rethinking theory in community informatics. The Journal of Community Informatics, 4(3), $1-20$.

Wilson, J. Q. (1989). Bureaucracy: What government agencies do and why they do it. Basic Books.

Wilson, W. (1887). The study of administration. Political science quarterly,2(2), 197222.

Wholey, J. S. (1999). Performance-based management: Responding to the challenges. Public Productivity \& Management Review, 22(3), 288-307.

Wu, Y., \& Hendricks, R. (2009). Horizontal and vertical tax competition in Florida local governments. Public Finance Review, 37(3), 289-311.

Zammuto, R. F., \& Krakower, J. Y. (1991). Quantitative and qualitative studies of organizational culture (pp. 83-114). JAI Press Inc. 


\section{APPENDIX A}

\section{SURVEY ON THE USE OF PERFORMANCE INFORMATION IN FLORIDA'S COUNTIES}

For the purpose of our survey, performance information/data refers to feedback information on input, process, output and outcome of the activities performed by your department as well as its efficiency (a ratio of output and input) and its effectiveness (a ratio of outcome and output). Performance information/data includes but it is not limited to financial data. It can be both quantitative as well as qualitative.

By proceeding, you grant us your consent to participate in our study.

Performance Information Use and Performance Management

1. To what extent do you agree or disagree with the following statements: I use performance information to:

- Communicate program successes to stakeholders.

- Advocate for resources to support program needs.

- Explain the value of programs to the public.

- Make decisions.

- Think of new approaches for doing old things.

- Set priorities.

- Identify problems that need attention.

- Rewarding government employees that the respondent manages or supervises.
- 1. Strongly disagree

- 2. Disagree

- 3 Neither agree or disagree

- 4. Agree

- 5. Strongly agree 


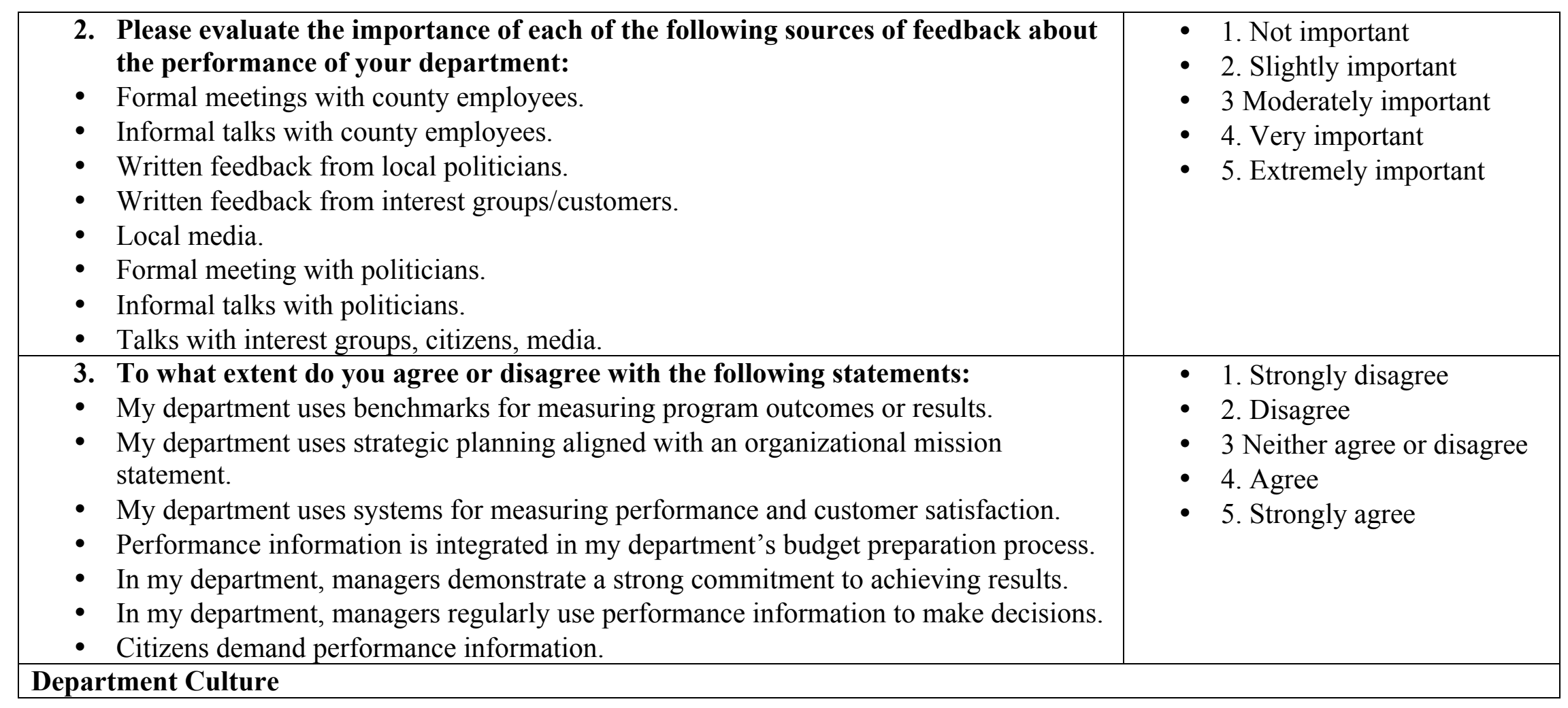




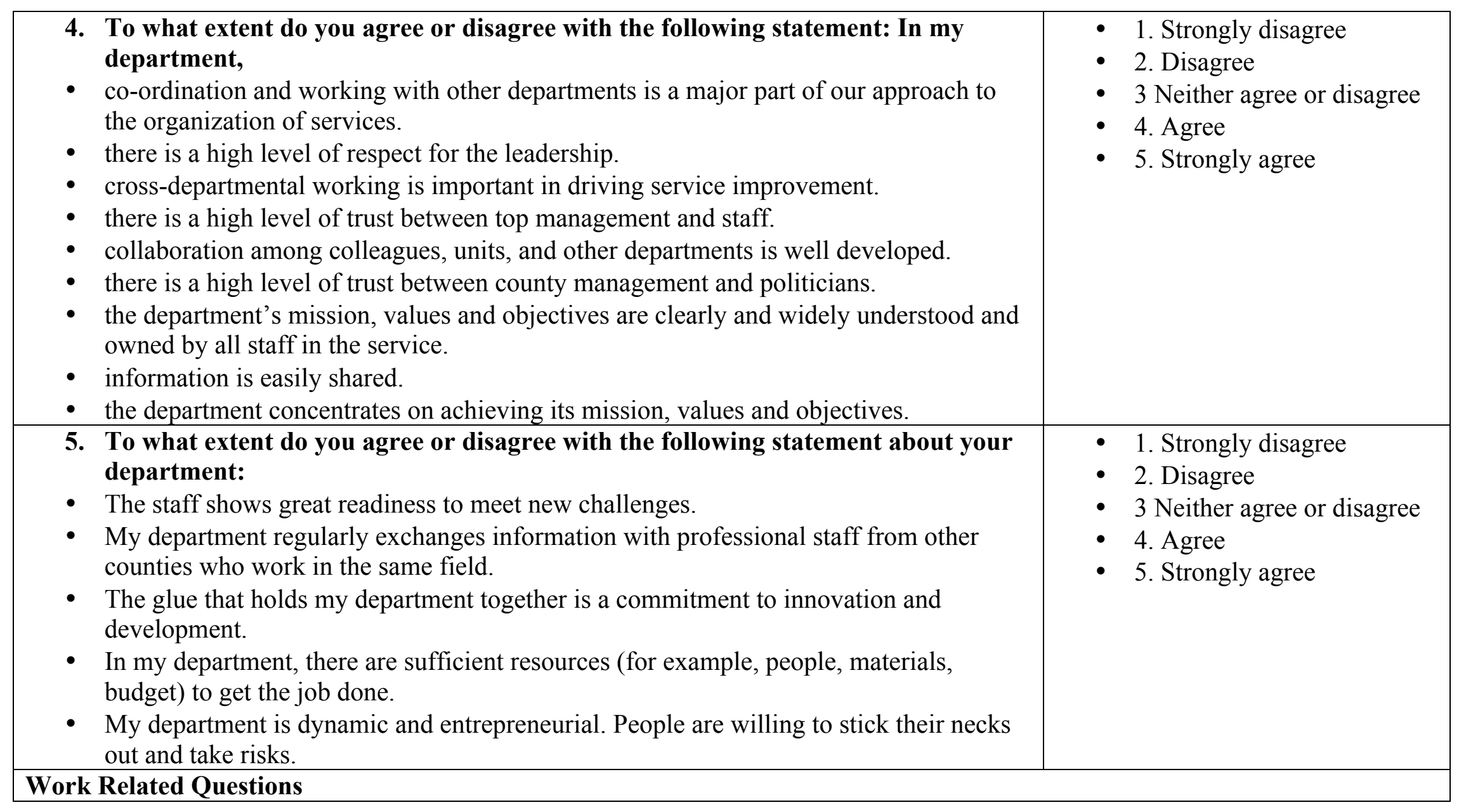




\begin{tabular}{|c|c|}
\hline $\begin{array}{l}\text { 6. To what extent do you agree or disagree with the following statement: } \\
\text { - I enjoy my work. } \\
\text { - Working hard is recognized. } \\
\text { - I find my job engaging. } \\
\text { - My pay varies widely. It consists of a fixed salary part and a performance-related } \\
\text { bonus. } \\
\text { - My job is fun. } \\
\text { - Hard work is adequately rewarded. }\end{array}$ & $\begin{array}{ll}\text { - } & \text { 1. Strongly disagree } \\
\text { - } & \text { 2. Disagree } \\
\text { - } & \text { 3 Neither agree or disagree } \\
\text { - } & \text { 4. Agree } \\
\text { - } & \text { 5. Strongly agree }\end{array}$ \\
\hline $\begin{array}{l}\text { 7. To what extent do you agree or disagree with the following statement: } \\
\text { - Meaningful public service is very important to me. } \\
\text { - I am often reminded by daily events about how dependent we are on one another. } \\
\text { - Making a difference in society means more to me than personal achievements. } \\
\text { - I am prepared to make enormous sacrifices for the good of society. } \\
\text { - I am not afraid to go to bat for the rights of others even if it means I will be ridiculed. }\end{array}$ & $\begin{array}{ll}\text { - } & \text { 1. Strongly disagree } \\
\text { - } & \text { 2. Disagree } \\
\text { - } & \text { 3 Neither agree or disagree } \\
\text { - } & \text { 4. Agree } \\
\text { - } & \text { 5. Strongly agree }\end{array}$ \\
\hline \multicolumn{2}{|l|}{ Demographics } \\
\hline What is your supervisory status? & $\begin{array}{l}\text { - } 1 . \text { Department head } \\
\text { - } 2 . \text { Middle management } \\
\text { - } \text { 3. Supervisor } \\
\text { 4. Other }\end{array}$ \\
\hline How long have you been working in your current department? & $\begin{array}{l}\text { - } 1 .<1 \text { year } \\
\text { - } 2.1 \text { to } 5 \text { years } \\
\text { - } 3.6 \text { to } 10 \text { years } \\
\text { - } 4.11 \text { to } 15 \text { years } \\
\text { - } 5.15 \text { to } 20 \text { years } \\
\text { - } 6 .>20 \text { years }\end{array}$ \\
\hline What is your age group? & $\begin{array}{ll}\text { - } & 1.25 \text { and under } \\
\text { - } & 2.26-29 \\
\text { - } & 3.30-39 \\
\end{array}$ \\
\hline
\end{tabular}




\begin{tabular}{|c|c|}
\hline & $\begin{array}{ll} & 4.40-49 \\
- & 5.50-59 \\
\cdot & 6.60 \text { or older }\end{array}$ \\
\hline Number of employees reporting directly to you & Open-ended question. \\
\hline What is the name of your department? & Open-ended question. \\
\hline
\end{tabular}




\section{VIGNETTE:}

1) Picture yourself in the following scenario. Do not consider your own organization when answering the two proposed questions. The Human Resource (HR) manager of a County Government has requested your help in the performance appraisal process of a county's employee. The employee to be evaluated has been employed for 10 years in the County Government. Throughout the years, he has developed work experience, and is well respected in the organization. The HR manager also provides you the following information about his team work performance. During the current appraisal period, the employee has significantly contributed to the achievement of $85 \%$ of the goals set for his team, and the team leader gave him 4 out of 5 points in the performance appraisal. However, the employee has failed to meet 2 out of 5 deadlines assigned to him by the group leader, and the project statistics show that he performed better than $50 \%$ of his group members but not as good as the top performers.

Given the aforementioned information,

a. Would you reward this employee financially? $1=$ not at all, $10=$ as much as possible

b. Would you verbally recognize this employee? $1=$ not at all, $10=$ as much as possible

2) Picture yourself in the following scenario. Do not consider your own organization when answering the two proposed questions. The Human Resource (HR) manager of a County Government has requested your help in the performance appraisal process of a county's employee. The employee to be evaluated has been employed for 10 years in the County Government. Throughout the years, he has developed work experience, and is well respected in the organization. The HR manager also provides you the following information about his team work performance. During the current appraisal period, the employee has significantly contributed to the achievement of $85 \%$ of the goals set for his team, and the team leader gave him 4 out of 5 points in the performance appraisal. However, his colleagues complained to his supervisor that the employee did not fulfill individual responsibilities in support of his team, and the county commissioners complained that he didn't willingly share information about the completion of the projects assigned to the group.

Given the aforementioned information,

a. Would you reward this employee financially? $1=$ not at all, $10=$ as much as possible

b. Would you verbally recognize this employee? $1=$ not at all, $10=$ as much as possible

3) Picture yourself in the following scenario. Do not consider your own organization when answering the two proposed questions. The Human Resource (HR) manager of a County Government has requested your help in the performance appraisal process of a county's 
employee. The employee to be evaluated has been employed for 10 years in the County Government. Throughout the years, he has developed work experience, and is well respected in the organization. The HR manager also provides you the following information about his team work performance. During the current appraisal period, his supervisor through an informal talk with other team members became aware of his positive contribution to the team morale. Moreover, one of the County's commissioners pointed out to his supervisor the great contribution he made to his team in finding additional resources for the county libraries to be open one more hour per day. However, his colleagues complained to his supervisor that the employee did not fulfil individual responsibilities in support of his team, and the county commissioners complained that he didn't willingly share information about the completion of the projects assigned to the group.

Given the aforementioned information,

a. Would you reward this employee financially? $1=$ not at all, $10=$ as much as possible

b. Would you verbally recognize this employee? $1=$ not at all, $10=$ as much as possible

4) Picture yourself in the following scenario. Do not consider your own organization when answering the two proposed questions. The Human Resource (HR) manager of a County Government has requested your help in the performance appraisal process of a county's employee. The employee to be evaluated has been employed for 10 years in the County Government. Throughout the years, he has developed work experience, and is well respected in the organization. The HR manager also provides you the following information about his team work performance. During the current appraisal period, his supervisor through an informal talk with other team members became aware of his positive contribution to the team morale. Moreover, one of the County's commissioners pointed out to his supervisor the great contribution he made to his team in finding additional resources for the county libraries to be open one more hour per day. However, the employee has failed to meet 2 out of 5 deadlines assigned to him by the group leader, and the project statistics show that he performed better than $50 \%$ of his group members but not as good as the top performers.

Given the aforementioned information,

a. Would you reward this employee financially? $1=$ not at all, $10=$ as much as possible

b. Would you verbally recognize this employee? $1=$ not at all, $10=$ as much as possible

5) Picture yourself in the following scenario. Do not consider your own organization when answering the two proposed questions. The Human Resource (HR) manager of a County Government has requested your help in the performance appraisal process of a county's employee. The employee to be evaluated has been employed for 10 years in the County Government. Throughout the years, he has developed work experience, and is well respected in the organization. 
Given the aforementioned information,

a. Would you reward this employee financially? $1=$ not at all, 10=as much as possible

b. Would you verbally recognize this employee? $1=$ not at all, $10=$ as much as possible 


\section{APPENDIX B}

Michele Tantardini is a Ph.D. Candidate in Public Affairs at Florida International University, and along with the Public Administration Department, is conducting an important research project focusing on performance management. He is asking you to help him with obtaining a good response rate by completing his survey.

The information produced by this study will enable local governments to more effectively make use of or integrate performance management data into their operations.

The records of this study will be kept private and will be protected to the fullest extent provided by law. In any sort of report he might publish, he will not include any information that will make it possible to identify a participant. Anonymity and confidentiality are fully guaranteed.

The FCCMA Board of Directors approved his request to send the survey to FCCMA members at its August 12 Board Meeting.

Thank you very much for your time and collaboration.

Carol Russell

Executive Assistant 


\section{APPENDIX C}

Semi-structured interview questions to managers and middle managers (1 hour).

\section{$\underline{\text { Performance Management }}$}

1. Tell me a little bit more about the department performance management system.

2. How is the department performance management system designed?

a. Who is in charge of it?

i. Who sets the goals and performance indicators?

b. What are the main phases (and timing) of the performance cycle?

c. How goals and performance indicators are set?

d. How is your department performance reviewed?

e. Are there any rewards for organizational performance?

\section{Performance Information Use}

1. Could you tell me a little bit more how decisions are made in your department?

2. Do you base your decision making process on performance information?

a. If yes, what kind? Can you give me examples?

b. Can you give me an example of a decision that impacted your department or the delivery of a public service based on the use of performance information?

3. How do you gather performance information? Is performance information easily available to you? Do you trust the content of the information you are provided? 
Organizational Social Capital (OSC)

Structural dimension:

1. Do you collaborate with other managers in your department?

a. If yes, how is the relationship? Formal or informal? Stable or temporary?

b. What types of collaboration do you engage in?

2. Do you collaborate with other managers outside your department?

c. If yes, how is the relationship? Formal or informal? Stable or temporary?

d. What types of collaboration do you engage in?

3. How do you interact with your employees? How is the relationship with them? Hierarchical? Formal VS. Informal?

4. Are there any (team building) activities in your department or across departments?

e. If yes, how are they managed?

f. Do you perform any other activity to create a "group" sprit in your department?

\section{Relational dimension:}

1. How intensely do you have to supervise/oversee your employees? Is it necessary to engage in a close and constant oversight or they are granted with a high degree of autonomy?

2. How are working relationship among the members of your department? Are they good or bureaucratic issues get into the way? 
3. Do you trust your employees? Do you trust other managers in your department? Do you trust other managers outside your department? Do you trust local politicians?

a. If yes, why? Can you give me an example of a situation that enable trust between you and another manager/employee/politician?

b. If no, why? Can you give me an example of a situation that enable distrust between you and another manager/employee/politician?

4. Do you perform any activity in order to create trust among members of your department?

c. If no, how would you do it?

Cognitive dimension:

1. Does your department (organization) has shared goals? Can you give me examples?

2. Are those goal enacted collectively? Are employees properly informed about departmental/organizational goals?

3. How do you measure/ quantify the individual contribution to the achievement of these goals? 


\section{APPENDIX D}

\section{Focus group questions to employees (1 hour).}

\section{Organizational Social Capital (OSC)}

Structural dimension:

5. Do you collaborate with other employees in your department?

g. If yes, how is the relationship? Formal or informal? Stable or temporary?

h. What types of collaboration do you engage in?

6. Do you collaborate with other employees outside your department?

i. If yes, how is the relationship? Formal or informal? Stable or temporary?

j. What types of collaboration do you engage in?

7. How do you interact with your manager? How is the relationship with him/her? Hierarchical? Formal VS. Informal?

8. Are there any (team building) activities in your department or across departments?

k. If yes, how are they managed?

1. Do you engage in any other activity to create a "group" sprit in your department?

\section{Relational dimension:}

5. How intensely are you supervised/overseen by your manager? Does he engage you in a close and constant oversight or does he/she grant you with a high degree of autonomy? 
6. How are working relationship among the members of your department? Are they good or bureaucratic issues get into the way?

7. Do you trust your peers? Do you trust you supervisor? Do you trust other employees/managers outside your department? Do you trust local politicians?

d. If yes, why? Can you give me an example of a situation that enable trust between you and another manager/employee/politician?

e. If no, why? Can you give me an example of a situation that enable distrust between you and another manager/employee/politician?

8. Do you take part to any activity in order to create trust among members of your department?

f. If no, how would you do it?

Cognitive dimension:

4. Does your department (organization) has shared goals? Can you give me examples?

5. Are those goal enacted collectively? Are employees properly informed about departmental/organizational goals? 
VITA

MICHELE TANTARDINI

Born, Bellano (CO), Italy

2008

B.A., Public Administration

Bocconi University

Milan, Italy

2010

MSs, Public Administration

Bocconi University

Milan, Italy

$2010-2012$

Research Assistant

Department of Public Administration

SDA Bocconi School of Management, Milano (Italy)

2011-2012

Teaching Assistant,

Department of Policy Analysis and Public Management

Università Commerciale Luigi Bocconi, Milano (Italy)

2015

ASPA Founder Fellowship

2015

FIU Dissertation Year Fellowship

2015

Morris W.H. Collins Award

2016

J.C. Garcia Zamor Best Paper Award

2016

Ph.D. Public Affairs

Florida international University

Miami, Florida

\section{PUBLICATIONS}

Valotti, G., Galli, D., Giacomelli, G., \& Tantardini, M. (2015). Spending Review e qualità della spesa pubblica. Milano, Egea.

Tantardini, M. \& Kroll, A. (2015). The role of organizational social capital in performance management. Public Performance and Management Review.

Tantardini, M. \& Garcia-Zamor, J.C. (2014). Organizational social capital and anticorruption policies: An exploratory analysis. Public Organization Review, 15(4), 599-609.

Lecci, F., Rotolo, A., \& Tantardini, M. (2013). Performance management: Letteratura di riferimento ed esperienze internazionali e nazionali. In AA. VV. (Eds.), La 
valutazione delle performance per il governo strategico delle Aziende Sanitarie Pubbliche (pp. 25-44). Milano, EGEA.

Galli, D., Tantardini, M., \& Valotti, G. (2012). Spending review: Un metodo per migliorare la qualità della spesa. Economia \& Management, 6, 1-7.

Tantardini, M. (2012). Regno Unito. In G. Valotti (Eds.), Quale performance? Indicatori e sistemi di misurazione in uso nei Ministeri di sette Paesi OCSE. Proposte per le amministrazioni centrali italiane (pp. 23-46). Milano: EGEA.

Tantardini, M. (2012). Australia. In G. Valotti (Eds.), Quale performance? Indicatori e sistemi di misurazione in uso nei Ministeri di sette Paesi OCSE. Proposte per le amministrazioni centrali italiane (pp. 69-88). Milano: EGEA.

Tantardini, M. (2012). Germania. In G. Valotti (Eds.), Quale performance? Indicatori e sistemi di misurazione in uso nei Ministeri di sette Paesi OCSE. Proposte per le amministrazioni centrali italiane (pp. 131-142). Milano: EGEA.

Tantardini, M. (2012). Finlandia. In G. Valotti (Eds.), Quale performance? Indicatori e sistemi di misurazione in uso nei Ministeri di sette Paesi OCSE. Proposte per le amministrazioni centrali italiane (pp. 143-158). Milano: EGEA. 